\title{
Visualizing Innovation: Modelling and Simulation in Support of Defence Innovation Networks
}

by

\author{
Erik Esselaar
}

A thesis submitted to the Faculty of Graduate and Postdoctoral Affairs in partial fulfillment of the requirements for the degree of

Master of Applied Science

In

Technology Innovation Management

Carleton University

Ottawa, Ontario

(C) 2011

Erik Esselaar 
Library and Archives

Canada

Published Heritage

Branch

395 Wellington Street

Ottawa ON K1A ON4

Canada
Bibliothèque et

Archives Canada

Direction du

Patrimoine de l'édition

395 , rue Wellington

Ottawa ON K1A ON4

Canada
Your file Votre référence

ISBN: 978-0-494-83041-3

Our file Notre référence

ISBN: 978-0-494-83041-3
NOTICE:

The author has granted a nonexclusive license allowing Library and Archives Canada to reproduce, publish, archive, preserve, conserve, communicate to the public by telecommunication or on the Internet, loan, distribute and sell theses worldwide, for commercial or noncommercial purposes, in microform, paper, electronic and/or any other formats.

The author retains copyright ownership and moral rights in this thesis. Neither the thesis nor substantial extracts from it may be printed or otherwise reproduced without the author's permission.
AVIS:

L'auteur a accordé une licence non exclusive permettant à la Bibliothèque et Archives Canada de reproduire, publier, archiver, sauvegarder, conserver, transmettre au public par télécommunication ou par l'Internet, prêter, distribuer et vendre des thèses partout dans le monde, à des fins commerciales ou autres, sur support microforme, papier, électronique et/ou autres formats.

L'auteur conserve la propriété du droit d'auteur et des droits moraux qui protège cette thèse. $\mathrm{Ni}$ la thèse ni des extraits substantiels de celle-ci ne doivent être imprimés ou autrement reproduits sans son autorisation.
In compliance with the Canadian Privacy Act some supporting forms may have been removed from this thesis.

While these forms may be included in the document page count, their removal does not represent any loss of content from the thesis.
Conformément à la loi canadienne sur la protection de la vie privée, quelques formulaires secondaires ont été enlevés de cette thèse.

Bien que ces formulaires aient inclus dans la pagination, il n'y aura aucun contenu manquant.

\section{Canadä}


The undersigned hereby recommend to

the Faculty of Graduate Studies and Research acceptance of the thesis

\title{
Visualizing Innovation: Modelling and Simulation in Support of Defence Innovation Networks
}

\author{
Submitted by \\ Erik M. Esselaar, B.Sc.
}

In partial fulfillment of the requirements for the degree of Master of Applied Science in Technology Innovation Management

Dr. Howard M. Schwartz, Department Chair

Dr. Gabriel A. Wainer, Thesis Supervisor

Carleton University

September 2011 


\section{Abstract}

Military Forces have been motivated to partner in innovative efforts under the auspices of interoperability, risk reduction, and cost savings. While networks involving a supplier-consumer value chain do exist, there are more prevalent collaborative connections that have an international span. This thesis proposes that these are Innovation Networks, and that the organizations and relationships therein can be analyzed using salient theory. This thesis shows that having a means of visualizing the innovation network could assist challenges in these networks. As an additional line of investigation, this thesis delves into the study of Modelling and Simulation (M\&S) itself, offering a categorization of how M\&S supports military applications. This research encompasses qualitative case studies on innovation networks, centered around defence technology demonstration projects which involved M\&S technologies. This work analyzed empirical evidence, drawing on relevant theory and applied practices from various disciplines, including Modelling and Simulation, Military Transformation and Innovation Theory. 


\section{Acknowledgements}

Like life, many major endeavours can be likened to a journey, rather than just a destination. I must give my wife Kim, and my sons Kai and Ethan the greatest thanks for their support throughout this journey. Mere words cannot do justice to the amount of gratitude I have for them and all that they sacrificed for me along the way. On my journey I have learned and grown a lot - most importantly I have grown to appreciate all that my family does for me, and how I should be thankful of all that they are, evermore.

The greatest encouraging presence at Carleton has been Professor Gabriel Wainer. Thank you, Gabriel, for being that continually supportive foundation, urging me to contribute the most that I could to the community. Carleton's TIM Program has provided some inspiring visions that provided me with guidance along this journey. I am most appreciative to Professors Tony Bailetti, Douglas King, Steven Muegge, and Michael Weiss for their input and expertise.

Without their sponsorship and guidance, I wouldn't have been able to embark on this journey in the first place: I thank the Canadian Forces Warfare Centre for sponsoring my research. For their input and support - whether earlier in the formulation of this research and / or later in reviews of my drafts - I wish to thank Professors Paul Roman, Tuncer Ören, Commander (Retired) George Prudat, Lieutenant-Colonel (Retired) Dave McComb and Dr. Dave Allen. 
While it has certainly been a journey, I am very, very happy to have reached a destination.

$\sim$ EME, March $1^{\text {st }}, 2011$

This research was sponsored by the Canadian Forces Warfare Centre. 


\section{TABLE OF CONTENTS}

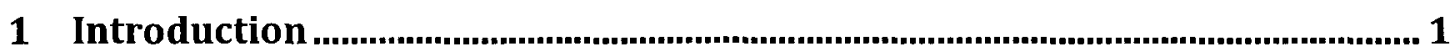

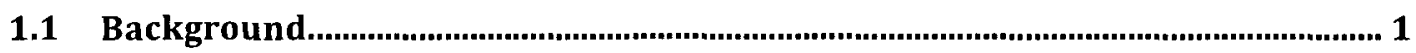

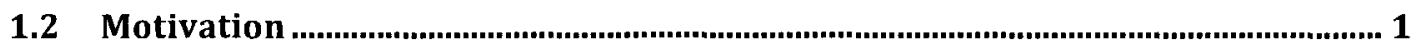

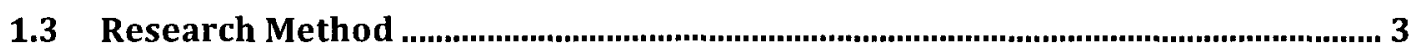

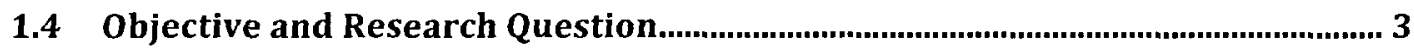

1.5 Deliverables and Contribution .................................................................................... 4

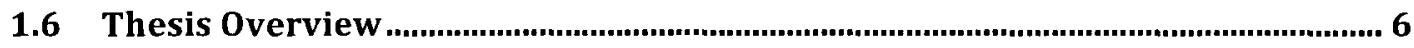

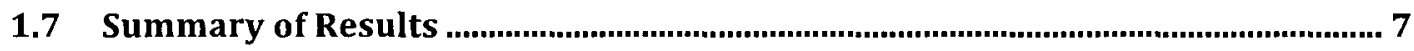

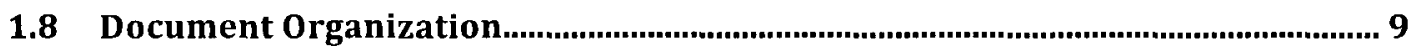

2 Literature Review...................................................................................................10

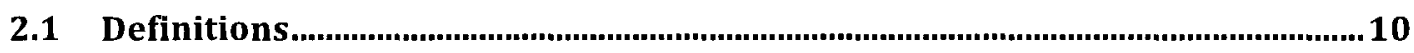

2.2 Literature Streams Overview ............................................................................... 13

2.3 Modelling and Simulation ........................................................................................ 15

2.3.1 Brief History of Modelling and Simulation ................................................................. 16

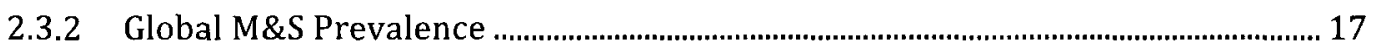

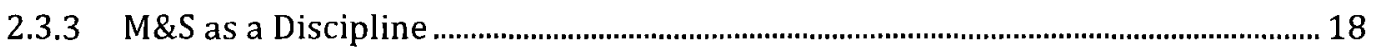

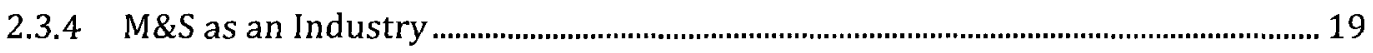

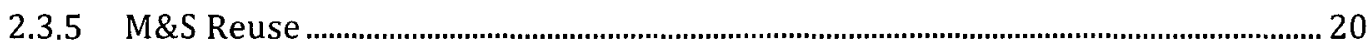

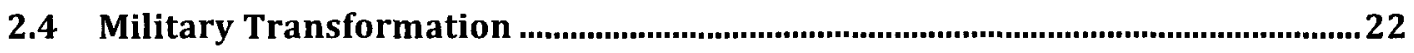

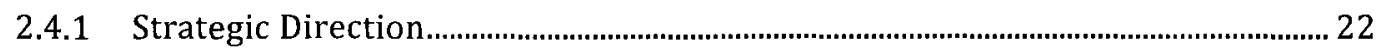

2.4.2 Science and Technology Advancement and Disruption .............................................. 23 


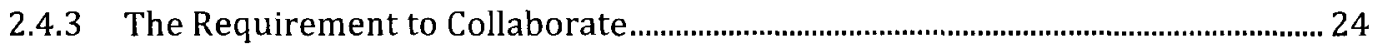

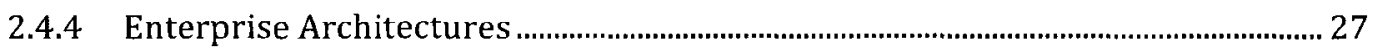

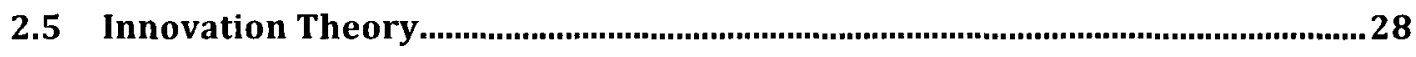

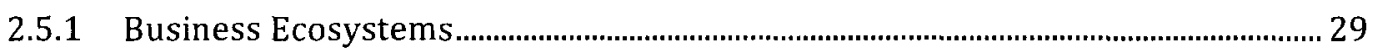

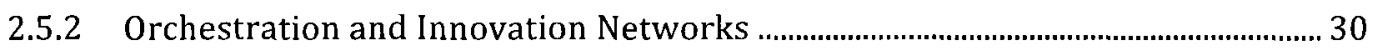

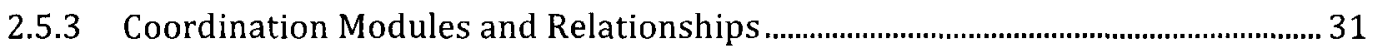

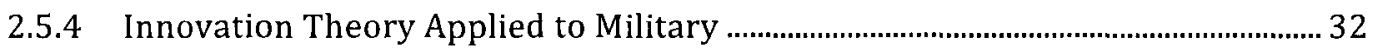

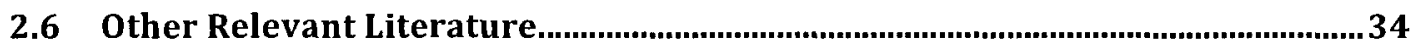

2.6.1 Visualization and Social Network Theory ..................................................................... 34

2.6.2 People, Processes and Technologies ……......................................................................... 35

2.7 Lessons Learned from the Literature ............................................................................ 36

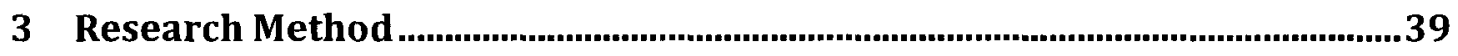

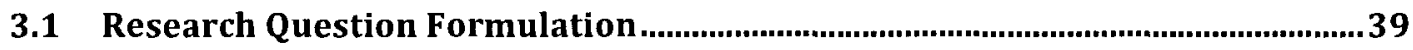

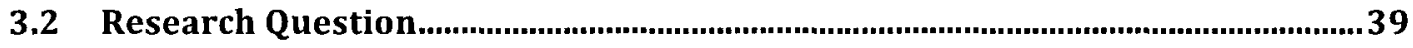

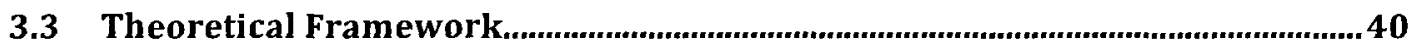

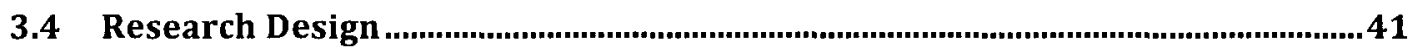

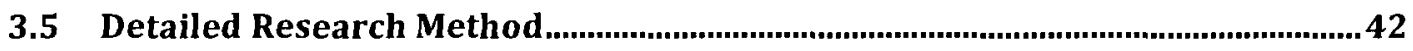

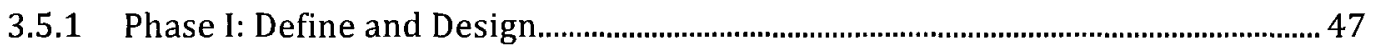

3.5.2 Phase II: Prepare, Collect and Analyze …….................................................................. 54

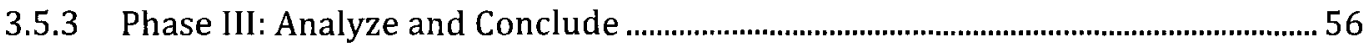

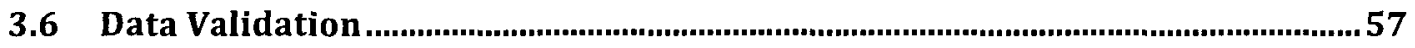

3.7 Closure

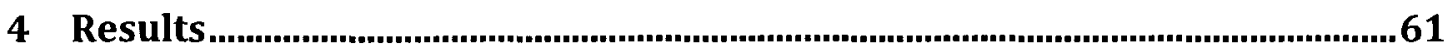




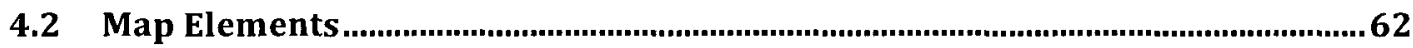

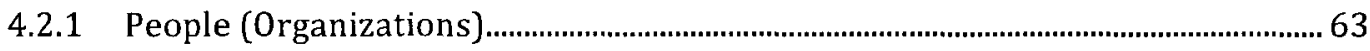

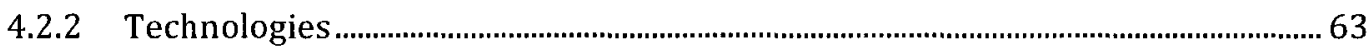

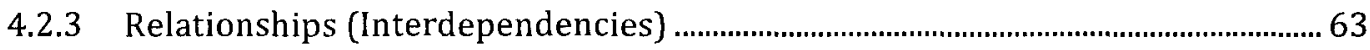

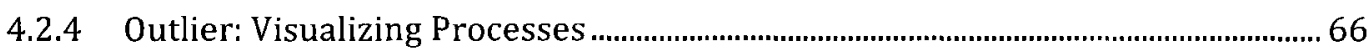

4.3 Categories of Modelling and Simulation Support to Military Applications......67

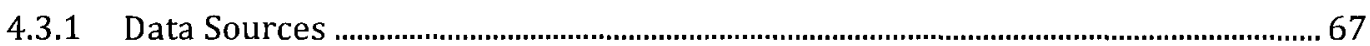

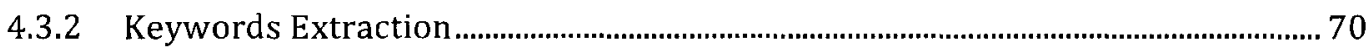

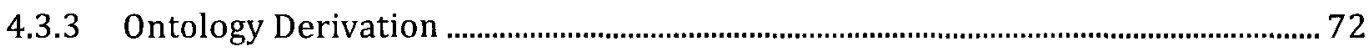

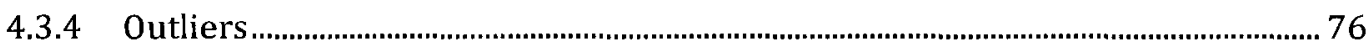

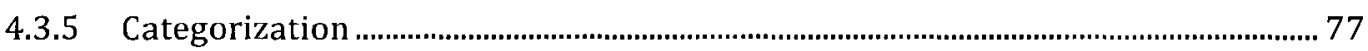

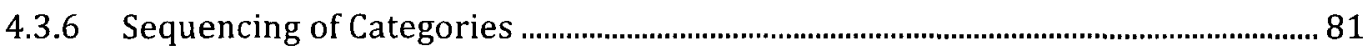

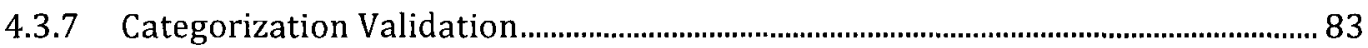

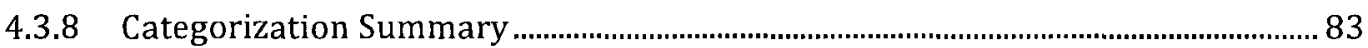

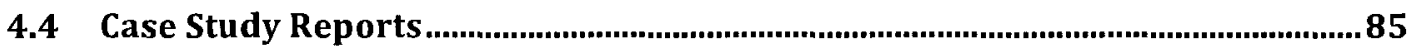

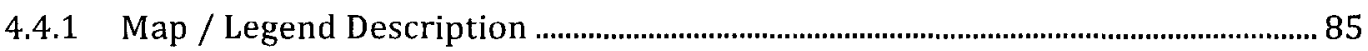

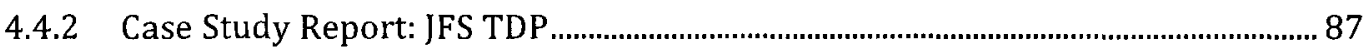

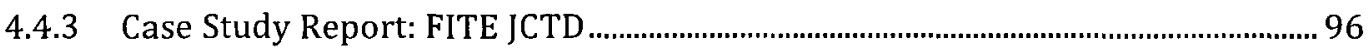

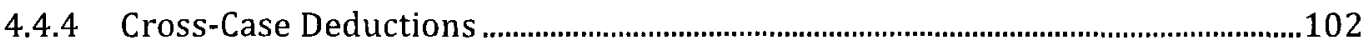

4.4.5 Other Network Map Elements - Organizations ............................................................113

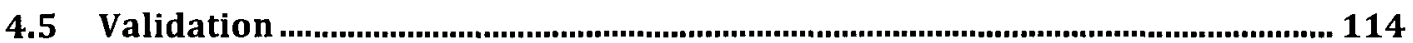

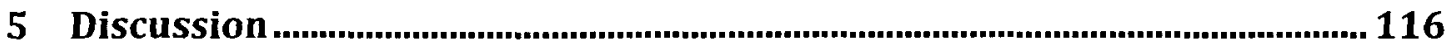




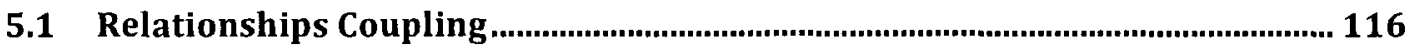

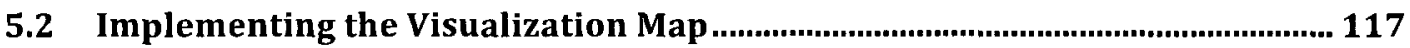

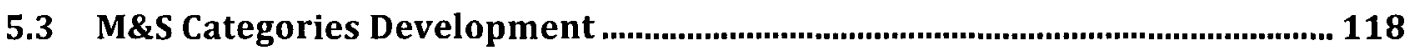

5.4 Enterprise Architectures.................................................................................. 119

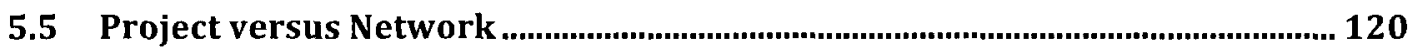

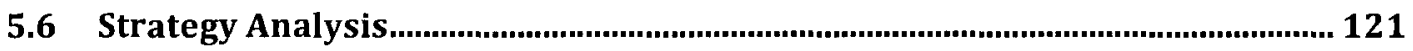

5.7 Research Findings Applicability to Other Domains ............................................ 122

5.8 Answers to Research Questions........................................................................... 123

5.8.1 Main Research Question - and Answer...................................................................123

5.8.2 Supporting Research Questions - and Answers ......................................................124

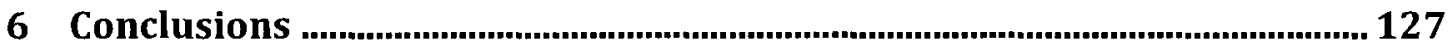

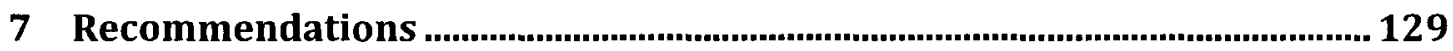

7.1 Categorization Evolution and Adoption ............................................................. 129

7.2 Network Encompassing Projects: Collaborative Network Mapping................. 129

7.3 Tool Evolution and High-Level Requirements........................................................ 130

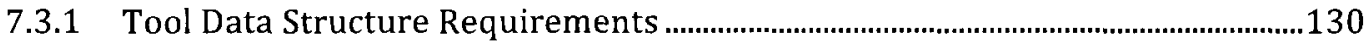

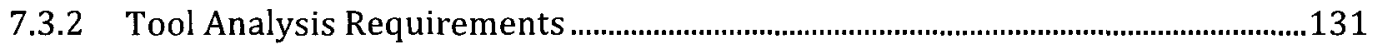

7.3.3 Tool Interoperability Requirements …...................................................................132

7.3.4 Tool Visualization Requirements................................................................................133

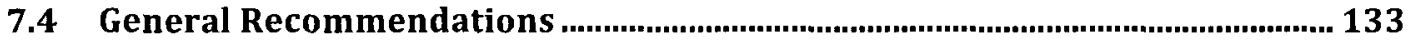

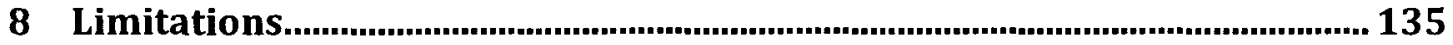

9 Future Work ...................................................................................................... 137 
9.1 Open-Source and Government-Off-The-Shelf.................................................. 137

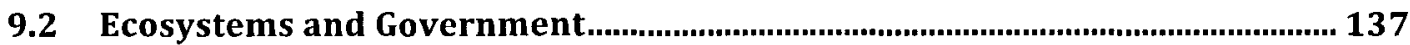

9.3 Developing an Innovation Network Management Environment...................... 138

9.4 Converging Innovation Networks and Enterprise Architectures..................... 138

9.5 Review Extant Canadian DND Innovation Databases........................................ 139

9.6 Maturation of Technology Readiness in Projects ................................................ 139

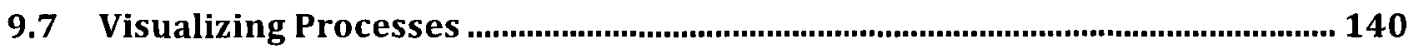

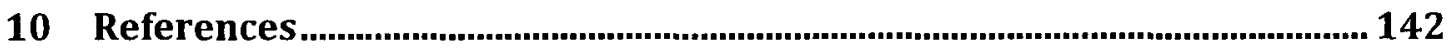

\section{List of Illustrations}

Figure 1-1 - Visual Definition of "Simulation" 13

Figure 2-1 - Trends and Challenges Shaping the Innovation Environment 38

Figure 4-1 - Relationships Legend 64

Figure 4-2 - Ontology Legend 73

Figure 4-3 - Mapping of Categories to L1 Organizations 74

Figure 4-4 - M\&S Support to Military Applications Overlap. 75

Figure 4-5 - Hierarchy of M\&S Support to Military Applications .76

Figure 4-4 - Category Sequencing. 82 


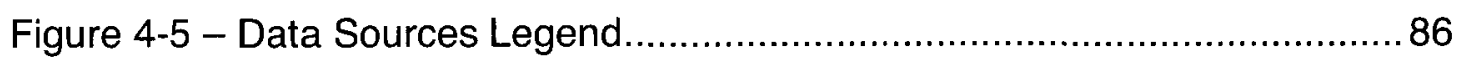

Figure 4-6 - Sample Social Network / Node and Link Data .............................. 87

Figure 4-7 - JFS TDP Organizations - Government..................................... 90

Figure 4-8 - JFS TDP Organizations - Industry ........................................... 91

Figure 4-9 - JFS TDP M\&S Technologies................................................ 92

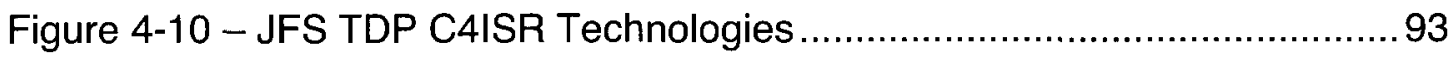

Figure 4-9 - FITE JCTD Key Organizations - Industry ..................................98

Figure 4-10 - FITE JCTD Key Organizations - Governments ..........................99

Figure 4-11 - FITE JCTD Key Technologies .............................................. 100

Figure 4-12 - Complete and Combined Network Map .................................. 103

Figure 4-13 - Government Organizations Common to Both Case Studies ....... 108

Figure 4-14 - Industry Members Common to Both Case Studies .................... 108

Figure 4-15 - Technology Common to Both Case Studies: VBS2 .................. 109

Figure 9-1 - High-level processes uncovered during research ........................141 


\section{List of Tables}

Table 2-1 - Literature Review Summary

Table 3-1 - Summary of Network Elements

Table 3-2 - Research Method Steps 46

Table 3-3 - Case Study Tactics, Validation and Reliability 58

Table 4-1 - M\&S Categorization Data Sources and Descriptions Overview 70

Table 4-2 - M\&S Keywords .72

Table 4-4 - Relationships Types and Collaborative Arrangement Types. 111

\section{List of Appendices}

Appendix 1 - Innovation Networks Map (DVD enclosed with report) Appendix 2 - List of Abbreviations

Keywords: Defence, Defense, Military, Innovation, Innovation Networks, Business Ecosystem, Business Transformation, Military Transformation, Simulation, Visualization, Modelling and Simulation, Modeling, Synthetic Environment 


\section{INTRODUCTION}

\subsection{Background}

Technological innovation within the private sector is sought for many reasons, including staying ahead of one's competitors, increasing profits, or reducing costs. Within the public sector, and specifically, the military domain, innovation is becoming ever more important. The military seeks to be innovative in order to remain ahead of adversaries encountered in military operations - when risk is measured not in dollars but in lives. Canadian and Allied Forces have often been motivated to partner in innovative efforts under the auspices of interoperability, cost savings, as well as risk reduction (project risk and risk to life).

While networks involving a traditional supplier-consumer value chain do exist, there are more prevalent collaborative connections that span internationally, and into other domains.

\subsection{Motivation}

With expansive globalization, and proliferation of advanced technologies, the innovative landscape is becoming evermore complex to manage. Billions of dollars are spent annually within Canada on defence acquisition programs, including a significant amount on innovative endeavours. Many different collaborative vehicles to permit innovation have emerged, and there has been an increasing amount of organizations and technologies linked by this web of collaborative vehicles. This has resulted in a highly complex global innovation 
environment. However, the tools to manage this complexity have not evolved as fast as the innovative environment. In these times of restricted personnel and financial resources, military planners resort to relatively simple and isolated tools to manage defence acquisition and innovation programs.

Additionally, with the complexity of technologies available, M\&S technologies have evolved - as has the community that uses and develops them. Within the evolving M\&S community there are a myriad of inter-related terms that blur what M\&S capabilities truly offer, and how they can be of benefit to the military. Furthermore non-M\&S practitioners do not properly understand how M\&S can be used in defence applications, and specifically, in innovative endeavours.

This research focuses on innovation in defence, specifically within the realm of Modelling and Simulation (M\&S) applied to defence innovation. The aim of this thesis is to explore how Defence innovators collaborate using M\&S. Organizations discussed within these networks span the Public and Private Sectors, originating in multiple countries. This thesis proposes that with the realities of today's environment, defence innovators need to improve collaboration through adoption of an innovation networks view, and the ability to better coordinate and orchestrate innovation - such as by actually visualizing the innovation network itself. 


\subsection{Research Method}

This research examined two case studies of demonstration projects, and determined how these focused networks collaborate to innovate, using M\&S technologies. The Case Study Method was employed, comparing and contrasting two cases, and analyzing in detail the organizations, technologies, relationships and interdependencies within the projects. The two cases were selected due to their contrasting use of M\&S technologies, as well as different nation's approach to innovation and collaboration. This research examined extant literature in several relevant domains, then performed in-case analysis, followed by a crosscase comparison. A categorization of M\&S used in support of military activities was generated, innovation network maps were generated, and in analyzing the network maps, gaps in collaboration and subsequent areas for improvement were identified.

\subsection{Objective and Research Question}

The objective of this research is to determine how collaboration and the resulting innovation output is achieved, in select innovation networks surrounding defence projects where M\&S technologies have an important role. Simply put, within specific defence projects that use M\&S, we examine which organizations they partner with, either as key partners, suppliers, contractors, allies, or other types of stakeholders. We then determine how these actors are related, how they interact, and how the end product(s) are produced. 
More specifically, the objective of this research is to answer the key research question:

"How do defence innovators collaborate to innovate using Modelling and Simulation, and can an innovation network viewpoint help identify areas for improving collaboration?"

\subsection{Deliverables and Contribution}

This research delivers visualizations of existing innovation networks, surrounding defence demonstration projects involving $M \& S$ technologies. Using the visualizations, areas for improved collaboration were identified. In support of these maps, key factors for mapping defence innovative networks were derived, and used to build the maps. Subordinate to these factors is a categorization of M\&S support to military applications, which is derived from theoretical and practical sources. This categorization as well as the maps enables us to understand how defence innovators collaborate, how to improve collaboration, and gives us understanding as to the relationships that are present.

This research contributes to the extant literature on innovation networks by providing insight into how defence innovation network members can better collaborate and innovate, using M\&S. Currently there is no formalized view on $M \& S$ in support of military applications; there are only project-specific, or organization-specific views on M\&S. This works proposes that an overarching 
categorization of M\&S in support of military applications does exist, and should be used as a means of standardizing how practitioners of M\&S within the Defence domain communicate about M\&S. This categorization can likely be used outside of the military domain. This categorization is a valuable contribution since it can be adopted, discussed, built upon and extended to formalize the overall practice of M\&S within and beyond the Defence domain. The M\&S categories served as an additional data element to map to each organization, where possible. This allowed for searching and grouping organizations into communities of practice, based on their involvement with different types of military activities that M\&S supports.

Additionally, research on network mapping, network visualization, innovation networks, and business ecosystems have not been extensively applied to the "business" of military innovation - especially not from the Government's point-ofview. As such, this work is paving the way for future research and development in this area. By initially mapping the selected innovation networks, this work can serve as a stepping stone in the development of the data networks to support Defence innovation, and simulation events themselves. This work also gives greater understanding as to how M\&S technologies can be used to support innovative efforts. In essence, this research bridges the functional domains of Business Theory, Military Operations and Modelling and Simulation to provide stakeholders within the Defence and Security community with a number of tools 
to apply to future defence innovation efforts, so that collaboration in defence innovation can be improved, reducing costs (increasing reuse), and shortening development timelines.

\subsection{Thesis Overview}

Canadian and Allied Forces have often been motivated to partner in innovative efforts under the auspices of interoperability, risk reduction, as well as cost savings. While networks involving a traditional supplier-consumer value chain do exist, there are collaborative connections that span into international and other domains. This thesis proposes that these are in fact innovation networks, and that the loose coupling between its partners can be analyzed using salient innovation network theory. This thesis will show that loose coupling does exist, and that challenges in these networks can be partially overcome by have a means of visualizing the innovation network.

As a peripheral yet important line of investigation, this thesis delves into the study of M\&S itself, offering a categorization and explanation of how M\&S is used in innovative endeavours, and beyond.

This research examines Unclassified data from technology demonstration projects within the defence domain, which involve M\&S technologies. However, the deductions drawn herein can be applied to Classified Projects, or projects outside of the Defence domain. Projects were selected from the US Joint Capability Technology Demonstration (JCTD) Program, as well as the Canadian 
Technology Demonstration Project (TDP) Program. Data was gathered through official (releasable) project documentation, as well as documents and website pages in the Public domain. This research encompasses qualitative case studies on specific innovation networks, centered around the specific technology demonstrations involving M\&S tools.

This work analyzes empirical evidence from actual defence projects, drawing on relevant theory and applied practices from various disciplines, including Modelling and Simulation, Social Network, Business Management, Business Ecosystems and Innovation Theories.

This work focuses on inter-relationships between organizations and technologies, and assists in the management of inter-dependencies. Within any endeavour, there will be collaboration and dependencies on things outside of your control. This thesis offers a vision of how to identify, map and manage these dependencies, so that issues can be identified at the forefront, and strategy can be planned accordingly.

\subsection{Summary of Results}

It was discovered that many terms used by international stakeholders to describe the application of $M \& S$ to military applications had structure, and a hierarchy. An ontology of terms for Modelling and Simulation Support to Military Applications was derived, that was organized into five high-level categories, with many relevant sub-categories. The high-level categories are as follows: 
- Operations and Planning

- Training and Education

- Acquisition and Support

- Concept Development and Experimentation

- Research, Development and Analysis

The important factors that were identified to be mapped out conformed to the "People, Processes and Technologies" model, however, this was modified to map out People (Organizations), Technologies, and the relationships that link them. Organizations and Technologies formed the nodes on the Innovation Network Map, and the relationships or dependencies formed the links.

There were a number of "Collaborative Vehicles" or different relationship types between organizations that were identified, spanning from formal Contracts to informal memberships. A mapping of Relationship Types to Collaboration Types was done as well, adding further value to the research.

An innovation network map was developed to map out many technologies and organizations between the two Case Study Projects - and the complex relationships that linked them (Appendix 1 - Innovation Network Map). Of the two Case Study Projects which had very different use of M\&S technologies, it was discovered that there were five organizations and one M\&S technology that were common to both Case Studies. This resulted in some observations of areas for potential collaboration that could occur in the future. 
Furthermore, there were a number of requirements that were detailed on the structure of an Innovation Network tool.

\subsection{Document Organization}

Chapter 2 offers a review of the salient literature, and summarizes relevant deductions that have guided this work. In Chapter 3 details the method by which the research was conducted, after which the results of the research are detailed in Chapter 4. A discussion of the results is conducted in Chapter 5. Concluding the document are Chapters 6, 7, 8 and 9 which detail the Thesis' Conclusions, Recommendations, Limitations and Future Work respectively. 


\section{LITERATURE REVIEW}

\subsection{Definitions}

This research spans both the Public and Private Sectors, most importantly within the Government / Military domain, as well as interdependencies with Academia and Industry. One of the key challenges that this research will delve into is the lack of clarity and unity in terminology used within the realm of M\&S since it is broadly used in a number of different domains.

As such, it is necessary to define a number of terms, as they will be used in this work. Much terminology that this work deals with have typically been fairly heavily weighted with meaning, and connote different things within different domains. Therefore, we begin with offering definitions of key terms, and a brief explanation of the general relevance of the term, as it will be used in this work.

- Innovation - "derived from Latin, meaning to introduce something new to the existing realm and order of things or to change the yield of resources" (Carayannis et al, 2008).

- Network - a connection of entities, including organizations. It includes the entities, as well as their logical connections. The term network may denote a social, innovation, or data network. However, when not specified in this work, it will be assumed to be an innovation network.

- Innovation Networks - "Innovation networks are real and virtual infrastructures and infratechnologies that serve to nurture creativity, trigger 
invention, and catalyze innovation in a public and / or private domain context (for instance, government-university-industry public-private research and technology development co-opetitive - a combination of cooperative and competitive -- partnerships)." (Carayannis and Campbell, 2006). This definition highlights the unique nature Innovation networks shall be shown to be a central concept within this work.

- Defence Innovation Network - an Innovation Network focused on the Defence, or Military domain.

- Business Ecosystems - "[Business ecosystems] are characterized by a large number of loosely interconnected participants who depend on each other for their mutual effectiveness and survival. [...] participants [..] share their fate with each other. If the ecosystem is healthy, individual species thrive." (lansiti and Levien, 2004a). The notion of Business Ecosystems speaks to the inter-relation between organizations, and that there are explicit and implicit dependencies.

- Model: "A representation of something, such as a physical entity (e.g. a person or car); an abstract entity (e.g. a religion); or a process (e.g. manufacturing steps in a factory). In computer-based simulation, models can be formal and based on mathematical notations" - adapted from the Canadian Department of National Defence's (DND)'s order on Modelling and Simulation (Department of National Defence, 2010). 
- Modelling: "the process of building a model" (Department of National Defence, 2010).

- Simulation: as the M\&S domain is multi-facetted, it can be expected that there are numerous definitions of the word "simulation", from each facet, perspective or view. The US and Canadian military definitions for simulation are fairly simplistic, essentially saying that it is a model implemented over time (Department of National Defence 2010; Department of Defense, 2007). However, Professors Ören, Zeigler and Wainer, amongst others, offer more compelling definitions (Ören, 2007; Wainer, 2009; Zeigler, Praehofer and Kim, 2000). This thesis Wainer's (2009) views to define simulation as "the reproduction of the dynamic behaviour of a system of interest with the goal of obtaining outcomes that can be applied to the system." (Wainer, 2009). The end result of simulation being a conclusion or set of conclusions speaks to its use as a decision support tool, for example, as used in experimentation. The replacement by the word "outcomes" was done to give additional weight to simulation used as a means of providing a unique experience, as simulation is used for training, entertainment, and other applications. For example, an outcome could be a conclusion, or an additional experience that has training benefit. Lastly, there are alternate definition methods such as a "visual" definition. This is of particular interest, as it allows the 
reader to observe a number of inter-relations, in a relatively simple, efficient and intuitive manner. The following figure is a visual definition of the word "simulation" (adapted from VisualThesaurus, 2010):

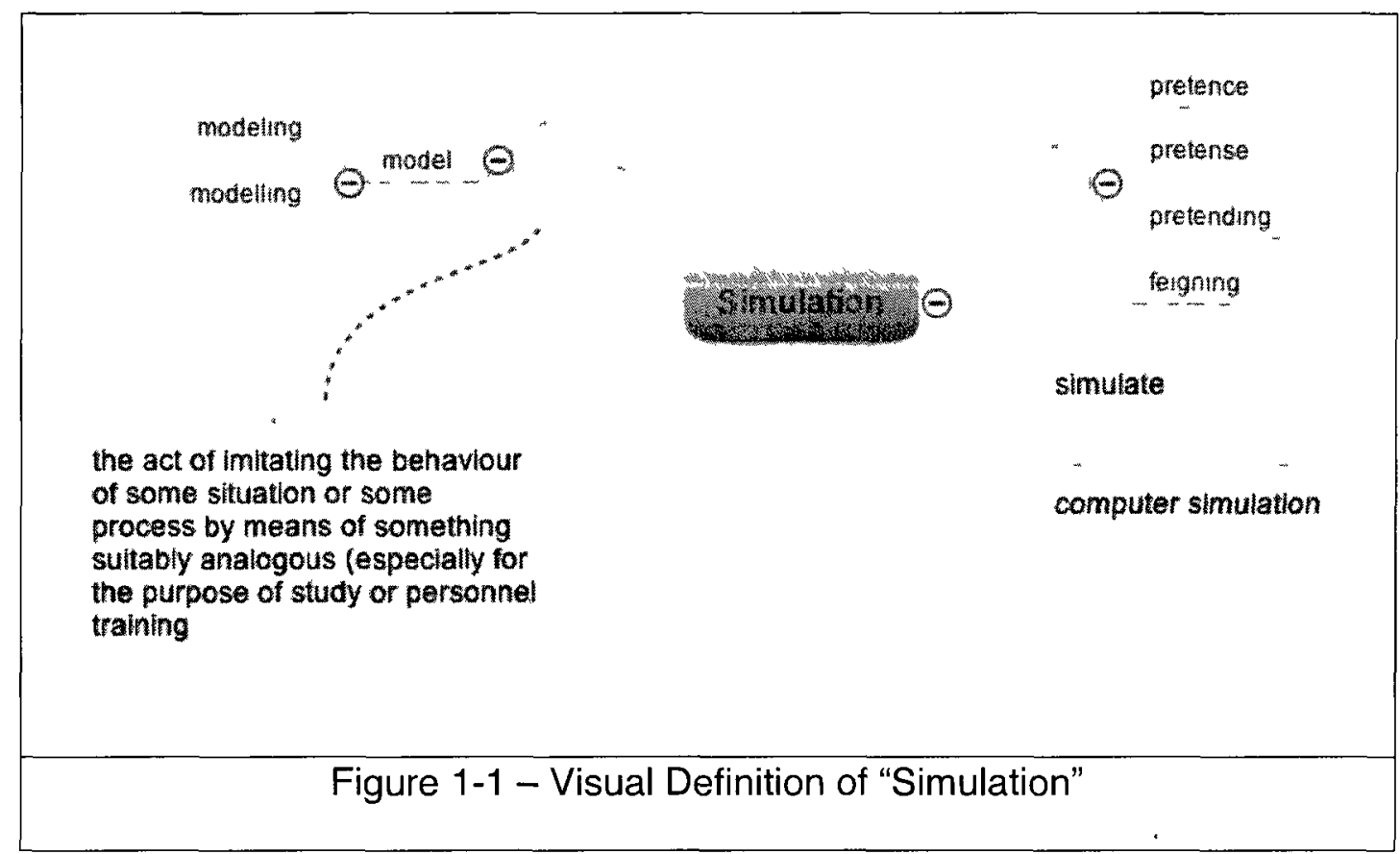

- Visualization: a visualization based on models, either over time through a simulation, or static, non-time based, interacting with a model of some sorts. Examples / ranges of use: nGrain model used for mine clearance, or for mechanic for visualizing tech plans when maintaining, or commander visualizing battlefield prior to an operation.

\subsection{Literature Streams Overview}

This work spanned a number of domains and disciplines of expertise. This includes practices within Business, Government, Academia, and spanning areas 
of expertise such as Innovation, Modelling and Simulation, as well as Defence (military) Transformation. The latter areas were the focal streams in the literature review. The following sections provide a review of the salient literature. Table 2-1 summarizes the key streams. Section 2.5 includes some additional key literature reviewed that did not conveniently fit into these three key literature streams:

\begin{tabular}{|c|c|c|c|}
\hline & STIREA & 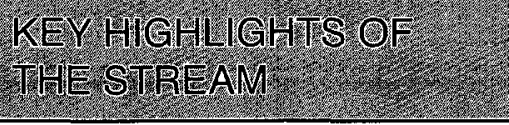 & REY REFERENGES \\
\hline 2.2 & $\begin{array}{l}\text { Modelling and } \\
\text { Simulation }\end{array}$ & $\begin{array}{l}\text { - Measurable cost savings } \\
\text { are "stunning" when able to } \\
\text { effectively manage } \\
\text { simulation resources } \\
\text { - Simulation as a tool, } \\
\text { enabler; } \\
\text { - Applications for modelling } \\
\text { and simulation; }\end{array}$ & $\begin{array}{l}\text { Zeigler, Praehofer \& } \\
\text { Kim, 2000; TTCP, 2006; } \\
\text { Wainer, 2009; Ören, } \\
\text { 2010; Sokolowski \& } \\
\text { Banks, 2009; DND 2005; } \\
\text { DND 2006a, 2006b; }\end{array}$ \\
\hline 2.3 & $\begin{array}{l}\text { Military } \\
\text { Transformation }\end{array}$ & $\begin{array}{l}\text { - Requirement to } \\
\text { collaborate with diverse } \\
\text { organizations. } \\
\text { - Critical for DND to partner } \\
\text { with other organizations } \\
\text { before it is required in } \\
\text { actual operations. } \\
\text { - Transformation required } \\
\text { to meet current and future } \\
\text { operational challenges. } \\
\text { - Current / future } \\
\text { operations characterized } \\
\text { by Network-Enabled } \\
\text { Operations }\end{array}$ & $\begin{array}{l}\text { Near, 2009; McComb, } \\
\text { 2009a; McComb, 2007; } \\
\text { Coll, 2009. DND, 2008; } \\
\text { DND, 2006a; Alberts \& } \\
\text { Hayes 2003; Alberts \& } \\
\text { Hayes 2007; }\end{array}$ \\
\hline
\end{tabular}




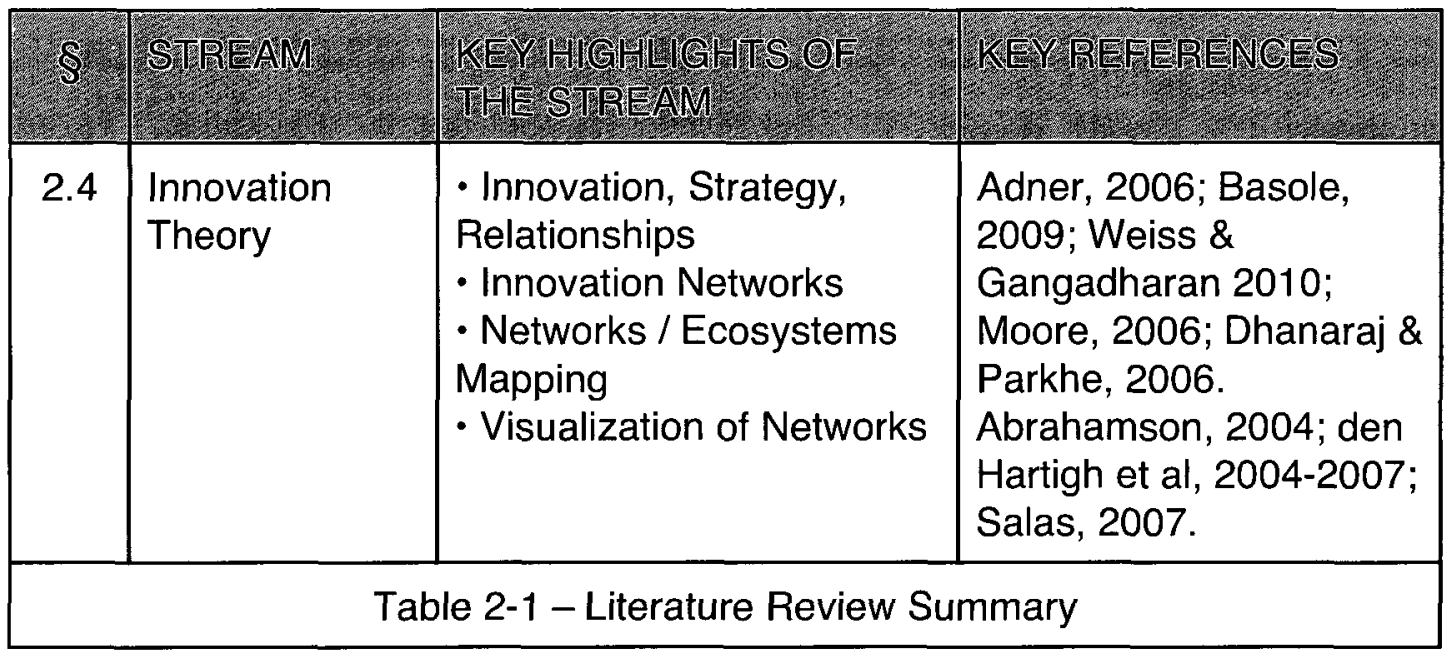

\subsection{Modelling and Simulation}

Within the military Modelling and Simulation (M\&S) community, there is a well-known motto that has caused some discussion, and various reactions to it: "All But War Is Simulation." (Lowood \& Lenoir, 2003). Keeping the validity of this saying aside, this motto does reinforce the notion that simulation can be broadly defined to include rehearsals, using physical scaled models for planning, all the way up to the most sophisticated systems integrating live, virtual and constructive simulation systems. However, more importantly, the undertone of this motto reminds M\&S practitioners of the seriousness of using M\&S tools in support of military operations. This seriousness and gravity of implications of misuse of simulation has also prompted the formulation and adoption of a Code of Ethics for Simulationists (SCS, 2006). Use of simulation is not just a game, especially 
not in the military domain. M\&S has a long history of serious use, in support of military endeavours, and beyond.

\subsubsection{Brief History of Modelling and Simulation}

Evidence of M\&S can be found even back in ancient Rome, when the Roman Army would simulate battle by having two of their own contingents train before battle (Sokolowski \& Banks, 2009). However, computed simulation can be traced back to 1777 , when a manual Monte Carlo method was used to estimate $\pi$ (pi). More modern use of computer simulation surfaced in World War II (Nance \& Sargent, 2002). Within the military domain, simulation has been extensively used for training - arguably the best known simulators of complex systems are aircraft simulators. The first aircraft simulator, the "Link Flight Simulator", was patented in 1929 by the American, Edward Link (Sokolowski \& Banks, 2009). As with many cases for using simulation for training, this was done for many reasons, primarily due to the heightened cost and risk of training on real aircraft. However, military M\&S has grown far beyond its prevalence in training. Modern militaries across the globe have now increasingly used M\&S technologies to address a wide array of objectives, spanning from Training, to Education, Acquisition, Operational Research and Analysis, Engineering, Research and Development, and also in support of actual military Planning and Operations. 


\subsubsection{Global M\&S Prevalence}

"Simulation is like a gem: it is multifaceted."-Tuncer Ören (Zeigler, 1984)

Within the Defence and Security sector, there is increasing pressure to "do more with less", forcing governments and militaries worldwide to rely more on development programs by international allies. It has been thought that a critical group of technologies that enables organizations to be more efficient is $M \& S$ - to the point where the US Congress had deemed that M\&S is a "critical technology" (Department of Defense, 2009). M\&S is deemed to be a key technology in cutting costs and increasing efficiency, where decision makers can use modelling and simulation to guide decisions, in lieu of investing in (or engaging in) costly and risky endeavours (Department of Defense, 2009).

The requirement to be more efficient has manifested itself in the wide array of technical and development partnerships between international militaries, such as The Technical Cooperation Program (TTCP, 2010), the NATO Research and Technology Organisation (NATO Research and Technology Organisation, 2010). Within, and beyond these partnership groups there are many collaborative efforts, sub-groups, panels, etc. in M\&S. There are military M\&S partnerships within Concept Development and Experimentation (CD\&E), Human Factors, Training, Acquisition, as well as many others. Dr. Ören's lengthy index of international M\&S organizations is a testament to this (Ören, 2010; Sokolowski \& Banks, 2009). 


\subsubsection{M\&S as a Discipline}

There appears to be coalescence of M\&S expertise, in a variety of institutions internationally, however there is still some debate as to whether it is a discipline unto itself. The empirical evidence of M\&S Centres of Excellence (CoE) abound. Within the Canadian Forces alone, each military service (Army, Navy, Air Force) has consolidated centres of M\&S expertise, and even a designated coordination office for M\&S issues. The establishment of Services' M\&S coordination offices is even mandated by Federal Defence Policy (Department of National Defence, 2006b; Department of National Defence, 2006a). The US DoD views M\&S as a discipline that "enables capabilities that are critical to meet DoD challenges" (Department of Defense, 2009).

Within academia, there are numerous examples where M\&S centres have been established between various disciplines. This includes the Virginia Modeling and Simulation Center (VMASC), and even Carleton University's own Visualization and Simulation Centre (V-Sim). These centres - within the Government, Academia, and elsewhere - can be seen as proof that M\&S is a discipline unto itself. There is an apparent convergence of organizational expertise around M\&S, internationally.

As a partnership between Academia and Industry, Dr. Ören from the University of Ottawa and Mr. Waite from Aegis Technologies Group have led the "Modelling and Simulation Body of Knowledge" (M\&S BoK) effort (Ören \& Waite, 
2007). They describe the challenges in the M\&S community, and the need to establish an M\&S BoK, comparable to the professionalization in the practice of

Project Management, with the PMBOK (Ören \& Waite, 2007; Ören, 2010). One of the first tasks that the M\&S BoK effort has taken on is to assemble an index of M\&S terminology (Ören, 2010).

Again, when considering the seriousness of various applications of M\&S, including the military, a Code of Ethics has been developed for "Simulationists" and adopted by 12 organizations internationally, including the international NorthAtlantic Treaty Organization Research and Technology Organization's Modeling and Simulation Group (NATO RTO MSG). (Ören, 2002).

All of these points can be summarized by an apparent desire by some groups to professionalize the "discipline of M\&S". Ören (Sokolowski \& Banks, 2009) described the study of simulation:

"Simulation as a discipline is like mathematics and logic. It can be studied per se to develop its own theories, methodologies, technologies and tools; and it can be used in a multitude of problem areas in many disciplines." (Sokolowski \& Banks, 2009)

\subsubsection{M\&S as an Industry}

The M\&S market is immense, however not having been recognized as an industry unto itself has hampered accurate estimates of its size and growth. 
Recent analysis from Frost and Sullivan estimates that there was $\$ 22.2$ Billion (USD) spent by the U.S. Military Training and Simulation Market in 2009 alone (Frost, 2010). While the U.S. is likely the largest consumer of M\&S technologies, this figure represents but one nation in one fiscal year. Furthermore, Frost (2010) forecasts that there will be a compound annual growth rate of 1.4 percent from Fiscal Year 2009-2015. This analysis confirms notions held by M\&S practitioners that the market is large and continuing to expand as new applications of M\&S are developed.

In 2010, a coalition of M\&S Practitioners, led by the American National Training and Simulation Association (NTSA), applied to the Office of Management and Budget (OMB) to have M\&S companies recognized as their own industry (National Center For Simulation, 2010). While this attempt was turned down, there are renewed efforts to still pursue this course of action.

Whether M\&S is eventually established as a "formal industry", or develops consensus on its own Body of Knowledge is not of importance in this work; what should be noted is that there is sufficient evidence that there is great interest, investment and development that make it an interesting domain to be a part of and to conduct research into.

\subsubsection{M\&S Reuse}

Amongst M\&S practitioners, reusing previous work (and avoiding redundant and wasteful effort) is a recurrent challenge. While the benefits are obvious to 
some, in many cases these benefits do not outweigh the cost in terms of time, effort or resources in order to enforce reuse of previous work that has been done by parallel or partner organizations.

The US DoD's Modeling and Simulation Coordination Office (M\&S CO) sets standards for use of M\&S in the DoD. M\&S CO conducted a study on the issue of reuse of M\&S assets, having it formally reviewed in a report. Shea \& Graham (2009) evaluated various business models in order to seek out ways to overcome this challenge. They lay out six categories of reasons why M\&S resources are not reused, and it can be said that all of these challenges also apply to Canadian M\&S practitioners (Shea \& Graham, 2009).

The governance of M\&S in DND is described in administrative orders that have directed that the departmental-level Synthetic Environment Coordination Office shall "coordinate development of a M\&S resource repository [MSRR], which acts as a bank for M\&S shareable models, data and information" (Department of National Defence, 2006b). Such a repository is still in development with the prime purpose of promoting reuse of M\&S assets across the DND and CF. It can be inferred that having visibility into what M\&S technologies organizations within the DND/CF have, and are developing is of interest to stakeholders within the defence community. 


\subsection{Military Transformation}

Within many modern militaries, evolution of the military personnel, processes, and technologies is known as "military transformation". There are a number of military transformation efforts, as well as military transformation documents that have been published in recent years. The salient thrusts within military transformation shall be summarized in this Section.

\subsubsection{Strategic Direction}

The Canada First Defence Strategy (CFDS) focuses on how the Canadian Forces must transform and modernize in order to continue to fulfill its mandate within the Government of Canada (Department of National Defence, 2008). The CFDS details six roles for the Canadian Forces ranging from humanitarian missions to domestic security to high-intensity combat operations. In essence, the updated CFDS details to the DND/CF what missions and roles it must be prepared to fulfill.

Within the Department of National Defence (DND), strategic planners put a significant body of effort into trying to determine how future military operations may be characterized. This is documented in a series of publications, termed the "Future Security Environment (FSE)", within which are a set of 45 deductions on various factors, including Geopolitical, Social, Technological, Economic and many other factors (Department of National Defence, 2009b). Based on this 
broad range of factors with regards to the future, the key deduction in this work reads as follows:

A complex future security environment will demand a comprehensive, integrated, adaptive, and networked focus in the application of government policy. [emphasis added] (Department of National Defence, 2009b)

This statement serves as a one-line target for defence innovators. Using the CFDS and the FSE, military planners are able to focus defence priorities towards the most urgent gaps in capabilities. These notions of "integrated" and "networked" not only have implications for the technologies involved, but also for the defence innovators that must collaborate to innovate.

\subsubsection{Science and Technology Advancement and Disruption}

The branch of the Canadian Department of National Defence (DND) that is charged with innovating on behalf of the entire department is Defence Research and Development Canada (DRDC). Their Defence Science and Technology Strategy seeks to identify disruptive technologies, and create conditions for successful innovations throughout defence (Department of National Defence, 2006). The FSE documents confirm the motive for this strategy: "Science and technology trends are characterized by innovation and rapid change." (Department of National Defence, 2009b). 
Disruptive innovation, in some circles, is tightly linked in military parlance to "forces transformation". Dr. Alberts describes this as such:

"Information Age Transformation focuses its attention on the nature and process of transformation, identifying critical path items including the need for creating conditions for disruptive innovation and a variety of experimentation activities." [emphasis added] (Alberts \& Hayes 2003)

Dr. Alberts and Dr. Hayes' publications through the US Command and Control Research Program (CCRP) are foundational works (Alberts \& Hayes, 2003; Alberts \& Hayes, 2007) which have been used as inputs to many allied nations own transformation efforts - including DND/CF's FSE. These works highlight a future military force's requirement to be agile, networked within an environment that is increasingly complex - both in military operational as well as technological terms. These documents set forth the argument that military transformation is required in order to better meet the current and future operational challenges.

\subsubsection{The Requirement to Collaborate}

A recurrent theme within both the international and Canadian strategic documents is that military operations (as well as advances in technology) shall continue to be collaborative and multinational in nature. There is an ever-present requirement for interoperability between various systems and organizations. 
Within the Canadian DND, DRDC holds establishing linkages with partners high in their strategy. Not only do defence scientists partner with the military services, but they develop close bonds with Defence Industry, national and regional research centres, Academia, as well as allied militaries and foreign research centres (Department of National Defence, 2006).

Ecosystems, can be seen as an analogy, or lens, through which to examine business networks. They are being increasingly used in the technology sector, however they have been used to a limited degree in the discussion of Government- or Public-led innovation. However, this is just a matter of time. The lead agency for M\&S in the US DoD is the Modeling and Simulation Coordination Office (M\&S CO) that sets standards and advocates for coordination and collaboration to solve many issues regarding M\&S throughout their Department. They have recently published a report regarding the development of a roadmap for evolving an integrated architecture for various Live, Virtual, Constructive (LVC) Simulations. One of the key propositions made is detailed in the following section of their LVC Architecture Roadmap report:

"We propose that the DoD M\&S business environment is best described as a business ecosystem." (Department of Defense, 2008)

Recently, DRDC has laid out strategy for improving their roles and strategy for partnerships (Williams, 2010). This included the formal identification of two key 
Ecosystems with which DRDC is embedded: a Defence and Security Ecosystem, and a Global S\&T Innovation Ecosystem (Williams, 2010). This can be better seen through their partnerships in such international endeavours such as The Technical Cooperation Program (TTCP), and the North Atlantic Treaty Organization's (NATO) Research and Technology Organization (RTO) and Allied Command Transformation (ACT) group - as well as many other partnerships. Denoting these relationships and interdependencies as being within an "ecosystem" has particular importance, which shall be further discussed within Section 2.4.5. This connection - of Ecosystems and Innovation Networks to the domain of M\&S in defence has much merit, as this research will show.

For many reasons, including economy of effort and resources, interoperability, it has been noted that it is critical for DND to partner with other organizations before it is required to do so on actual operations (Department of National Defence, 2006; Department of National Defence, 2008). The requirement to establish a pan-sector centre of excellence in innovation has been described as a "Defence And Security Innovation Centre (DASIC)" by Major (Retired) Bob Near (Near, 2007). Major Near makes the case that collaboration in innovation in the Defence and Security sector, between government, academia and industry is required - for many of the aforementioned reasons (Near, 2007).

As an example of Governments' willingness and intent to collaborate, the Coalition Warrior Interoperability Demonstration (CWID) has been established as 
an annual multi-national-level event. One of the top objectives for the demonstration includes the intent to "Enhance Coalition, Military, Government Agency and [Non-Goverment-Organization] Partnership Building Capabilities" (Department of Defense, 2009).

These concepts, strategies, events lead us to believe that the requirement to collaborate internationally, but also between various players within an innovation network will continue to be important for success in military operations.

\subsubsection{Enterprise Architectures}

As an important development from the military command and control computer systems area of expertise, the notion of Enterprise Architectures (EA) has come to the forefront in the development of complex military systems. Various standards exist, and are evolving continually. This includes the U.S. Department of Defense Architectural Framework (DoDAF) standard (Department of Defense, 2010), the Canadian Department of National Defence Architectural Framework (DNDAF) standard (Department of National Defence, 2010), and the Unified Profile for DoDAF and MODAF (UPDM) standard (UPDM Group, 2010).

These inter-related standards have definite overlap in scope and intent, and seem to be converging towards a possible international standard, along the lines of the UPDM standard which seeks to unify the US DoD and UK MOD's frameworks. Of note, these frameworks set out the standards for a set of interrelated views for complex systems, which offer defence innovators with a 
rigorous system for analyzing and designing complex systems. Some of the views and tools in development, some of which are still at a nascent stage, have promise to give a visualization of programmatic and organizational aspects of an innovation network. This includes the "Project Views" within the evolving DoDAF 2.0 (Department of Defense, 2010) and "Acquisition Views" within the evolving UPDM 2.0 (UPDM Group, 2010). However, at the time of this research, neither the Enterprise Architecture tools, nor the standards had evolved sufficiently to be used for this research. A full analysis of the applicability of Enterprise Architectures was outside the scope of this work, however there are some Recommendations (Chapter 7) and areas of Future Work (Chapter 9) which detail some possible avenues forward.

\subsection{Innovation Theory}

There are many areas of research within the domain of Innovation that are of relevance to this work. While there are examples of innovation in defence at many different levels within the DND and CF, the aforementioned Defence Research and Development Canada (DRDC) is the Departmental lead for military Science and Technology within DND.

The following Section summarizes the Innovation Theory stream of literature reviewed, focusing on applicable literature outside the defence realm that are of merit to this research. 


\subsubsection{Business Ecosystems}

The notion of Business Ecosystems has been introduced and evolved over almost two decades by the works of Moore, lansiti and Levien, amongst a number of others (Moore, 1993; lansiti \& Levien, 2002; lansiti \& Levien, 2004; lansiti \& Levien, 2004a; Moore, 2006).

The term "ecosystem" evokes the view of inter-relationships and dependencies between the constituent players in the ecosystem (or nodes in a network). There are numerous examples of business ecosystems that come to mind - whereby a keystone business collaborates with a number of other organizations, such that the overall network of players collaborate to the benefit of the overall network (or ecosystem). Examples include IBM's Eclipse Ecosystem, The Twitter Ecosystem, Google's Android Ecosystem and Apple's iPod Ecosystem - each of these centred around certain platforms or technologies, but where the various players have different contributory roles to play, for the overall benefit of all players.

The literature focuses on Business Ecosystems, and strategies for a given business or group of businesses within an ecosystem. There is little evidence of using the Business Ecosystem model within a Government or Public Sector context, including the military, with the exception of the aforementioned documents (Williams, 2010; Department of Defense, 2008). The applicability of 
the Ecosystem model to this research shall be further discussed in the Sections below.

\subsubsection{Orchestration and Innovation Networks}

A challenge within many innovative endeavours is orchestrating collaboration between the participants - especially if they are geographically and / or organizationally separated. A more challenging aspect is how to plan, coordinate and lead various organizations, when a softer type of leadership is required. A situation such as this might be more akin to orchestrating a musical composition (Dhanaraj \& Parkhe, 2006). Dhanaraj and Parkhe described how innovation networks often involve a "loose coupling" between the nodes or organizational members within the innovation network. As Dhanaraj \& Parkhe had identified, the type of indirect leadership required of the lead organization is akin to orchestration (Dhanaraj \& Parkhe, 2006).

In absence of measures that account for the loose coupling, there is a risk of innovating in silos (also known as "stove pipes"; Gray, 2008). Challenges include mobility of knowledge between the constituent organizations within an innovation network (including intellectual property issues). Gray gives lessons from the medical industry, and uses Dhanaraj and Parkhe's views on orchestration as a suggested method of bringing together geographically distributed teams. She suggests that looking at transdisciplinary teams that are distributed geographically are best viewed as innovation networks. Gray discusses 
discussing brokerage roles and innovation networks - from a perspective of leadership of the innovation network.

The notion of loose coupling and networks (with regards to loosely coupled systems, and standards) is also discussed in lansiti and Levien (2004b). What we can learn from this is that where there is loose coupling between nodes (or organizations) within a given innovation network, we can use the "softer" orchestrative strategies as discussed by Dhanaraj and Parkhe, as well as Gray's works (Dhanaraj \& Parkhe, 2006; Gray, 2008).

\subsubsection{Coordination Modules and Relationships}

Within a given grouping of organizations involved in a particular endeavour, work by Bailetti and Callahan (1993) evaluated methods of coordination internationally. They looked at four cases, and decomposed the complex relationships into five "coordination modules" from which international collaborative relationships would be based (Bailetti \& Callaghan, 1993). The five coordination modules are (Bailetti \& Callaghan, 1993):

- Strategic management module;

- Intra-organizational module;

- Joint management module;

- Technology exchange module; and

- Customer interaction module. 
These coordination modules can be used to further analyze the specific relationships between clusters of organizations within a given innovation network. The types of linkages between the nodes (organizations) can be categorized into types of coordination modules, or ensembles of coordination modules (Bailetti \& Callaghan, 1993).

The Ecosystem model puts emphasis on interconnection and networking of organizations - nothing is done in isolation. A key deduction is that relationships are of key importance in planning strategy for an organization. Gulatti and Kletter (2005) puts forth a view of the "Relationship-Centered Organization" (Gulatti \& Kletter, 2005). Their views of how to plan strategy for an organization complements views on ecosystems, innovation networks and coordination modules, as described above.

\subsubsection{Innovation Theory Applied to Military}

It is not a far stretch to review the salient innovation theory (summarized above) from a military perspective. This section will attempt to do that, bringing out particular military examples in applying innovation theory.

Abrahamson's work focuses on recombinant innovation, or, simply put, looking at how to best use existing resources in new and novel ways in order to improve overall performance (Abrahamson, 2004). This type of innovation is distinctly different from that "out of left field" drastically disruptive technology innovation, which may not have been foreseen by the masses (Abrahamson, 
2004). While many of his examples do focus on businesses within the IT industry, many of his propositions can be logically extended to the realm of defence innovation, including the stakeholders that take part in the delivery of defence technologies.

For example, in the US, a first-person shooter "Serious Game" called "America's Army" was introduced as a recruiting tool for the US Army. This game that was designed based on the Entertainment and Gaming industry's technologies, initially used as a recruiting tool, evolved into a training technology for serving military members (Smith, 2006). This is a good example how an existing technology was used in new and novel ways, with unexpected benefits.

Classical innovation theory from Christensen et al (2004), including Christensen's Law of Disruption (Christensen et al 2004) has surfaced in military conceptual documents such as Alberts' and Hayes' works (Alberts, \& Hayes 2003; Alberts, \& Hayes 2007). The notion of technological disruption continuing into the future, and becoming something that can be expected, and planned for, has become part of our strategy vision documents as well - including the Future Security Environment publications (Department of National Defence, 2009b).

Adner (2006) postulates that "Successful innovation requires tracking your partners and potential adopters as closely as you track your own development process" (Adner, 2006). Applying this to our notion of ecosystems, innovation networks, and Defence Innovation Networks in particular, Adner could be said to 
be advocating mapping a Defence Innovation Network, down to the adopters / end-users / military members to use these technologies in actual operations.

Innovative endeavours in the military realm often include collaborative events (technical demonstrations, experiments or exercises), funding, technologies - all which require a great degree of planning, collaboration and partnership. Since there is often no formal authority or "Chain of Command" between nations in technical partnerships, the relationship adheres more to a "loose coupling" that is formed between the organizations.

\subsection{Other Relevant Literature}

Outside of the three main literature review streams above were some areas of interest that have relevance to this research. These areas are discussed below.

\subsubsection{Visualization and Social Network Theory}

Visualization can be used as both an explanatory and communication tool to make sense of complex data (Basole, 2009). Visualization has been identified as an essential step in the scientific process of moving from data to knowledge (Basole, 2009). Visualization approaches can be extremely valuable in business strategy, scenario planning, and problem solving. Applying this to the notion of complex networks, including innovation networks, and in the case of this research, to Defence Innovation Networks had not been done before within the literature reviewed. 
Mapping and visualizing Ecosystems is an evolving area of research. Weiss and Ganadharan (2009) sought out to map the complex "Mashup Ecosystem", involving complex APIs, and Mashups (Weiss and Gangadharan, 2009). They used social networking analysis methods, applied to the case of ecosystems to firstly map, and then analyze the overall ecosystem, including mapping measures of degree centrality, and interaction strength (Weiss and Gangadharan, 2009). Weiss and Gangadharan mapped out the technologies (APIs), companies (Mashups) and how they were interrelated.

The complex relationships between numerous technologies and numerous organizations that was demonstrated in Weiss and Gangadharan's (2009), as well as Basole (2009), gives indications on avenues forward on how to map and visualize a complex network.

\subsubsection{People, Processes and Technologies}

When considering introduction of systems, and in particular, Information Technology (IT) and software development, three key factors must be considered: People, Processes and Technologies (Khodabandeh \& Palazzi, 1994). The People, Processes, Technologies "Framework" seems to have originated from Khodabandeh and Palazzi (1994), but has been used in many different areas to represent the fact that technological advancement has implications beyond the mere hardware and software - the People, and the Processes by which they use the technology must evolve as well. 
This framework has casual use within military environments, and there are variants on it as well (such as Man, Machine, and Methods). Assuming that this framework is of interest to the question of Defence Innovation Networks, and Business Ecosystems, previous examples of mapping ecosystems seem to focus on the People and Technologies aspects, and not as much in mapping or analyzing the process aspect.

Ecosystems as described by lansiti and Levien (lansiti \& Levien, 2002; lansiti \& Levien, 2004; lansiti \& Levien, 2004a) focus on a number of "People" or organizations, inter-linked around a core technology or platform.

What we can learn from this work is that it would be of interest to be able to visually depict all three aspects, and query them as well; however, there is only precedence on the "People" and "Technologies", and this may prove difficult.

\subsection{Lessons Learned from the Literature}

There are a number of key deductions drawn from the literature, which have guided this research. The key points are discussed in the following section.

Rapidly evolving technology, increasing complexity in military operations, diminishing federal budgets, amongst other trends, have all pushed for Governments agencies to innovate more effectively. This has led to increased partnerships between countries, between industries, and even within a given organization, to better use existing resources between its constituent parts. 
As described above, the US DoD M\&S Business has been viewed as a Business Ecosystem (Department of Defense, 2008) and this helps identify strategies for collaboration, integration and interoperability. The notion of a Business Ecosystem can also be seen as a specific innovation network, where the roles of the various nodes ascribe to the "ecosystem" roles (e.g. Keystone, Niche Player, Dominator, etc.). This work will look at a more general Defence Innovation Network, which may have some similarities with Business Ecosystems, but may not conveniently align with the Keystone, Niche and other roles of its players.

Innovation Networks (and ecosystems) can be mapped and visualized in order to give a greater understanding of the complex relationships between the key elements in the network. There are examples of how People (Organizations) and Technologies have been mapped out and analyzed in the past.

More importantly, it has been noted that any given innovation network, or ecosystem is not a group nor entity unto themselves. The networks can be mapped out extensively, and defining the network's exact limits could be a challenging, if not futile exercise.

There are a number of key trends in technologies and the overall "operational" and business environment that are of relevance to this work. Additionally, there are some key challenges that constrain this operating environment, and fuel the motivation for this work. These "Trends" and "Challenges" form the context for 
this research. It is withın this context that the conclusions of this Thesis will be the most relevant, as will be described in the following chapters.

Figure 2-1 summarizes the Trends and Challenges that bound the Defence "Innovation Environment" which is the focus of this research.

With this review of the salıent literature behind us, we are now ready to discuss the method by which we will answer the key research question, and supporting questions.

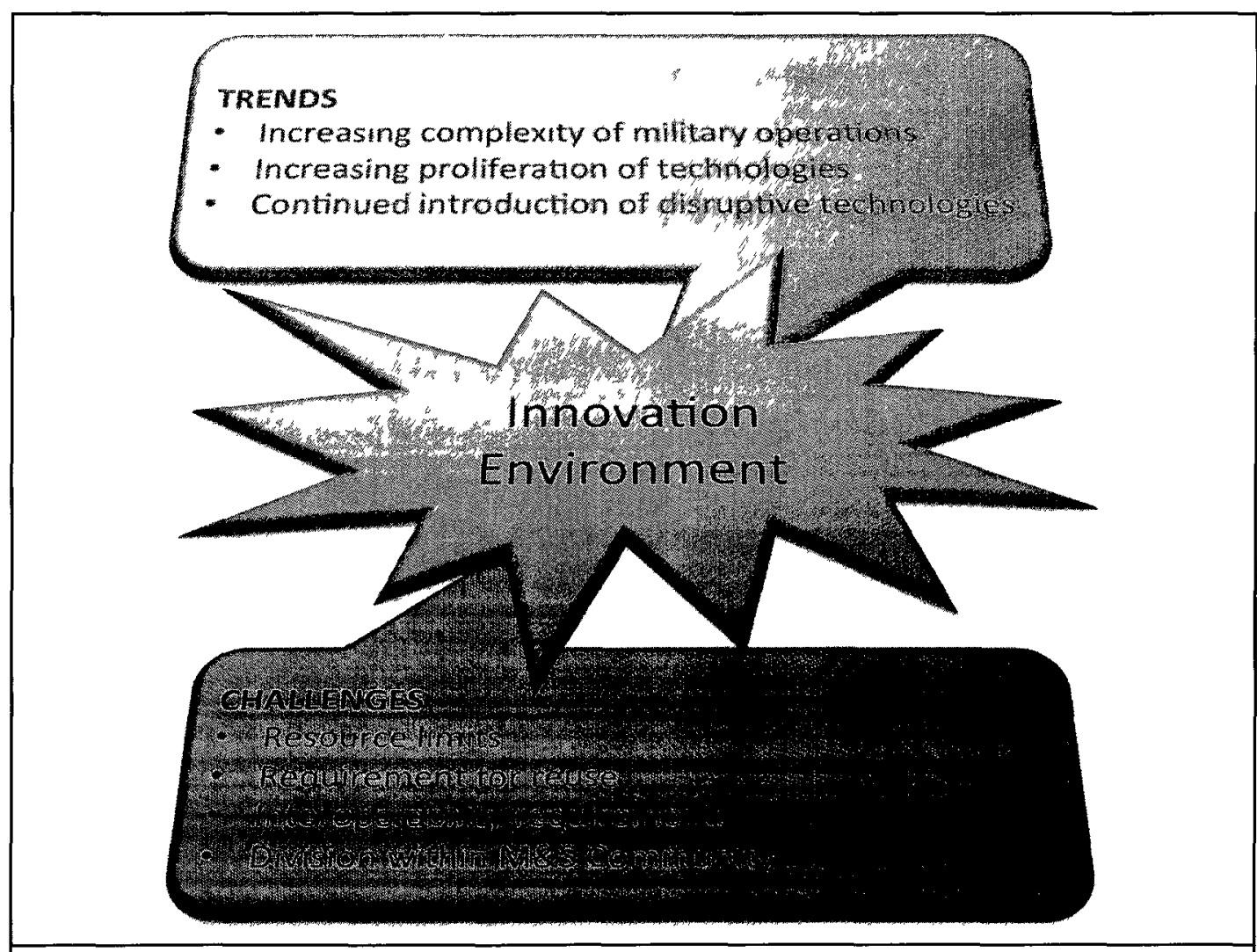

Figure 2-1 - Trends and Challenges Shapıng the Innovation Environment 


\section{RESEARCH METHOD}

\subsection{Research Question Formulation}

Based on the literature review summarized above, including the Trends and Challenges discussed, we are drawn towards two lines of investigation. Firstly, along the lines of Modelling and Simulation (M\&S), the question has arisen on how M\&S is used through a number of communities in defence, and if there is a unifying aspect of M\&S that could span the divided community. Secondly, from the perspective of innovation and collaboration, the question arises as to whether viewing the defence innovation environment as an innovation network be of benefit.

\subsection{Research Question}

The key research question being answered in this thesis is: "How do defence innovators collaborate to innovate using Modelling and Simulation, and can an innovation network viewpoint help identify areas for improving collaboration?"

This question is answered through an investigation along the lines of the following subordinate, more detailed questions:

Q1. How do defence innovators use Modelling and Simulation (M\&S) technologies in their innovative processes? 
Q2. How do defence innovators collaborate, and what are the types of relationships in defence innovation?

Q3. Is an innovation networks view appropriate for defence innovators?

Q4. What is the mapping of collaborators, partners, and key stakeholders involved in given demonstration projects?

Q5. Can visualization of an innovation network assist in planning strategies for defence innovation (specifically, research and development demonstration projects)?

Q6. Are there areas for improved collaboration, increased reuse within the given demonstration projects?

\subsection{Theoretical Framework}

This thesis uses applicable theory from the literature streams discussed in Chapter 2, namely Innovation Theory and M\&S.

Dhanaraj and Parkhe (2009) work on orchestrating innovation networks is used as a theoretical foundation for this research (Dhanaraj \& Parkhe, 2006). Furthermore, ecosystems theory, including the components to map within an ecosystem, as well as an innovation network is applied to this work.

Basole (2009), Weiss and Gangadharan (2009) works on mapping and visualizing ecosystems and networks is applied to this research, and forms the basis of the innovation network map that is being created (Basole, 2009; Weiss \& Gangadharan, 2010). Determining which network elements to map in an 
innovation network was drawn from both ecosystems theory, as well as innovation networks theory (Basole, 2009; Weiss \& Gangadharan, 2010; Gray, 2008; Gulatti \& Kletter, 2005). Applying the approach in Basole (2009), the following Table 3-1 illustrates the innovation network elements that were mapped (Basole, 2009):

\begin{tabular}{|c|c|}
\hline Element & Description \\
\hline Node & Organization or Technology in the Innovation Network \\
\hline Name & The name of the organization or technology \\
\hline Type & The type of node: Organization or Technology \\
\hline Details & Details on the node in question, including relevance \\
\hline Key Role & If key role, describe / highlight \\
\hline Data Source & Source of data for node \\
\hline $\begin{array}{l}\text { Link } \\
\text { Type } \\
\text { Direction }\end{array}$ & $\begin{array}{l}\text { Relationship between nodes in network (contract, } \\
\text { agreement, etc.) } \\
\text { Type of relationship (formal/informal, contract, agreement, } \\
\text { technical, etc.) }\end{array}$ \\
\hline Data Source & $\begin{array}{l}\text { Directed (uni- or bi-directional) or undirected } \\
\text { Data source / evidence of link between nodes }\end{array}$ \\
\hline & Table 3-1 - Summary of Network Elements \\
\hline
\end{tabular}

\subsection{Research Design}

This research examined Unclassified technology demonstration projects within the defence domain, which involve M\&S technologies. Projects were selected from the US Joint Capability Technology Demonstration (JCTD) 
Program, as well as the Canadian Technology Demonstration Project (TDP) Program. Data was gathered through official (releasable) project documentation. Although JCTDs and Canadian TDPs have notable differences, for the purposes of this research they are each expected to provide valuable insight on how interorganizational collaboration is done today, and how it may be improved in the future. This research encompasses qualitative case studies on specific innovation networks, centered around the specific technology demonstrations involving M\&S tools.

Based on theory on Case Studies (Eisenhardt, 1989; Eisenhardt \& Graebner, 2007; Yin, 2003b; Yin, 2003a), the research design must include four elements: what questions to study, what data are relevant, what data to collect, and how to analyze the results. These elements are described in the sections below.

\subsection{Detailed Research Method}

The reason for using a case study arises out of the desire to understand complex social phenomena. Yin cites examples where case studies can be an appropriate research method. Yin's examples that resonate with this research including international relations, maturation of industries, and managerial processes (Yin, 2003b). Case studies are an appropriate research method when there are more "how" or "why" questions are being sought out, when "the investigator has little control over events, and when the focus is on a contemporary phenomenon with some real-life context" (Yin, 2003b). 
This research follows a Two-Case explanatory Case Study (Yin, 2003a). This research seeks to expand theory on innovation networks, applying them to the defence modelling and simulation environment. A Two-Case Case Study has the benefits of being able to compare and contrast different approaches to a particular problem domain. The two cases were selected due to their differing uses of M\&S in support of defence innovation, as well as different nation's approach to innovation and collaboration (with regards to funding levels and international participation). These two cases could be said to be sufficiently opposing that this study would be classified as a "Two-Tail" case study (Yin, 2003b), examining M\&S use from different sides of the spectrum of M\&S support to military applications.

The following steps were used: (adapted from Yin, 2003b)

\begin{tabular}{|l|l|l|}
\hline \multicolumn{1}{|c|}{ Phase } & \multicolumn{1}{c|}{ Activity } & \multicolumn{1}{c|}{ Details and Deliverables } \\
\hline $\begin{array}{l}\text { I. Define \& } \\
\text { Design }\end{array}$ & $\begin{array}{l}\text { Literature review } / \\
\text { develop theory }\end{array}$ & $\begin{array}{l}\text { - Identify theoretical framework upon } \\
\text { which to build research } \\
\text { - Derive Innovation Network key Map } \\
\text { Elements from Literature Review } \\
\text { - Develop the study's questions } \\
\text { - Develop M\&S Support Categories to } \\
\text { military applications }\end{array}$ \\
\hline
\end{tabular}




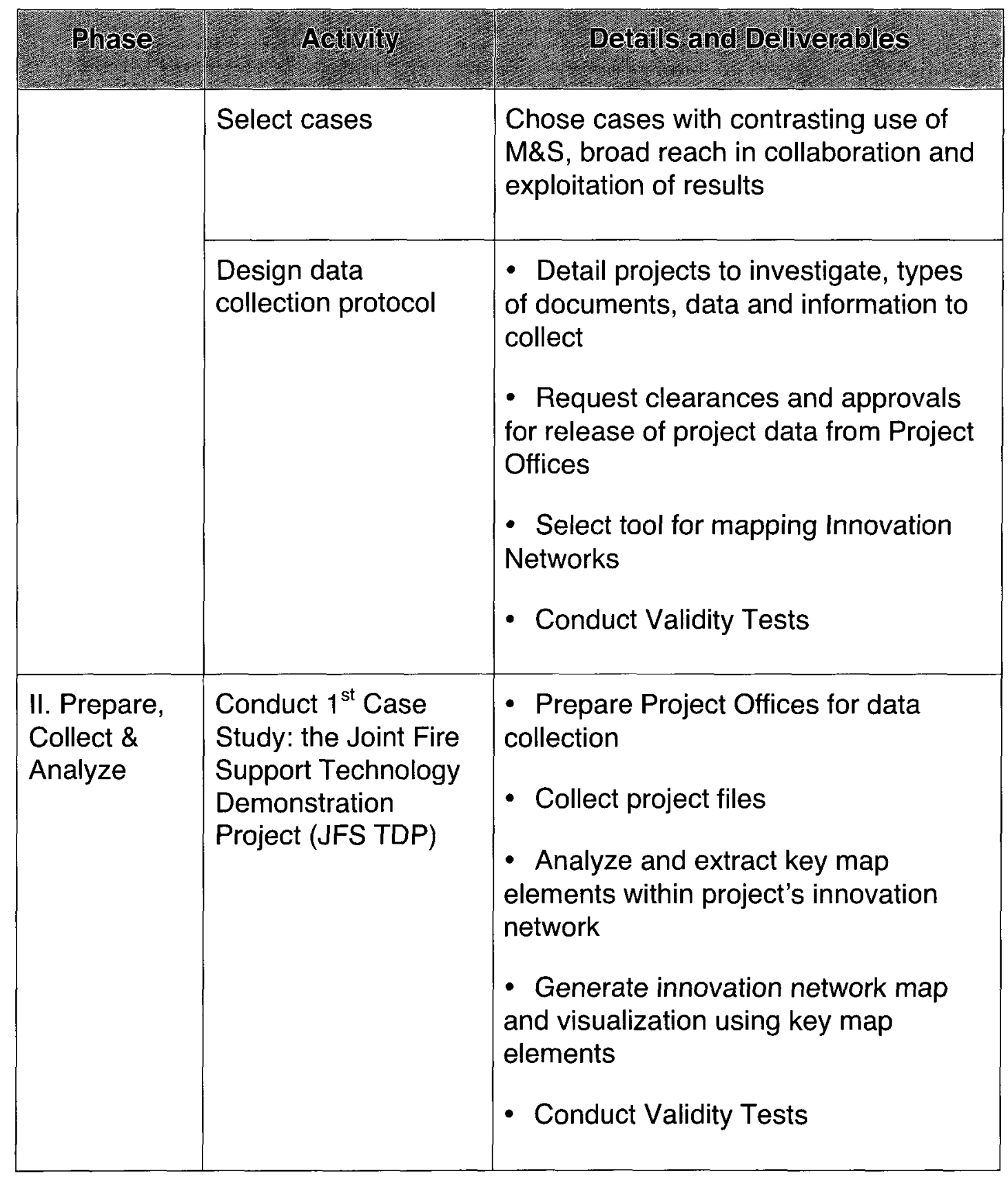




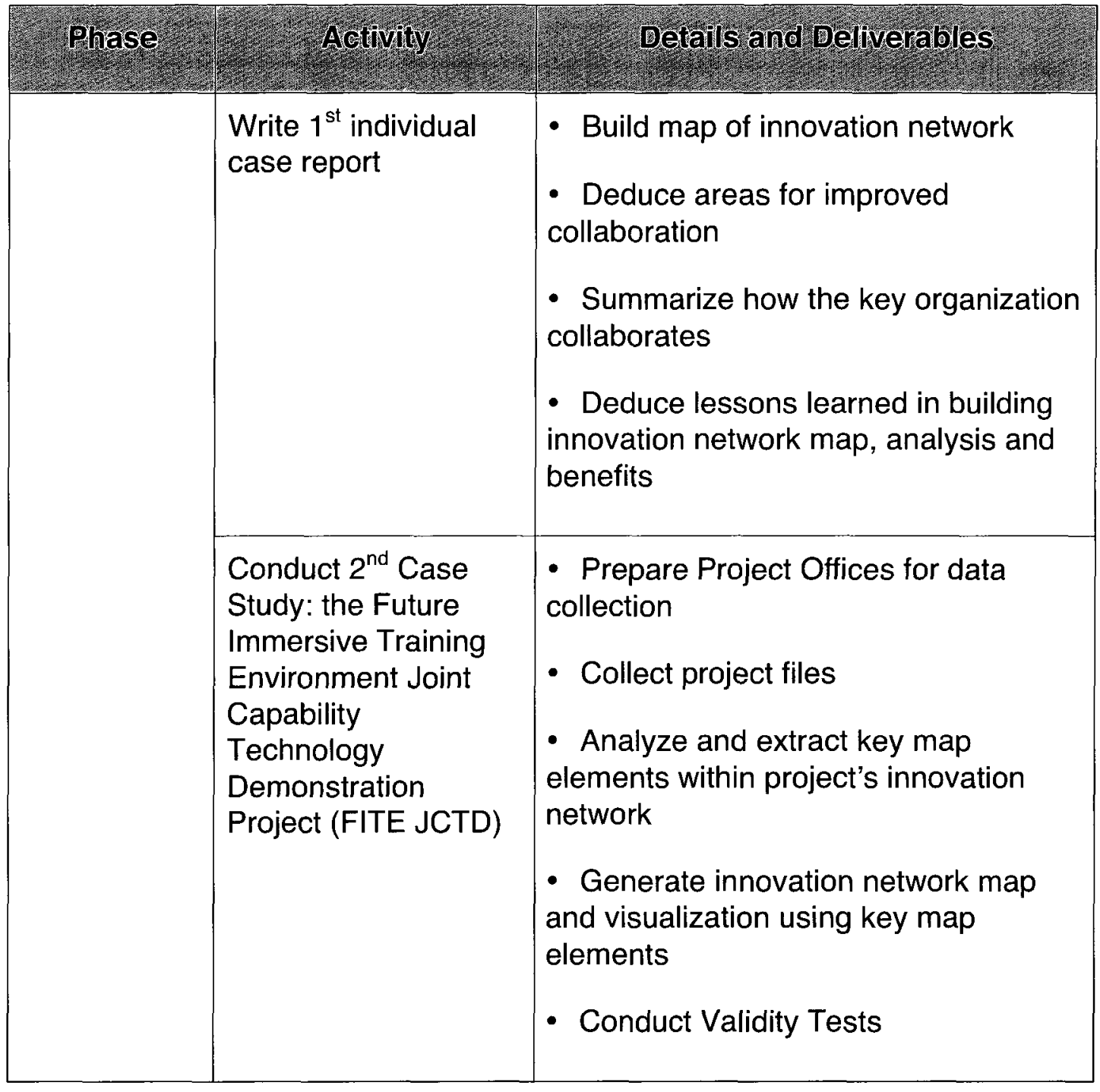




\begin{tabular}{|c|c|c|}
\hline Ph & Activi & Details and Deliverables \\
\hline & $\begin{array}{l}\text { Write } 2^{\text {nd }} \text { individual } \\
\text { case report }\end{array}$ & $\begin{array}{l}\text { - Build map of innovation network } \\
\text { - Deduce areas for improved } \\
\text { collaboration } \\
\text { - Summarize how the key organization } \\
\text { collaborates } \\
\text { - Deduce lessons learned in building } \\
\text { innovation network map, analysis and } \\
\text { benefits } \\
\text { - Conduct Validity Tests }\end{array}$ \\
\hline \multirow[t]{3}{*}{$\begin{array}{l}\text { III. Analyze \& } \\
\text { Conclude }\end{array}$} & $\begin{array}{l}\text { Draw cross-case } \\
\text { conclusions }\end{array}$ & $\begin{array}{l}\text { - Physically draw the innovation } \\
\text { network map superset, including sub- } \\
\text { networks from each demonstration } \\
\text { project. } \\
\text { - Conduct Validity Tests }\end{array}$ \\
\hline & Modify theory & $\begin{array}{l}\text { - Extend innovation network and } \\
\text { ecosystems theory with applications to } \\
\text { defence innovation } \\
\text { - Analyze linkages and apply } \\
\text { "coordination module" theory }\end{array}$ \\
\hline & $\begin{array}{l}\text { Write cross-case } \\
\text { report }\end{array}$ & $\begin{array}{l}\text { - Key deductions drawn from } \\
\text { differences and similarities between } \\
\text { JFS TDP, FITE JCTD, as well as } \\
\text { overall US/Canadian Defence } \\
\text { innovation approaches } \\
\text { - Conduct Validity Tests }\end{array}$ \\
\hline \multicolumn{3}{|c|}{ Table 3-2 - Research Method Steps } \\
\hline
\end{tabular}


Now follows a discussion of some of the key activities that were executed in the conduct of this research. The Steps or Sub-Steps that have already been discussed (e.g. Literature Review and Research Questions) will not be reviewed again; however, the following sections shall focus on the activities that warrant explanation. While data validation occurred through the various steps, a discussion on how data validation was done succeeds this Section, and will be discussed in Section 3.6.

\subsubsection{Phase I: Define and Design}

Social research (Eisenhardt, 1989; Eisenhardt \& Graebner, 2007; Yin, 2003b; Yin, 2003a) details that there are some key elements to a Case Study that should be determined in its design. Additionally, there were unique activities that were conducted in this research. These are discussed in this section.

\subsubsection{Develop M\&S Support Categories}

In order to better explain how M\&S tools and technologies were used within these cases, and beyond, a secondary line of investigation was pursued to better understand the application of M\&S to the defence domain. This was done through a review of a sub-set of the literature (discussed above), focusing on M\&S applications to defence. National (Canadian) and international sources were used to derive an ontology of terms used to describe applications of M\&S in defence. That ontology was developed into a hierarchy of M\&S applications 
categories and sub-categories that gives a structured overview of what types of applications M\&S could be used for. It must be noted that while the M\&S Support Categories would be broad-reaching, it was not anticipated that the focal case studies would involve that many categories or sub-categories. As such, the M\&S Support Categories are a supporting deliverable to the innovation network map that was to be constructed. However, the M\&S Support Categories offer a contribution beyond the limits of the innovation networks that were mapped.

\subsubsection{Unit of Analysis and Case Study Selection}

This work examined defence research and development (R\&D) projects involving M\&S, and were selected from a population of dozens of past and present R\&D projects in Canada and the United States. Within each of those projects the unit of analysis was an innovation network element. The innovation network elements included nodes representing organizations or technologies, and links representing relationships or dependencies between organizations and/or technologies. The overall population of innovation network elements around one project encompasses all organizations, technologies, relationships and interdependencies within that project. The innovation network elements used in this research were a sample of the major innovation network elements, since they were sourced from many project documents, from each project, and all major organizations, technologies, relationships and interdependencies were discussed in the project documents. 
The case study projects were selected from within the Canadian Department of National Defence (DND) and US Department of Defense (DoD) R\&D programs. These cases were selected because of the innovation that is done in defence development projects. They were selected from many projects from each nation, and they were selected due to their contrasting use of M\&S technologies in their innovative endeavours - for the US project it was a focal group of technologies under development, and for the Canadian project it was a supporting technology, in the background. Additionally, the projects were selected due to their different approach to innovation and collaboration (with regards to funding levels and international participation)

The following projects were studied:

\section{a. Joint Fires Support Technology Demonstration Project (JFS}

TDP). The JFS TDP is led by Defence Research and Development Canada (DRDC) within the Canadian DND. This is a unique Joint project, involving technologies from across military services (Air Force, Navy, Army). Here is a summary of the project:

i. $\quad$ Budget. $\$ 7.5 \mathrm{M}(\mathrm{CAD})$ plus $\$ 3.8 \mathrm{M}(\mathrm{CAD})$ in-kind from partner organizations

ii. $\quad$ Project Duration. April 2006 - March 2013.

iii. Number of Organizations. 43 
iv. Number of Core Technologies Under Development. $7 \mathrm{M} \& \mathrm{~S}$

technologies plus 17 Command and Control-related Systems - total

24 core technologies being developed or evaluated.

\section{b. Future Immersive Training Environment Joint Capability}

Technology Demonstration (FITE JCTD). The FITE JCTD is managed within the United States Joint Forces Command (US JFCOM). Here is a summary of the project:

i. $\quad$ Budget. $\$ 36 \mathrm{M}$ (USD)

ii. $\quad$ Project Duration. January 2009 - January 2011

iii. Number of Organizations. 89 (varying roles, varying levels of involvement - from observers to suppliers, and core team as well)

iv. Number of Core Technologies Under Development. 12

A more detailed discussion of each project, focusing on the results after analyzing the projects, shall be detailed in Chapter 4 .

\subsubsection{Data Collection Protocol}

The research questions, and literature review indicated that the research should seek to map out innovation networks surrounding the case studies involved. Once the cases were selected, the possible data set was focused to the sub-set of data that would be both relevant, reasonably available, and releasable. Data was drawn from and released through the project offices, as well as through open sources on the internet (e.g. published articles about the projects under 
study). This Project Data was fused with open-source data sources including the Modelling and Simulation Body of Knowledge - M\&S BoK (Ören, 2010).

The map elements that were to be mapped out were People (Organizations), Technologies, and Relationships. These elements shall be further explained in Chapter 4, however, it is important to note how these elements were sought out in data, and incorporated into the map.

Data on People (Organizations). Data on the People (Organizations) involved in the projects was sought within the M\&S BoK (Ören, 2010), as well as Project Documents, and open source documents.

Data on Technologies. Data on the technologies involved within the Projects were drawn from the Project Documents, including technical specifications, systems design documents, and architectural schemata.

Data on Relationships. Data on the relationships between organizations were drawn from unclassified and releasable project documents, and relevant agreements between the organizations managing and directing the projects. Some examples of these document types are:

- Data Exchange Agreements (DEAs)

- Memoranda of Understanding (MoUs)

- $\quad$ Service-Level Agreements (SLAs)

- $\quad$ Technology Transfer Agreements (TTAs)

- $\quad$ Project Arrangements (PAs) 
- Contracts and deliverables, including Statements of Work (SOWs), Foreign Military Sales (FMS) Contracts, deliverables, reports, etc.

\subsubsection{Network Visualization Tool Selection}

With the data collection planned, it was necessary to identify early on what suitable tool would suffice for modelling the innovation networks. It was found that there was no tool that met all the modelling requirements of an innovation network (e.g. designed to model in-depth details, visualization requirements (e.g. colour-coding, scalability), as well as the analytical requirements to extract information (e.g. searching, reporting, social network analysis).

There were a number of different technologies available to map out relationships and linkages. These include Architectural Framework Tools within the defence domain that strongly support visualization of complex systems. While the DoDAF 2.0 standard does encompass Project Views (Department of Defense, 2010) that promise a potential possibility to map some organizations and relationships, there were no readily available tools that supported this newer standard yet. The evolving UPDM 2.0 standard (UPDM Group, 2010) includes to "Acquisition Views" which build on DoDAF 2.0 Project Views, and are expected to similarly have the ability to map organizations and relationships. However UPDM 2.0 has not been ratified yet, and there are no available tools to support UPDM 2.0 nor DoDAF 2.0 yet. The Canadian DNDAF 1.7 standard did not have any dedicated views for mapping out complex relationships and organizations, 
although it is anticipated that a future revision of the DNDAF standard may (Department of National Defence, 2010). In summary, while the Enterprise Architecture movement in defence would be a logical domain within which to map out innovation networks surrounding distinct defence projects or complex systems, there were no suitable standards nor tools supporting them yet.

Within the "traditional" social network area of research, there were many tools that have been used in the past. These tools typically focus on link-node representation, with weights and direction assigned to the links. Tools such as Indiana University's Network Workbench have been prevalent in other network analyses. These tools typically have simplistic visualization, and rigid design and layout, limiting the ability to customize the visualization and highlight unique aspects and hierarchies, as are present in this research. The social network modelling tools reviewed focused on modelling larger scale networks, when there are many more links and nodes, which was not anticipated within this research.

A beautiful marriage between visualization and complexity is the BLOOM Project's Ecosystem Browser (Horsfall et al, 2010). This tool, which is still under development, is based on an open-source visualization engine called "Flare". Unfortunately, while this tool would likely have been very well suited to the needs of this research, it was still under development and hadn't been developed sufficiently to support this research. 
The emergence of "Mind Mapping" tools have become a "widely used method" of mapping within the domain of visual methods for knowledge sharing (Eppler, 2006). Tools such as Mindjet's MindManager can be used for mapping out complex problem spaces, including relationships between the various elements within a given map. These tools focus on ease-of-use, and visualization of the complex problem space.

Of the available Mind Mapping Tools reviewed, ConceptDRAW MindMap 6.2.16.0 (CS Odessa, 2010) was selected to map the innovation networks within this research. This tool's strength in visualization, the inherent hierarchy of the network map, and its ability to represent many different types of data types and structures made it ideally suited to the requirements of this research. Additionally, it had a basic search capability for finding keywords within the network map, as well as an Import / Export capability that gives the possibility of extracting the map generated within this research for potential future use in other tools. ConceptDRAW MindMap was deemed suitable for this "proof of concept" visualization of the innovation network, and aided the research in identifying detailed requirements for a more robust tool that could be developed in the future (detailed in Chapter 7, Recommendations).

\subsubsection{Phase II: Prepare, Collect and Analyze}

With the foundational Phase I complete, available data was acquired and analyzed, and the salient innovation network map elements were extracted and 
inputted into the visualization tool. As detailed in Table 3-1, first for the Joint Fires Support Technology Demonstration Project (JFS TDP), and secondly for the Future Immersive Training Environment Joint Capability Technology Demonstration (FITE JCTD), any files that had information on various technologies, or people (organizations) involved, were directly entered into the visualization tool. If evidence was found of a given organization being involved, but their exact relationship was not evident, an assumption on their relationship was made, based on the nature of the organization. A mix of data types (project documents, white papers, articles) were used to corroborate information and validate the data that was inputted into the visualization tool.

With regards to technologies, a mix of supporting documents were used to map the technologies involved. Primarily technical drawings and systems design documents were used (when available), however some white papers, reports and articles were used to capture the core systems / technologies that were used, as well as some of the inter-dependencies between them. Technologies were separated in the innovation network map, so that there would be one section listing all of the core technologies involved. A future iteration of such a map could allow for various versions of a specific technology to be represented in the map, however this map simply represented whether a given technology was involved, or not. 
Each data source type (JFS TDP Project documents, FITE JCTD Project documents, Internet, M\&S BoK, or specifically DND websites) was assigned a symbol and nodes (People or Technologies) were labeled with which data source gave its inclusion in the map.

Relationships were represented by various arrows between the nodes. Whenever an explicit relationship was expressed within a document, it was represented in the map, whether it be a relationship between an organization and a technology, between organizations, or between technologies. Details on the data source of the relationship was included in both nodes "notes" on either end of the relationship. A legend was developed to represent the spectrum of relationships that were found in the data.

Once the individual projects were mapped out, the maps were visually reviewed to deduce if there were any apparent gaps in collaboration, or potential areas for improved collaboration. An assessment of how the lead organization for each project orchestrated collaboration and effort within its innovation network was made. Based on the innovation network maps generated, lessons were gathered on the mapping effort and extracted into Chapter 7, Recommendations, for future tool development.

\subsubsection{Phase III: Analyze and Conclude}

The last phase sought to take a wider view of the entire Innovation Network map by looking at the combination of the two innovation networks, alongside one- 
another. Organizations and technologies that were involved in both projects were identified, and deductions were drawn on potential synergies between the projects that could have been leveraged, if such a visualization and approach had been used at the outset.

A final round of analysis was done, between the projects, to determine the key players, and any special roles that were present. The key organization with the most links was coloured with a box the same colour as the project data source (Dark Grey border for JFS TDP and Pink border for FITE JCTD). Lastly, organizations and technologies that were common to both projects were highlighted with a green border, to show that they were common elements.

Using Bailetti and Callahan (1993), the relationships were then mapped to the five type coordination modules (Bailetti and Callahan, 1993). Recommendations were then made on the types of collaborative agreements that would be used in such endeavours.

\subsection{Data Validation}

The standard case study tests of validity are well-documented and summarized in numerous social studies texts (Yin, 2003b). Table 3-3 summarizes how these tests apply to this research (adapted from Yin, 2003b): 


\begin{tabular}{|c|c|c|}
\hline Tests & Case Study Tactic & Phase of Research \\
\hline $\begin{array}{l}\text { Construct } \\
\text { Validity }\end{array}$ & $\begin{array}{l}\text { Use multiple sources of } \\
\text { evidence } \\
\text { Establish chain of } \\
\text { evidence } \\
\text { Have key informants } \\
\text { review draft case study } \\
\text { report }\end{array}$ & $\begin{array}{l}\text { Data collection (Phase II) } \\
\text { Data collection (Phase II) } \\
\text { Composition (Phase III) }\end{array}$ \\
\hline $\begin{array}{l}\text { Internal } \\
\text { Validity }\end{array}$ & $\begin{array}{l}\text { Do pattern-matching } \\
\text { Do explanation-building } \\
\text { Address rival } \\
\text { explanations } \\
\text { Use logic models }\end{array}$ & $\begin{array}{l}\text { Data Analysis (all tactics) - Phase II } \\
\text { and Phase III }\end{array}$ \\
\hline $\begin{array}{l}\text { External } \\
\text { Validity }\end{array}$ & Use replication logic & Research design (Phase I) \\
\hline Reliability & $\begin{array}{l}\text { Use case study protocol } \\
\text { Develop case study } \\
\text { databases }\end{array}$ & Data Collection (Phase II) \\
\hline
\end{tabular}

Section 4.5 within Chapter 4 (Results), details the validation steps that were actually executed. This section describes in a bit more detail some of the aspects of the validation tactics that were highlighted in Table 3-3.

Construct Validity. Multiple sources of evidence were used, and a chain of evidence was represented directly in the innovation network map (data sources, 
relationship types). Where possible, between one and three key members (Project Management staff, and Supporting staff) working with the projects reviewed the innovation network map and the preliminary results of the research. Additionally, external peer reviews were sought out from within the Canadian Forces Warfare Centre (CFWC), the military M\&S community, as well as specific fora within the Science and Technology community.

Internal Validity. Within each case study, explanations were derived for the patterns that emerged. Furthermore, these patterns were linked to the "coordination modules" theory as well.

External Validity. Replication logic was used in this research to ensure that the method applied to each project would remain the same, so that the results could be compared and linked.

Reliability. The data sets were separated for each project, and the Innovation Network Map itself served as a case study database, denoting where network elements were derived from.

\subsection{Closure}

A simple "Stopping Rule" used within this research was to map out all the "core" technologies and organizations within each project, and the key relationships between the organizations within each project - both technical, organizational, and organization-technology relationships as well. Secondary relationships, as well as data from other sources (conferences, professional 
organizations, other supporting organizations) were also inputted, however if they did not have a key role in the given projects, the innovation networks demonstrated this.

It must be noted that these innovation networks could be extended on indefinitely, they were limited to the focal projects, organizations encountered, and the distinct key data sources involved (JFS TDP Project Documents, FITE JCTD Project Documents and M\&S BoK). 


\section{RESULTS}

The results of this research shall be presented in the sequence as identified in Chapter 3 (Research Method). Not all work generated shall be included in this Chapter, however, the key deductions and results shall be presented instead. Additional details on the work that has been done can be found in Appendix 1 , the Defence Innovation Networks Map.

\subsection{Framework Selection}

It was determined that the Defence Projects in study were subsets of complex, expansive, Global, multi-sector Innovation Networks. While there is some precedent for labeling these inter-related groups as an "Ecosystem" (see Chapter 2 for more), it was deemed that both Case Studies should be viewed as an Innovation Network. This was determined for a few reasons. Firstly, much of the existing literature on Business Ecosystems focuses on the firm's point of view, and gives little mention nor focus on the government's role in innovation. Simply put, the literature and theory focuses on the firm, and not the government's role, and certainly not delving into a government nor public sectorcentred perspective.

Secondly, the notion of networking, whether data networks, social networks, or networks of organizations, is well-rooted in military communities. For Defence Research and Development Canada (DRDC) who is the innovative lead within 
the Canadian Department of National Defence (DND), an innovation network is a very appropriate viewpoint for the type of collaboration that is done.

Although this work does use the term "Innovation Network" to describe the organizations and relationships collaborating in innovative endeavours within Defence, in the future there may likely be evolution of theory and practice in approaching innovation in defence as if it were an ecosystem - Chapter 2 summarizes what could be "seeds" of ecosystem terminology used in the defence domain.

\subsection{Map Elements}

As described in Chapter 3 (Research Method), one of the first tasks was to determine what should be mapped out in a Defence Innovation Network - i.e. what important elements should be collected and shown (visually).

As discussed in Chapter 2 (Literature Review) the People, Processes and Technologies model is pervasive in military Force Development, and can have some utility in this research. In addition, research in Ecosystems, including mapping thereof, looks at mapping various organizations (including people), as well as the interdependencies surrounding a given technology.

Building on these foundations, this work mapped out the following elements in the resulting Innovation Network Maps: People, Technologies and Relationships. These elements shall be briefly described in the following sub-sections. 


\subsubsection{People (Organizations)}

As discussed, many network maps (including ecosystem maps) focus on the key Organizations (or People, Players) in a given ecosystem. As such, a key part of the research was to map out the key players or organizations involved in each project. The organizations spanned different sectors, ranging from government organizations to industry to professional organizations.

\subsubsection{Technologies}

Innovation, Innovation Networks as well as Ecosystems theory tells us that networks of partnerships and dependencies are often organized around a core technology, product or platform (e.g. Apple's iPod Ecosystem, Eclipse Ecosystem, Google Search Ecosystem). Technologies involved were grouped into one of two groups: "Core" and "Support" technologies. The network map was flexible enough to allow for groups of technologies to be organized into systems and sub-systems. Where it was available, main systems were linked to their child sub-systems.

\subsubsection{Relationships (Interdependencies)}

Figure 4-1 summarizes the different types of Relationships that were mapped out: 


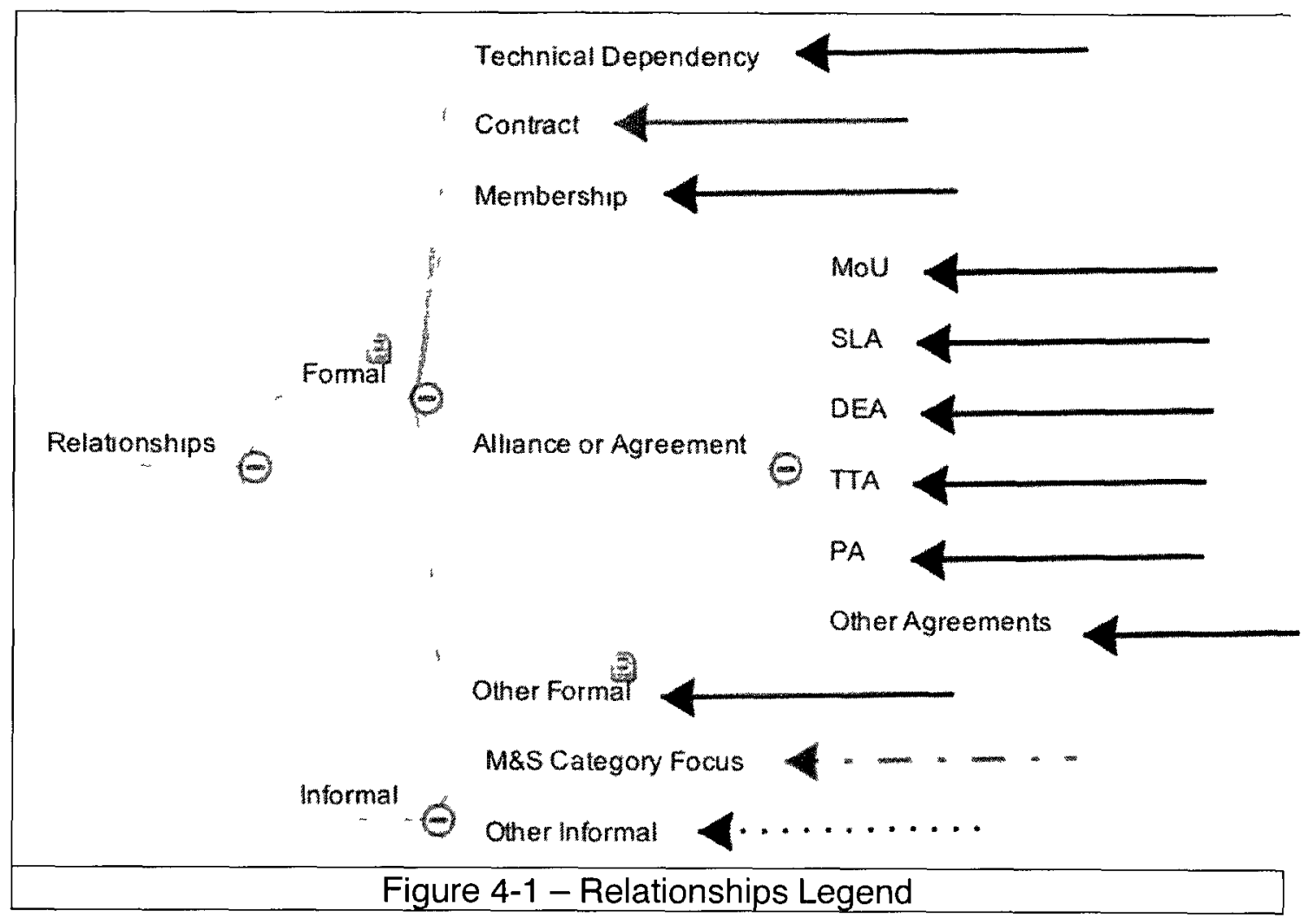

Collaborative Vehicles. After an initial review of the two Case Study's data was done, it was found that there were many mechanisms for collaboration between organizations. This ranged from more formal arrangements and agreements, with legal or pseudo-legal wording, to informal agreements. In many procurement and acquisition communities, formal contracts between parties can be described as "Contractual Vehicles" - to denote that they are a means of moving work, and in the end, a conduit for innovation to be done. In this vein, the term "Collaborative Vehicles" is coined to denote both formal and informal mechanisms by which organizations can collaborate. This includes formal 
contracts, with legal content and implications, as well as other formal agreements. The agreements between organizations permitted the legal or formal framework for the flow of data, information and resources. Some examples of agreements are Data Exchange Agreements (DEA), Service-Level Agreements (SLA), Technology Transfer Agreements (TTA), Memoranda of Understanding (MoU). These agreements are of key importance, as they can be the authority by which many innovative endeavours are conducted. For the most part, these agreements and contracts were time-bound, and have specific scope detailed. Often these agreements were the foundation from which collaborative Data Networks are formed, to connect the partnering organizations. Also, the agreements often call for a governance structure for meetings, and decisions to be made, through the establishment of Communities of Practice, Centres of Excellence, Standing Committees, Technical Panels, etc.

Resource Flows. Many previous efforts in ecosystem and innovation network mapping sought to map the flow of resources between organizations. The types of resources are typically in the form of Personnel, Funds, or Data / Information. Within the construct detailed above, the flow of resources is governed by, and permitted through the auspices of the relevant Collaborative Vehicle (e.g. contract or agreement). Within this body of work, rather than the specific resources, the authority by which resources were exchanged were mapped (i.e. the collaborative vehicle or other relationship linking the organizations). 
Technology Dependencies. Within Systems Engineering efforts, the requirement to map out inter-dependencies between complex systems and System-of-Systems has been done, including traditional interconnect diagrams and architectures. Within many Project data, such dependencies were found, and it was determined that they are of relevance, and could also be represented in the Innovation Map.

M\&S Support Categories. The M\&S Support Categories that were derived in this research (discussed below) could also be represented as an "Informal Relationship" to denote an organization's particular interest or focus, if apparent. How M\&S categories were linked to specific organizations is discussed within the Case Study Reports, below.

\subsubsection{Outlier: Visualizing Processes}

Although the People, Processes and Technologies model does have merit in overall evaluation of a capability and its impact on a complex environment, the mapping of processes within a network map was outside the scope of this work.

There are some recommendations and areas of future work that have been identified, which shed light on how visualizing the "Procedural" complexity within Innovation Networks may be addressed, including use of formalisms for procedures (e.g. Business Process Modeling Notation - BPMN). 


\subsection{Categories of Modelling and Simulation Support to Military}

\section{Applications}

Within the early phases of this research, it was assumed that there would be a formal, well-documented method of describing how Modelling and Simulation (M\&S) is used within the military domain - perhaps even a community-endorsed standard of M\&S applications within (or external) to the military. As described in Chapter 2, this was not true. There is division within the M\&S community, with academic focus on dissection of M\&S itself, with types of models, simulations being well-documented and described. However, a consensus on the application of various M\&S technologies through a continuum of military activities was lacking.

We will now give an overview of the data sources, keywords that were extracted from various literature, the ontology derived, and then the final groupings and Category definitions.

\subsubsection{Data Sources}

Building upon the Literature Review, as well as cues from the Case Study Project's data, a list of sources in the M\&S community were assembled. These sources had various ways of describing the use of M\&S, or military activities. The 20 sources were from both within the military, and some sources external to military applications of M\&S. They are summarized in Table 4-1 (full details are within the Defence Innovation Network Map - Appendix 1): 


\begin{tabular}{|c|c|c|c|}
\hline SER & $\begin{array}{c}\text { SOURCE } \\
\text { REFERENCE }\end{array}$ & SOURCE DESCRIPTION & $\begin{array}{c}\text { M\&S } \\
\text { DESCRIPTION / } \\
\text { OVERVIEW }\end{array}$ \\
\hline 1 & $\begin{array}{l}\text { (Department of } \\
\text { National Defence } \\
\text { 2010a) } \\
\end{array}$ & $\begin{array}{l}\text { Canadian Military - Canadian } \\
\text { Forces Warfare Centre's } \\
\text { Capability Definition Paper }\end{array}$ & $\begin{array}{l}\text { Five (5) areas } \\
\text { where M\&S can } \\
\text { be used. }\end{array}$ \\
\hline 2 & $\begin{array}{l}\text { (Department of } \\
\text { National Defence } \\
\text { 2010a) } \\
\end{array}$ & $\begin{array}{l}\text { Canadian Military - Canadian } \\
\text { Forces Distributed Simulation } \\
\text { Capability }\end{array}$ & $\begin{array}{l}\text { Eight (8) Core } \\
\text { Synthetic } \\
\text { Environments }\end{array}$ \\
\hline 3 & $\begin{array}{l}\text { (Department of } \\
\text { National Defence } \\
\text { 2005a) }\end{array}$ & $\begin{array}{l}\text { Canadian Military - Canadian } \\
\text { Land Force Command (Army) } \\
\text { Order }\end{array}$ & $\begin{array}{l}\text { Five (5) Domains } \\
\text { of M\&S }\end{array}$ \\
\hline 4 & $\begin{array}{l}\text { (Department of } \\
\text { National Defence } \\
\text { 2006) }\end{array}$ & $\begin{array}{l}\text { Canadian Military - DRDC's } \\
\text { Science and Technology } \\
\text { Strategy }\end{array}$ & $\begin{array}{l}\text { Two (2) Business } \\
\text { Lines (within } \\
\text { which M\&S } \\
\text { supports) }\end{array}$ \\
\hline 5 & $\begin{array}{l}\text { (Department of } \\
\text { National Defence } \\
\text { 2009a) }\end{array}$ & $\begin{array}{l}\text { Canadian Military - DRDC } \\
\text { CORA Website }\end{array}$ & $\begin{array}{l}\text { Three (3) } \\
\text { Domains and Six } \\
\text { (6) Issues where } \\
\text { OR\&A is used }\end{array}$ \\
\hline 6 & $\begin{array}{l}\text { (Kim et al. 2005) } \\
\text { and (Youssef et al. } \\
2006)\end{array}$ & $\begin{array}{l}\text { Canadian Military - DRDC } \\
\text { Ottawa - Joint Simulation and } \\
\text { Modelling for Analysis, } \\
\text { Requirements, Training and } \\
\text { Support (JSMARTS) Reports } \\
\text { / Tech Notes }\end{array}$ & $\begin{array}{l}\text { Five (5) or Four } \\
\text { (4) Phases of } \\
\text { Capability } \\
\text { Development / } \\
\text { Engineering } \\
\text { where M\&S would } \\
\text { be used }\end{array}$ \\
\hline 7 & (Espenant 2004) & $\begin{array}{l}\text { Canadian Military - } \\
\text { ADM(Materiel) JSMARTS } \\
\text { Workshop }\end{array}$ & $\begin{array}{l}\text { Four phases in } \\
\text { "SMARTS", with } 9 \\
\text { sub-activities } \\
\text { which M\&S } \\
\text { supports }\end{array}$ \\
\hline 8 & $\begin{array}{l}\text { (Roman and Surdu } \\
\text { 2009) and (Roman } \\
\text { and Surdu 2010) }\end{array}$ & $\begin{array}{l}\text { Canadian and US Military - } \\
\text { Article on Simulation Support } \\
\text { to Operations }\end{array}$ & $\begin{array}{l}\text { Five (5) } \\
\text { applications where } \\
\text { simulation can be } \\
\text { used in } \\
\text { Operations }\end{array}$ \\
\hline
\end{tabular}




\begin{tabular}{|c|c|c|c|}
\hline SER & $\begin{array}{c}\text { SOURCE } \\
\text { REFERENCE }\end{array}$ & SOURCE DESCRIPTION & $\begin{array}{c}\text { M\&S } \\
\text { DESCRIPTION / } \\
\text { OVERVIEW }\end{array}$ \\
\hline 9 & $\begin{array}{l}\text { (Department of } \\
\text { Defense 2009) }\end{array}$ & $\begin{array}{l}\text { U.S. Military - U.S. DoD's } \\
2008 \text { Modeling and } \\
\text { Simulation Corporate and } \\
\text { Cross-Cutting Business Plan }\end{array}$ & $\begin{array}{l}\text { Six (6) } \\
\text { communities } \\
\text { which use M\&S }\end{array}$ \\
\hline 10 & $\begin{array}{l}\text { (Department of } \\
\text { Defense 2010) }\end{array}$ & $\begin{array}{l}\text { U.S. Military - U.S. Army's } \\
\text { Program Executive Office for } \\
\text { Simulation, Training and } \\
\text { Instrumentation }\end{array}$ & $\begin{array}{l}\text { Three (3) domains } \\
\text { for simulation }\end{array}$ \\
\hline 11 & (NATO 2010) & $\begin{array}{l}\text { International Military - NATO } \\
\text { Modelling and Simulation } \\
\text { Group (NMSG) Proposal for } \\
\text { M\&S Center of Excellence }\end{array}$ & $\begin{array}{l}\text { Four (4) Pillars of } \\
\text { activity }\end{array}$ \\
\hline 12 & $\begin{array}{l}\text { (NATO Research } \\
\text { and Technology } \\
\text { Organisation 2010) }\end{array}$ & $\begin{array}{l}\text { International Military - NMSG } \\
\text { 062 Guide for M\&S for NATO } \\
\text { Network-Enabled Capability } \\
\text { (NNEC) }\end{array}$ & $\begin{array}{l}\text { Seven (7) } \\
\text { application areas } \\
\text { discussed }\end{array}$ \\
\hline 13 & $\begin{array}{l}\text { (NATO MSG } 091 \\
2010)\end{array}$ & $\begin{array}{l}\text { International Military - NMSG } \\
091 \text { C2 - M\&S Gaps Working } \\
\text { Group }\end{array}$ & $\begin{array}{l}\text { Three alternate / } \\
\text { candidate } \\
\text { frameworks } \\
\text { breaking down } \\
\text { life-cycle / phases: } \\
\text { a) six (6); b) seven } \\
\text { (7); c) and eight } \\
\text { (8) }\end{array}$ \\
\hline 14 & (I/ITSEC 2010) & $\begin{array}{l}\text { International Professional } \\
\text { Organization - NTSA's } \\
\text { I/ITSEC } 2010 \text { Program Guide }\end{array}$ & $\begin{array}{l}\text { Six (6) Paper } \\
\text { Tracks }\end{array}$ \\
\hline 15 & (SISO 2010) & $\begin{array}{l}\text { International Professional } \\
\text { Organization - Simulation } \\
\text { Interoperability Standards } \\
\text { Organization (SISO) } \\
\end{array}$ & $\begin{array}{l}\text { Four (4) User } \\
\text { Community } \\
\text { Forums }\end{array}$ \\
\hline 16 & $\begin{array}{l}\text { (SCS 2010) and } \\
\text { (Ören 2002) }\end{array}$ & $\begin{array}{l}\text { International Professional } \\
\text { Organization - Society for } \\
\text { Modeling and Simulation } \\
\text { International (SCS), Code of } \\
\text { Ethics }\end{array}$ & $\begin{array}{l}\text { Eight (8) Uses of } \\
\text { Simulation (not } \\
\text { exhaustive) }\end{array}$ \\
\hline
\end{tabular}




\begin{tabular}{|c|l|l|l|}
\hline SER & \multicolumn{1}{|c|}{$\begin{array}{c}\text { SOURCE } \\
\text { REFERENCE }\end{array}$} & \multicolumn{1}{|c|}{ SOURCE DESCRIPTION } & \multicolumn{1}{|c|}{$\begin{array}{c}\text { M\&S } \\
\text { DESCRIPTION } \\
\text { OVERVIEW }\end{array}$} \\
\hline 17 & (Law 2007) & Academia - Dr. Law & $\begin{array}{l}\text { Ten (10) } \\
\text { application areas } \\
\text { (types of } \\
\text { problems) }\end{array}$ \\
\hline 18 & $\begin{array}{l}\text { (Nance and Sargent } \\
2002)\end{array}$ & $\begin{array}{l}\text { Academia - Dr. Nance and } \\
\text { Dr. Sargent }\end{array}$ & Five (5) objectives \\
\hline 19 & (Ören 2007a) & Academia - Dr. Ören & $\begin{array}{l}\text { Three (3) uses, } \\
\text { with 13 } \\
\text { subordinate } \\
\text { applications }\end{array}$ \\
\hline 20 & (Wainer 2009) & Academia - Dr. Wainer & $\begin{array}{l}\text { Twelve (12) types } \\
\text { of simulation } \\
\text { models }\end{array}$ \\
\hline \multicolumn{2}{|c|}{ Table 4-1 - M\&S Categorization Data Sources and Descriptions Overview } \\
\hline
\end{tabular}

The organizations that were the sources of this data were also represented in the resultant Innovation Network Map. Furthermore, as an "added value" trial, select organizations' websites were analyzed to determine a primary focus in a particular category was made, using the Carleton TIM Program's Keyword Search and Analysis Tool - however the analysis and results are not included herein, in order to manage the scope of the research.

\subsubsection{Keywords Extraction}

The actual M\&S Description / Overviews from the 20 sources in Table 4-1 (right-hand column) were amalgamated into a new dataset. A list of 41 action words or keywords was extracted from this dataset, taking out superfluous words. 
Finally, each keyword was used in a word search through the dataset, and the frequency and resultant ranking are presented in Table 4-2:

\begin{tabular}{|c|c|c|}
\hline RANK & KEYWORD & FREQUENCY \\
\hline 1 & Training & 24 \\
\hline 2 & Acquisition & 19 \\
\hline 3 & Develop & 17 \\
\hline 4 & Analysis & 15 \\
\hline 5 & Concept & 13 \\
\hline 6 & Evaluation & 13 \\
\hline 7 & Operation & 12 \\
\hline 8 & Support & 10 \\
\hline 9 & Engineering & 9 \\
\hline 10 & Experiment & 9 \\
\hline 11 & Test & 9 \\
\hline 12 & Education & 8 \\
\hline 13 & Planning & 8 \\
\hline 14 & Rehearsal & 8 \\
\hline 15 & Research & 8 \\
\hline 16 & Mission & 7 \\
\hline 17 & Design & 6 \\
\hline 18 & Requirements & 6 \\
\hline 19 & Course & 5 \\
\hline 20 & Doctrine & 5 \\
\hline 21 & Entertainment & 4 \\
\hline 22 & Life (-Cycle) & 4 \\
\hline 23 & Decision & 3 \\
\hline 24 & Materiel & 3 \\
\hline 25 & Policy & 3 \\
\hline 26 & Proof (of Concept) & 3 \\
\hline 27 & Prototyping & 3 \\
\hline 28 & Understanding & 3 \\
\hline 29 & Alternative & 2 \\
\hline 30 & Definition & 2 \\
\hline 31 & Exercise & 2 \\
\hline 32 & Lessons (Learned) & 2 \\
\hline 33 & Prediction & 2 \\
\hline 34 & Procedures & 2 \\
\hline 35 & Diagnosis & 1 \\
\hline
\end{tabular}




\begin{tabular}{|c|l|c|}
\hline RANK & \multicolumn{1}{|c|}{ KEYWORD } & FREQUENCY \\
\hline 36 & Exploration & 1 \\
\hline 37 & Imitation & 1 \\
\hline 38 & Improvement & 1 \\
\hline 39 & Intelligence & 1 \\
\hline 40 & Learning & 1 \\
\hline 41 & Logistics Table 4-2 - M\&S Keywords \\
\hline \multicolumn{2}{|c|}{} \\
\hline
\end{tabular}

It should be noted that the top ranking keywords are prominently figured in the resulting categorization, and the supporting ontology.

\subsubsection{Ontology Derivation}

Upon review of the various data sources, it was evident that there was an emergent organization and hierarchy of terms. Not all terms were of equal weight, and there were some keywords that represented activities that were subordinate to other keywords / activities.

Groupings were made, based on the data sources, and the literature reviewed. After groupings were made, it was confirmed that the groupings were valid if there were at least two data sources which grouped the keywords as well.

\subsubsection{Ontology Legend}

Figure 4-2 gives a legend of the elements that were included in the ontology. Three types of relationships between ontology elements were used. Firstly, if a term or keyword was encompassed within another term, it was simply made subordinate to it. When the keyword or terms denote an activity, if that activity overlaps with another, it was linked with an orange arrow. Lastly, if the activity 
was within the mandate of a particular DND/CF Level 1 (L1) organization, then that was represented with a black arrow. Figure 4-3 summarizes these elements.

\begin{tabular}{|c|}
\hline Ontology Legend \\
Figure 4-2 - Ontology Legend \\
Activity Overlaps With
\end{tabular}

\subsubsection{Mandates and DND/CF L1 Organizations}

Within the Canadian Forces / Department of National Defence, there are "Level 1" (L1) organizations within the National Defence Headquarters (NDHQ). It was possible to group the categories such that the M\&S Categories of Support to military applications mapped one-to-one or one-to-few with NDHQ L1 organizations. Figure 4-3 depicts the mapping of the categories to the L1 organizations. The grouping, the DND/CF organizations, and this mapping, is described in more detail below. 


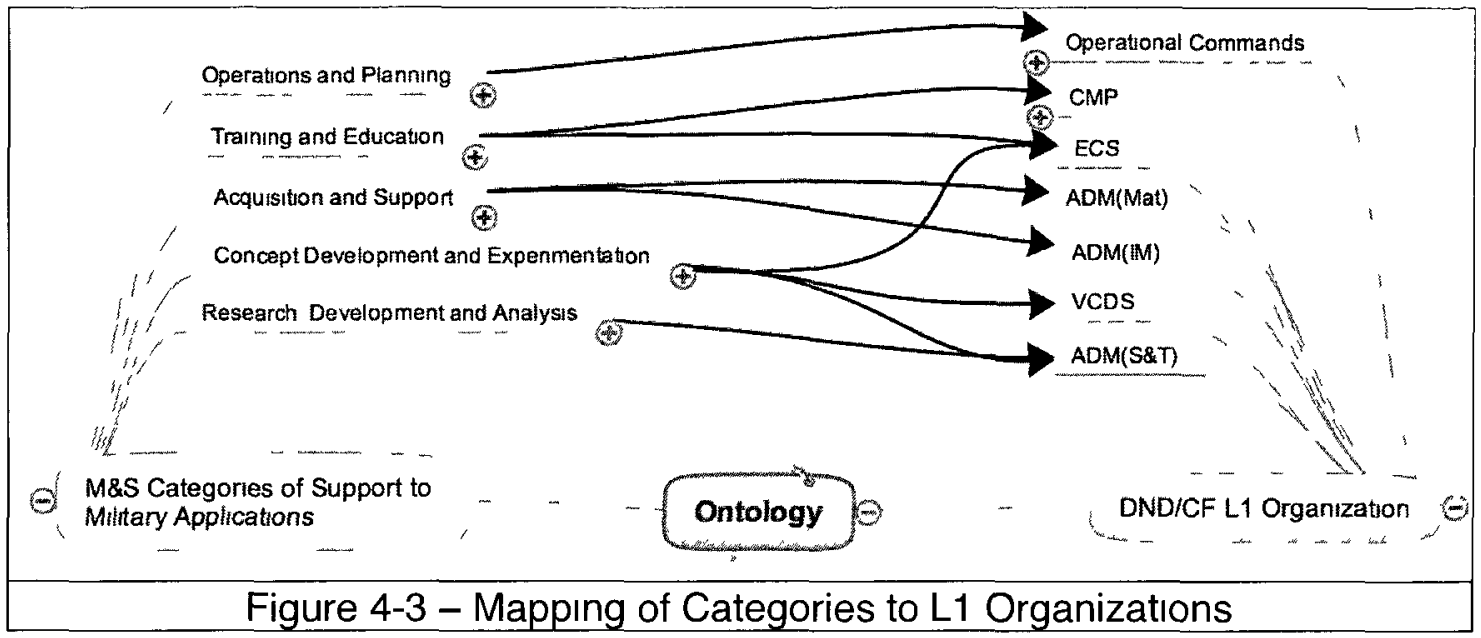

\subsubsection{Activity Overlap}

Figure 4-4 shows how the various M\&S categories overlap one another. This is further evolved later, into Figure 4-6.

\subsubsection{Hierarchy of M\&S Support to Military Applications}

Figure 4-5 presents a hierarchy of the many terms, as they are used to describe how M\&S supports military applicatıons. Of note, only the first two levels of the ontology are shown, due to legibility. The complete ontology is included within the electronic versıon of the Innovatıon Network Map, at Appendıx 1. 
(4) Operations and Planning

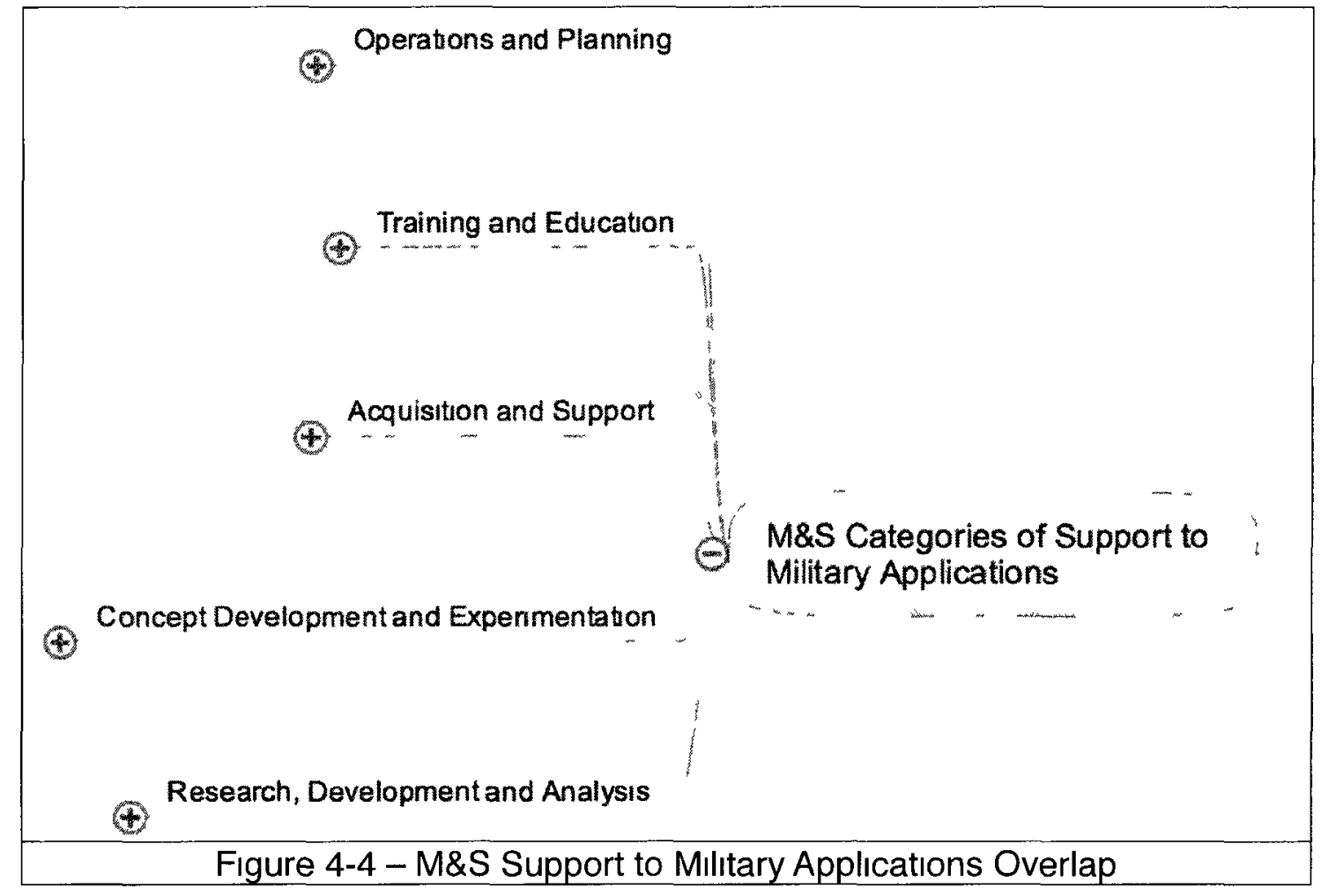




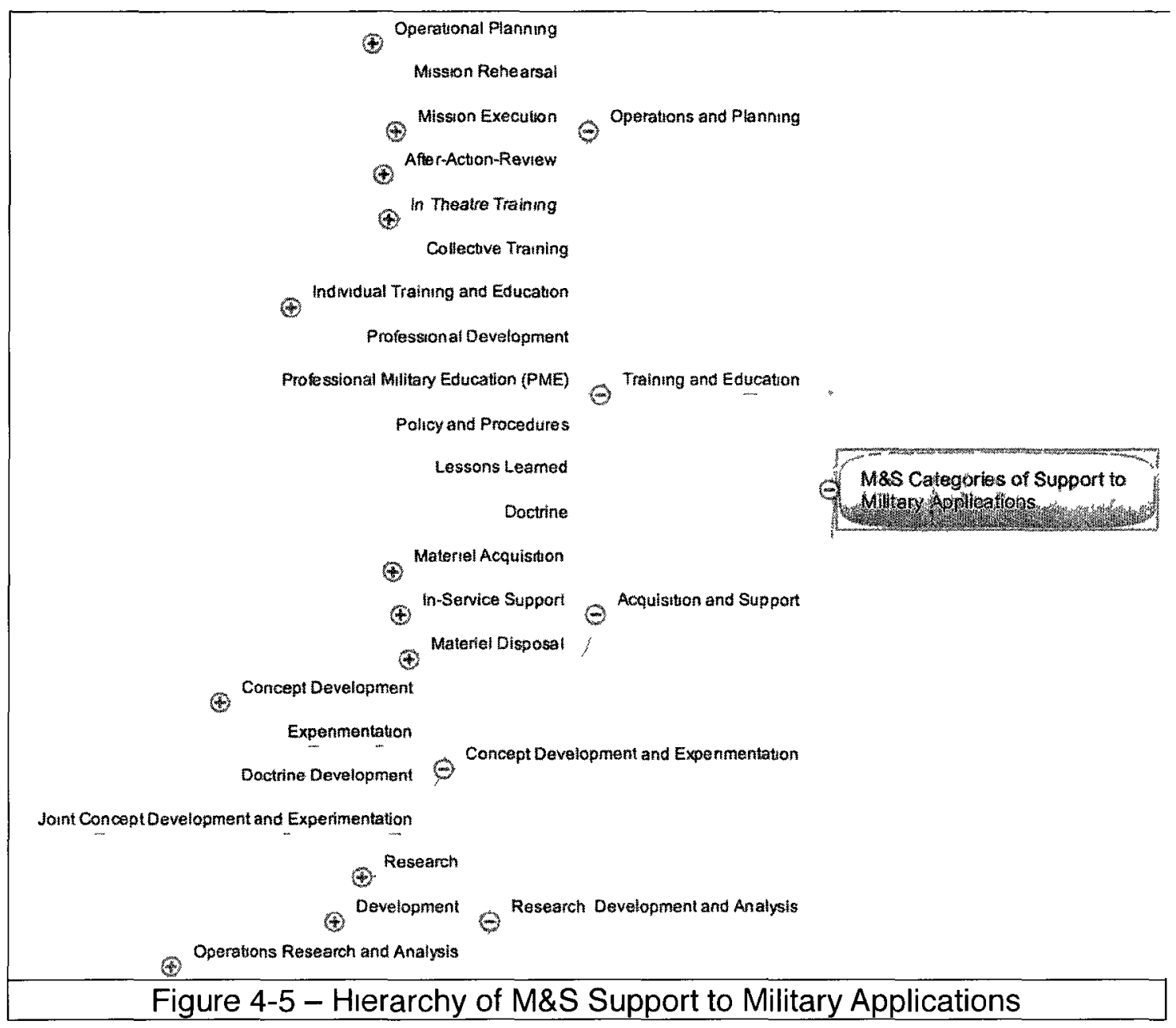

\subsubsection{Outliers}

There were two keywords or action words that could not be categorized appropriately within the identified groups of military applications where M\&S was particularly suited to support. They were "Imitation" and "Entertainment". While these two categories, as described in the references, dıd have cases where they were used in "Civilian" applications, they didn't have any direct use in mılitary applications. A link between the M\&S and Entertaınment Industry has been 
identified, particularly with the notion of "Serious Games" from the gaming industry into military use (Smith, 2006) - effectively taking an "Entertainment" product, and adapting it not for Entertainment as it was originally designed, but for Military Training. Additionally, many in the M\&S community have made the connection between the Entertainment Industry and Defence, through M\&S. Zyda and Sheehan made explicit linkages between the Entertainment Industry and Defence (Zyda and Sheehan, 1997), showing how developments and interests between the two communities overlap, and funding has been in similar areas. Although there is linkage between the industries, through common technologies being developed, the use of M\&S in defence primarily consisted of M\&S in support of other applications, and not explicitly using M\&S for "Entertainment" of military members.

\subsubsection{Categorization}

In review of the projects' documentation, salient literature, professional organizations, as well as many other practitioners' documentation, there were groupings of keywords that were evident, using the Ontology described earlier. In total, there were five (5) groupings that were determined, forming a categorization of military applications where M\&S technologies were particularly suited to support. Of note, the importance or relative priority of these categories are not equal. What is to be noted is that a number of groups of M\&S 
practitioners similarly view or group M\&S, using these keywords. The M\&S Support Categories to Military Applications are now discussed.

\subsubsection{Operations and Planning}

The "Operations and Planning" category of M\&S support to military applications is defined as the use of M\&S technologies through the planning phase into the execution phase and actual conduct of military operations. Subcategories, applications or activities included within this category are Mission Rehearsal, Operational Planning, Decision Support, Command Support, Battlefield Visualization, Wargaming, Course of Action Analysis, After-Action Review, and other similar activities. Essentially, using M\&S in an actual military theatre of operations, whether on domestic operations within Canada (e.g. support to Olympics, G8 Summit, or emergency relief such as a flood or ice storm) or abroad in another country. Within the DND/CF, the Operational Commands are key organizations responsible for military operations, and the planning thereof. These Operational Commands include Canada Command (CANADACOM), Canadian Expeditionary Forces Command (CEFCOM), Canadian Special Forces Command (CANSOFCOM) and others (Department of National Defence 2010b). There has been some focus on how Simulation could better support military operations, in the intensive combat environment. Roman and Surdu provided a framework for describing how M\&S can support operations, which is also supported (and encompassed) by this categorization 
(Roman and Surdu 2010). Of note, the Operations and Planning category directly maps to the military phase of "Force Employment".

\subsubsection{Training and Education}

The "Training and Education" category of M\&S support to military applications is defined as the use of M\&S technologies for training and/or educating military members, whether collectively as a group, or individually. Sub-categories, applications or activities included within this category are Collective and Individual Training and Education, Professional Development activities, Refresher and Continuation Training, and other similar activities. Within the DND/CF, the Environmental Chiefs of Staff (ECS) of the Army, Navy and Air Force, as well as the Chief of Military Personnel (CMP) are responsible for the training and education of its personnel. Of note, the Training and Education category directly maps to the military phase of "Force Generation".

\subsubsection{Acquisition and Support}

The "Acquisition and Support" category of M\&S support to military applications is defined as the use of M\&S technologies in support of the acquisition, fielding and life-cycle support of other technologies and equipment. Sub-categories, applications or activities included within this category are Simulation-Based Acquisition (SBA, SEBA, etc), some Engineering and Design activities, Options Analysis, Tests, Trials and Evaluations (including Operational Tests and Evaluation, and Engineering Tests and Evaluation), Bid Evaluation and 
other similar activities, covering the entire Materiel Acquisition and Support process. Within the DND/CF, the Assistant Deputy Ministers of Materiel and Information Management (ADM(Mat) and ADM(IM)) lead the acquisition and lifecycle support of the majority of technologies and equipment within the Canadian military. Of note, the Acquisition and Support category maps to the military phase of "Force Development".

\subsubsection{Concept Development and Experimentation}

The "Concept Development and Experimentation (CD\&E)" category of M\&S support to military applications is defined as the use of M\&S technologies in experimentation and / or the development of concepts. Sub-categories, applications or activities included within this category are Joint CD\&E, Joint Experimentation, Doctrine Development, Development of Tactics, Techniques and Procedures and other similar activities. Within the DND/CF, the ECS from the Army, Navy and Air Force, the Assistant Deputy Minister of Science and Technology (ADM(S\&T)), as well as groups within the Vice Chief of Defence Staff (VCDS) conduct CD\&E-related activities. Of note, the CD\&E category maps to the military phase of "Force Development".

\subsubsection{Research, Development and Analysis}

The "Research, Development and Analysis" category of M\&S support to military applications is defined as the use of M\&S technologies in support of research, development, and operational research and analysis activities. Sub- 
categories, applications or activities included within this category are basic and applied research, Technology Development, Technology Demonstrations, Operational Research and Analysis, and other similar activities. Within the DND/CF, the Assistant Deputy Minister of Science and Technology (ADM(S\&T)), who is also the CEO of Defence Research and Development Canada (DRDC), is responsible for leading Research, Development and Analysis. Of note, the Centre for Operational Research and Analysis (CORA) is a distinct branch within DRDC. Of note, the Research, Development and Analysis category maps within the military phase of "Force Development".

\subsubsection{Sequencing of Categories}

In the review of the various keywords, it became apparent that there was a timeline or degree of technological maturity associated with the words. That is, there were some activities where M\&S was particularly suited, where a given technology or concept was fairly immature (e.g. basic research, which would be at the far left of Figure 4-4), and there was an apparent continuum of activities, all the way through to combat operations, where simulation could support (e.g. conducting a rehearsal for a mission, while on a military operation, within the Operations and Planning category). Figure 4-4 depicts this sequencing, in a simple graphic. Of note, the sequencing "OTACR" (see Figure 4-4) is derived from the start point of each arrow or activity, working from the right, backwards. 
That is, Operations and Planning starts the latest, followed by Training and Education, followed by Acquisition and Support, and so on, as follows:

- O perations and Planning

- $T$ raining and Education

- A cquisition and Support

- C oncept Development and Experimentation

- R esearch, Development and Analysis

. This mnemonic is suggested so that members of the M\&S community can remember and make more use of the categorization. It must be noted that the length and size of the arrows is not to scale, and is merely symbolic of the overall sequencing and overlap of activities. The "Training and Education" category being darker, emphasizes that it was the most prevalent category for M\&S use. A detailed analysis of the sequencing and overlap of the categories was not done, however the graphical depiction of this concept was validated by military practitioners as appropriate.

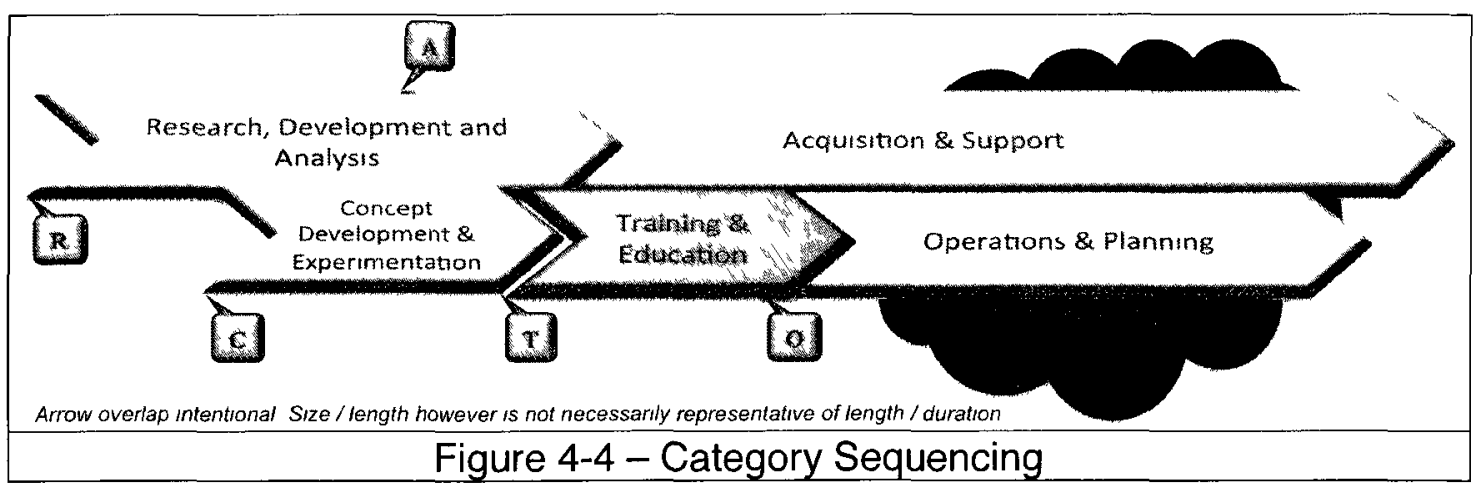




\subsubsection{Categorization Validation}

In the formulation of the Category names and keyword grouping, at least two of 20 data sources had to have the same grouping of keywords. The final category names and grouping, as described above, were reviewed by approximately 30 subject matter experts from the following groups: the Canadian Forces Warfare Centre (CFWC), members of The Technical Cooperation Program, members from a NATO Modelling and Simulation Group Workshop and a member from the Canadian Army Directorate of Land Synthetic Environments. The structure was validated as appropriate to describe the problem space through discussions with these representatives.

Furthermore, there are direct parallels between the final M\&S category grouping and the Canadian Army's "Five Synthetic Environment Domains". The key difference is the further detail, and the sub-categories that have been subsumed into the five overarching category names.

\subsubsection{Categorization Summary}

The categorization of how M\&S is used for various military applications was not originally intended to be a major deliverable for this work, however its creation, and applicability shall be shown even more so later, in the sections below.

Of note, even though there are many different types of activities or applications of M\&S to military use, much of the time, the use of M\&S in a 
particular event can be either construed as an Exercise event (i.e. in support of a particular Training or Education endeavour) or as part of an Experimental Event (i.e. as a means of supporting Decision Support). However, it must be noted that the use of M\&S in such activities as on Operations, or during planning does not neatly fit into either of these event types.

The key finding of this part of the research is that there is an inherent hierarchy of terms to describe M\&S use in the military. There are not necessarily 10 or 20 M\&S domains, but rather, there are a smaller number (this work proposes the five in "OTACR") of categories, that overlap one another. These keywords could be developed into an ontology, and were. Even after a hierarchy and ontology are derived, there are different weights or focus in the development of M\&S technologies in different areas. That is, there are areas that have mature use of $M \& S$ within that application (e.g. individual training using $M \& S$ ), and others that have interest and whose development is nascent (e.g. battlefield visualization while on operations).

Finally, it was noted by the author and members of the CFWC Joint Capability Development Team that there was benefit in using "Operator's" wording to construct the categories, versus a deconstruction of the type of simulation itself. It may be easier to relate to non-M\&S practitioners the potential use of M\&S by using words such as "Operations and Planning" or "Training and Education", etc, 
in lieu of stating that M\&S have Live, Virtual or Constructive applications, or stating that there are discrete event or continuous time applications of simulation.

A presentation of the results from the Two Case Studies which were the focus of the research shall now be done.

\subsection{Case Study Reports}

As described in Chapter 3 above, the Case Study projects were selected due to their different use of M\&S. The following sections shall detail the colour coding / Legend used, followed by a Case Study Report for each Project, followed by Cross-Case Deductions.

\subsubsection{Map / Legend Description}

The Network map that was generated (complete version attached at Appendix 1) unified information from a wide span of Data Sources. This included ranged from Canadian Department of National Defence (DND) internet websites, to Dr. Ören's M\&S Body of Knowledge (M\&S BoK) Index (Ören 2010), to various subject matter experts' Internet websites, to the websites and project documentation from the Case Studies themselves. Figure 4.5 summarizes the data sources that were inputted into the Innovation Network Map, as well as the symbology used to differentiate between the data sources. 


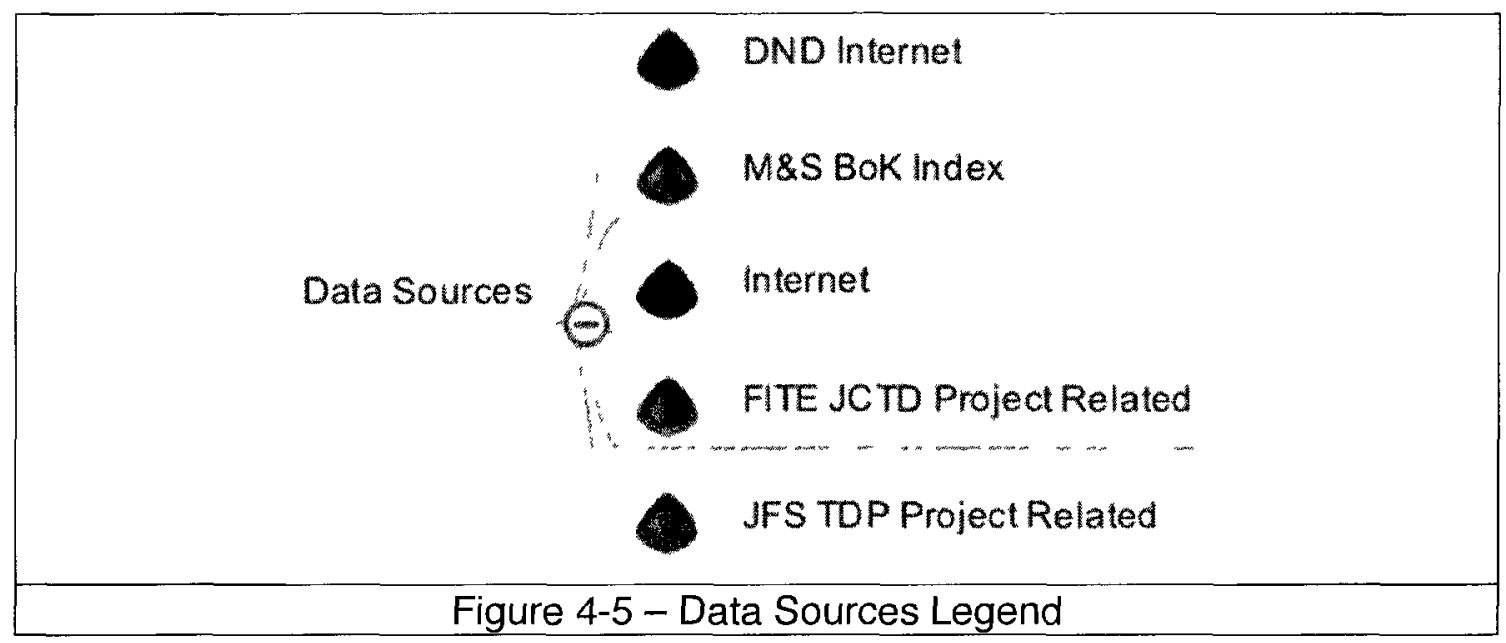

The visualization tool had the ability to be re-organized to suit the user's needs - for example, to generate a social network map. For example, the lead organization for the FITE JCTD project was the US Joint Forces Command (US JFCOM). The social network of organizations connected to US JFCOM is shown in Figure 4-6, to demonstrate the ability of the visualization tool to a) store information (including metadata) within each node on the node, as well as each link connected to it; and b) re-orient the map to focus on a single node, if desired. As described in Table 3-1, the network map stores information on the links and link data source in the node's notes, as well as the node's data source. The type of node is depicted by its colour (pink for technology and light blue for organization). All of these aspects are shown in Figure 4-6 (note that diagram is given for illustrative purposes only - not possible to view fully within this document, although the full map is available at Appendix 1): 


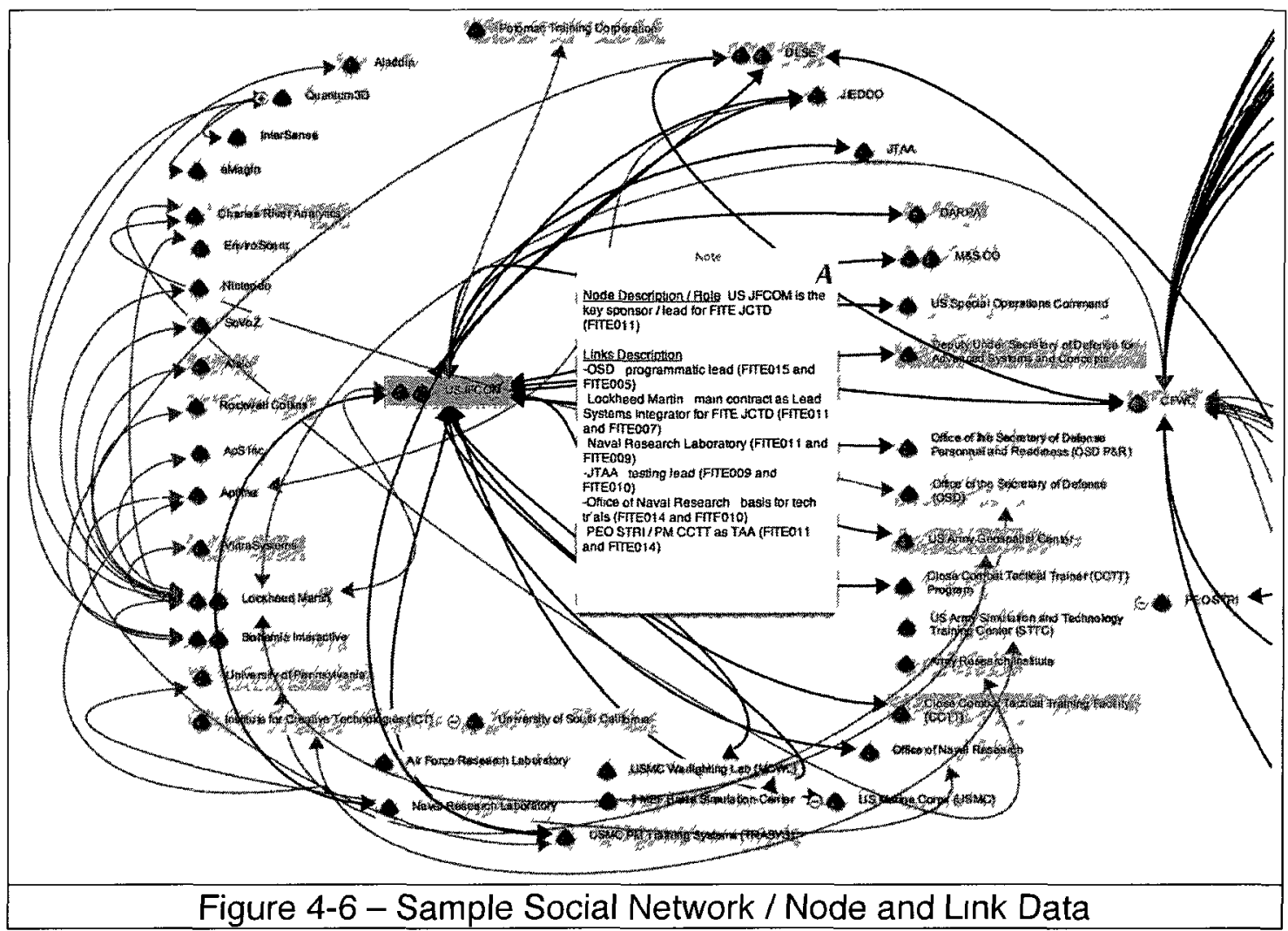

We will now review each Case Study in turn, then compare and analyse the Cases together.

\subsubsection{Case Study Report: JFS TDP}

The Joint Fires Support Technology Demonstration Project (JFS TDP) is a Canadian Department of National Defence (DND) Research and Development (R\&D) project. It is funded and managed through the R\&D branch of DND. Defence R\&D Canada (DRDC). It began in 2006 and is planned to close out in 2013. 
In simple terms, the objective of the Project is to "shorten the kill chain" or rather streamline the process between identification of an enemy target to engage with various weapons, and its successful prosecution through various technologies and procedures. The project is achieving this objective through an Experimentation Campaign plan, with numerous experiments, with increasing complexity over almost seven years.

\subsubsection{Data Sources}

As detailed in Chapter 3, the replication logic used was such that project documents were gathered, in order to extract data on the People (Organizations), Technologies, and relationships therein. The data was drawn largely through releasable project documentation.

The data set from the JFS TDP included over 600 documents, with thousands of pages of Project documentation. The data sources ranged from high-level Project Management documents, to detailed systems interconnect and technical drawings.

The overview portions of these documents were scanned, and were narrowed down to a final subset of documents that included the key Project management documents, as well as contractual documents and agreements, as well as technical diagrams. This final data set was much smaller and was used to generate the network map. 


\subsubsection{Network Map}

The following is a summary of the key information extracted from the JFS TDP data, and inputted in the Network Map:

People (Organizations). There were 43 organizations identified as collaborators or key players within JFS TDP - 29 Government (within Government of Canada or US / International) and 14 Industrial partners. They are depicted in Figure 4-7 and 4-8. The grey box around the Assistant Deputy Minister of Science and Technology (ADM(S\&T)) has a special role, which is stored in the Map's notes for that node: ADM(S\&T) is the Project Lead for JFS TDP. The Project Manager and main Project Sponsor is the Canadian Forces Warfare Centre (CFWC), and is denoted with a grey box as well. Lastly, organizations common to both Case Studies are highlighted with a green box DLSE and US JFCOM. This shall be discussed later in the Cross-Case Report, below. 


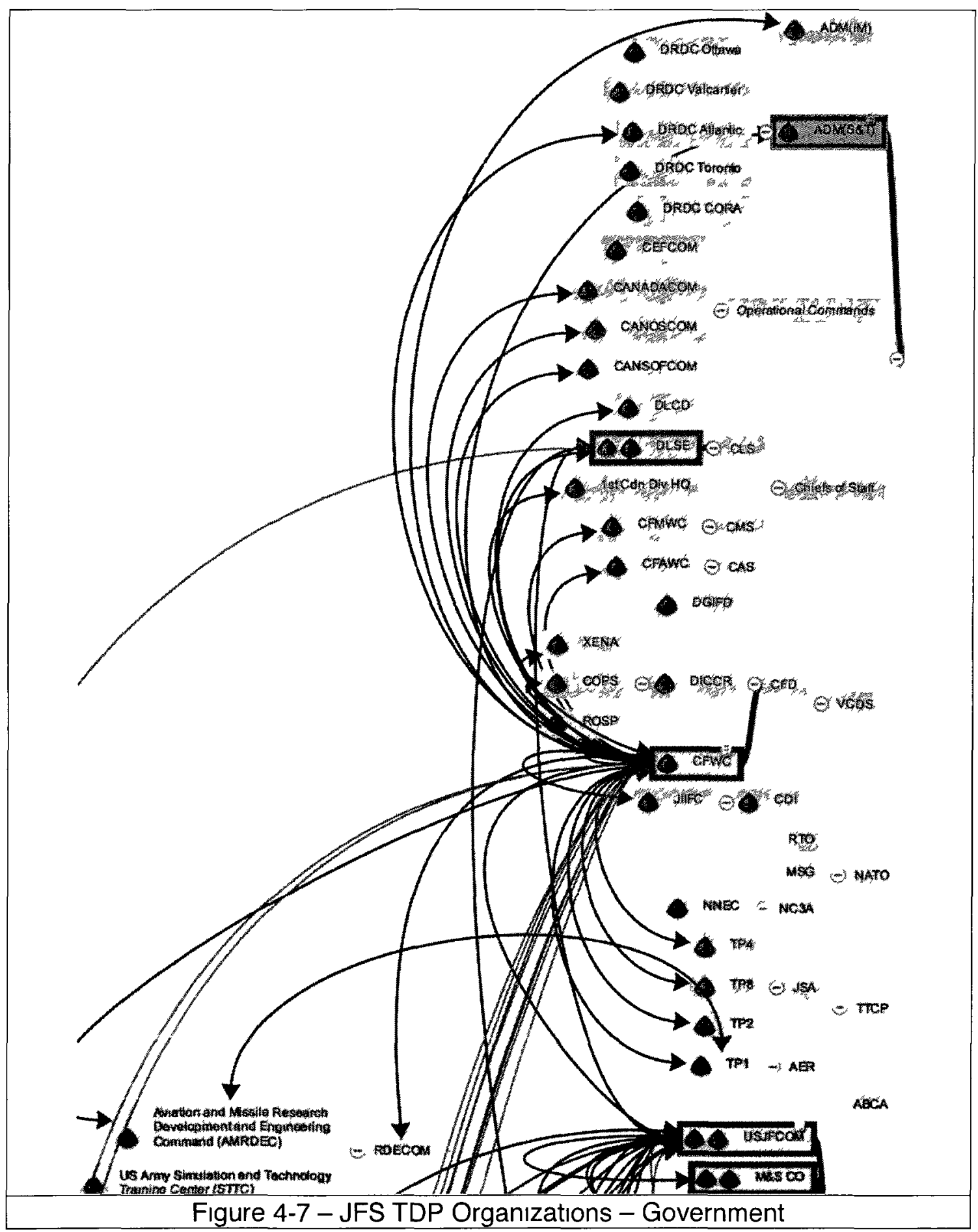


Furthermore, there was a sound industrial base as support to JFS TDP over the years. One of the lead contractors was Thales, and they are highlighted as such with a grey box. Industry members common to both Case Studies are highlighted in green - Lockheed Martın and Bohemia Interactive. This shall be discussed later in the Cross-Case Report, below. The Industry members that worked with JFS TDP are represented in Figure 4-8.

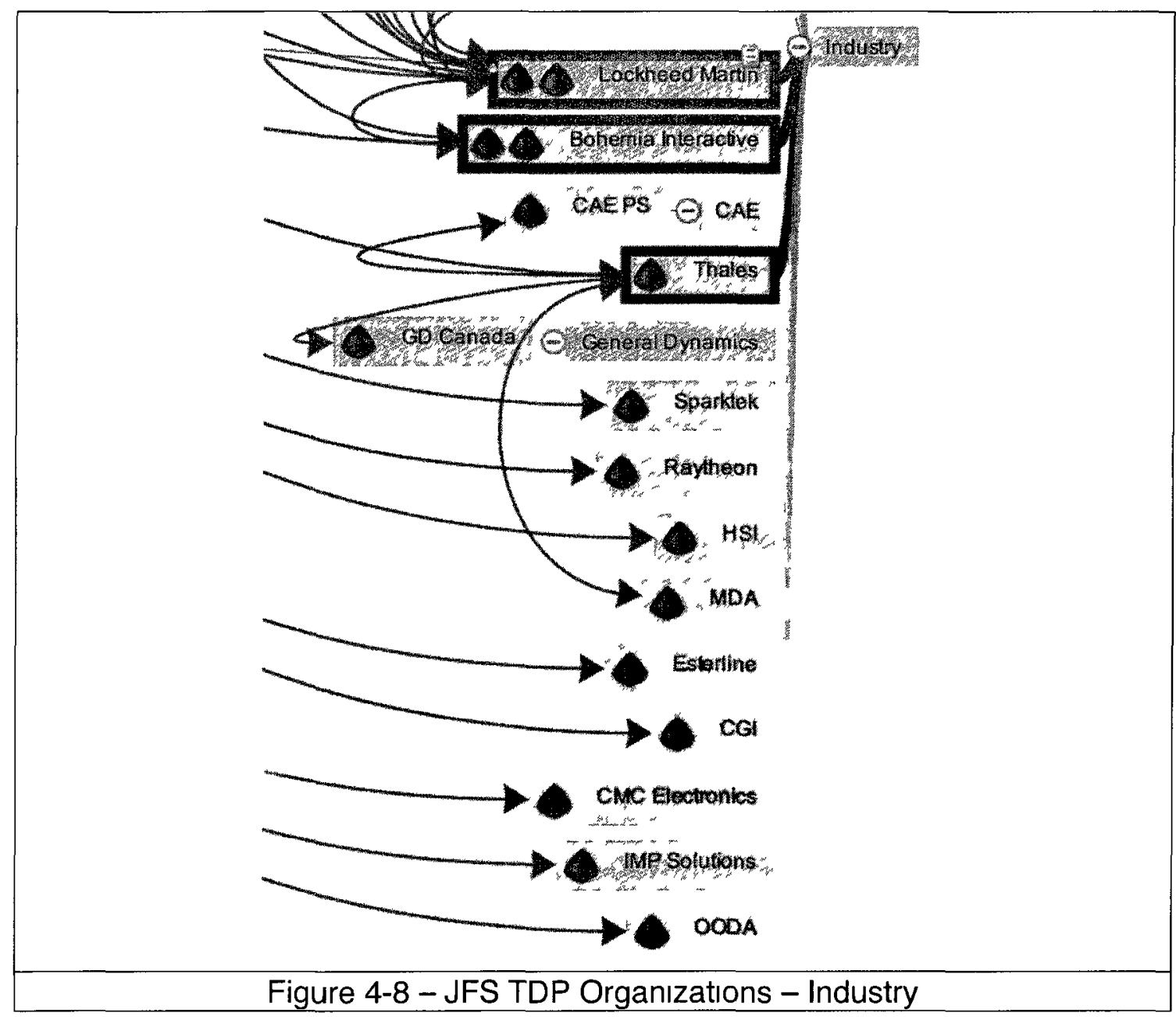


Technologies. There were 7 core M\&S technologies, 17 Command, Control, Communications, Computers, Intelligence, Surveillance and Reconnaissance (C4ISR) technologies, and 7 Gateways or other technologies. These technologies, and their inter-relationships and some dependencies are depicted in Figure 4-9 and 4-10. The common technology to both Case Studies is highlighted in Red, and the key technologies were highlighted in Green (key technology defined as a technology that had three or more technical dependencies):

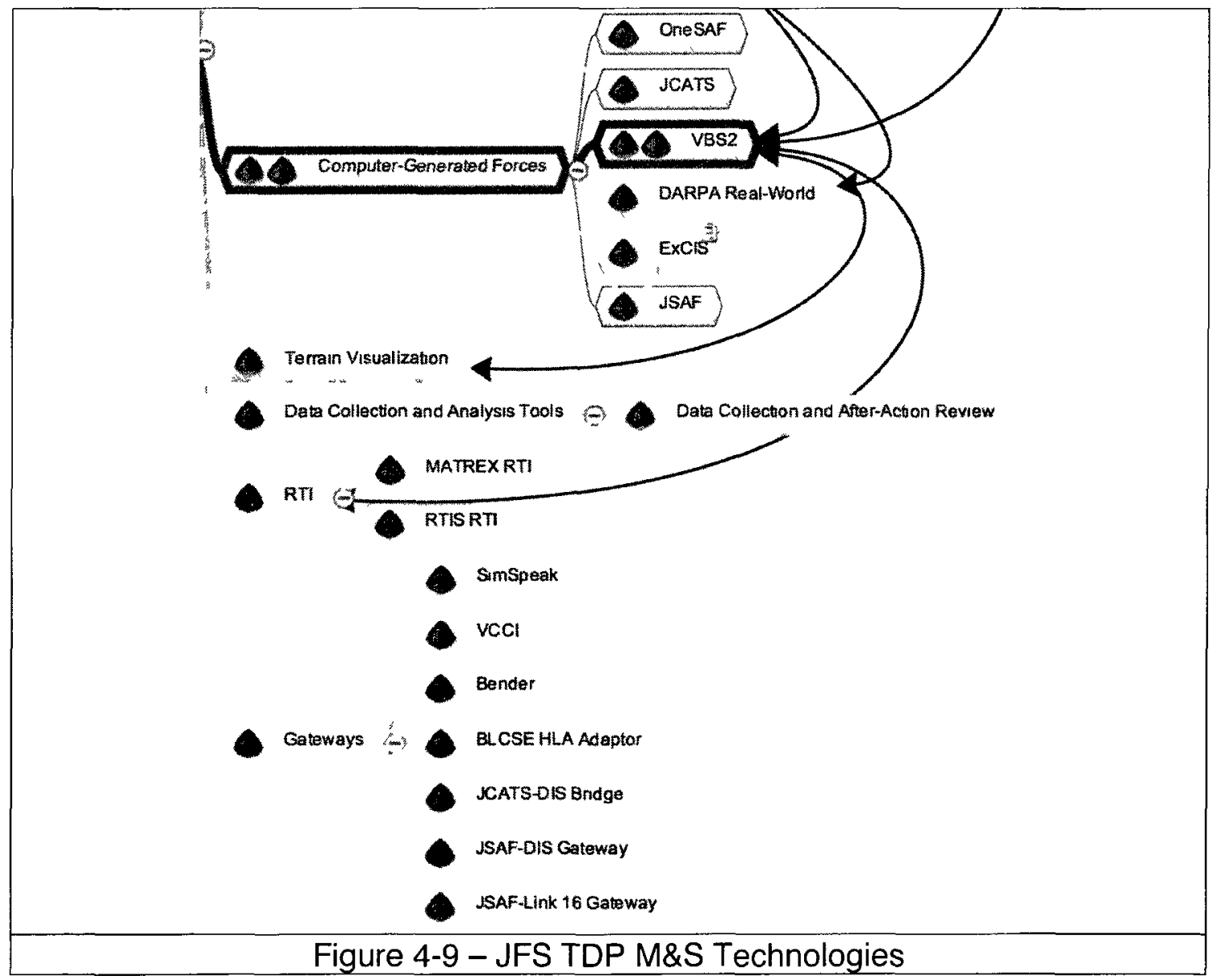




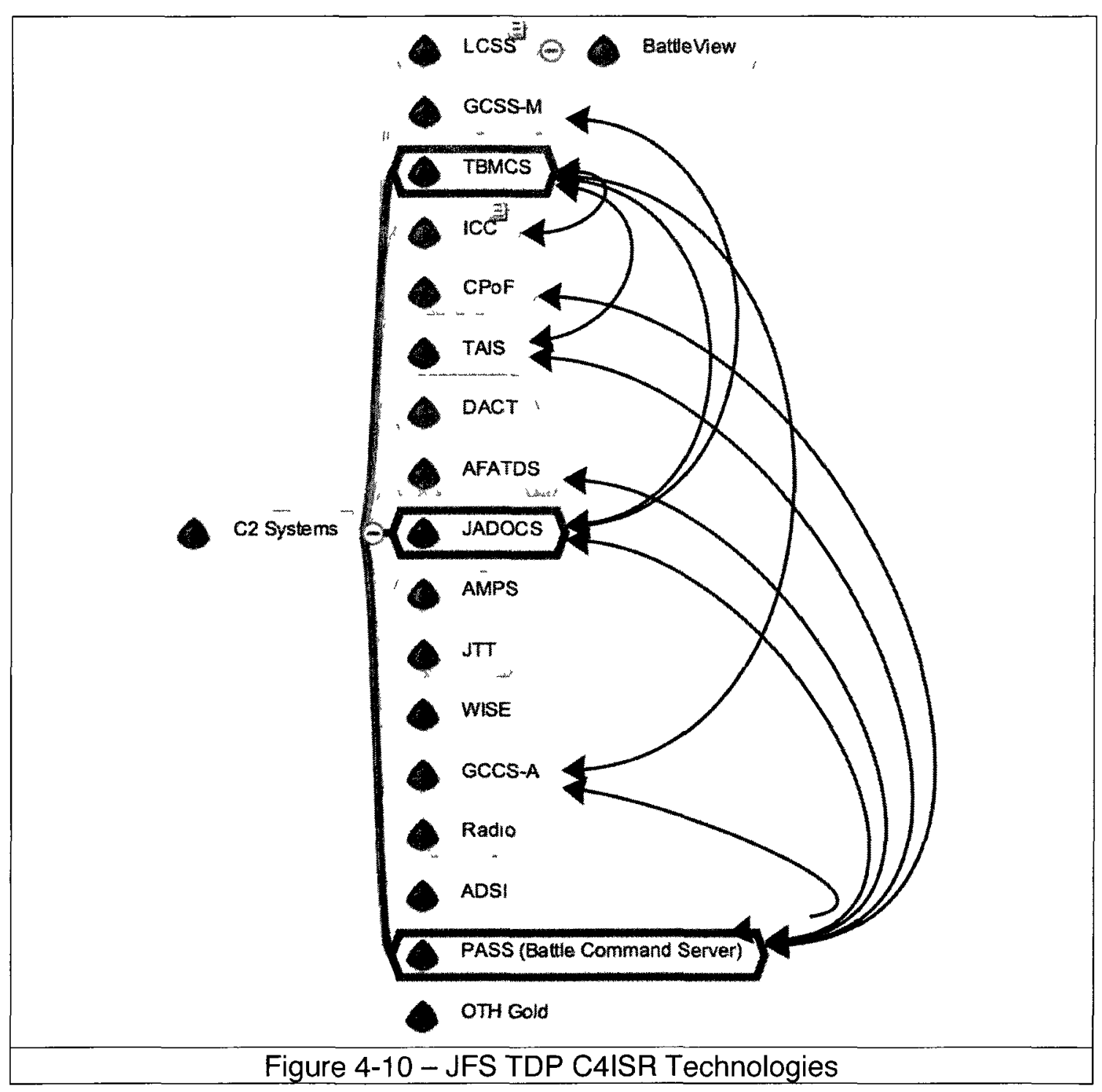

Relationships. Each arrow in the associated map represents at least one relationshıp, based on one or many documents reviewed. For example, the blue arrow between "CFWC" and "TTCP AER TP1" in Figure 4-7 represents the collaboratıve arrangement that was used for the Human Factors 3 / Coalition 
Attack Guidance Experiment (CAGE) in May 2010. Figures 4-7 and 4-8 depict some of these relationships.

Furthermore, some technical dependencies were identified between systems. For example, the red "technical dependency" arrow between "GCCS-A" and "PASS" in Figure 4-10 represents that the systems were integrated together, and a physical hardware and/or software linkage was present. Of note, the absence of a red "technical dependency" arrow does not denote that there is not in fact a dependency for the project, but simply that the such a relationship was not inputted from the dataset available - further analysis, and further refinement would likely reveal more dependencies that should be represented herein.

Lastly, relationships between organizations and technologies were represented as well. For example, the grey arrow coming from the "JADOCS" technology in Figure 4-10 goes to Raytheon, a grey arrow exists between Raytheon and CFWC, and another blue arrow goes from JFCOM to CFWC. These relationships represent the Foreign Military Sales contract, through US JFCOM to CFWC, then to Raytheon, to provide the "JADOCS" technology. Details on this relationship are contained in the "Notes" section of each node.

A full view of all the interrelationships is within the Innovation Network map, at Appendix 1. 


\subsubsection{Case Analysis}

Overall, the JFS TDP leveraged many international partners, and many industry partners. Many inter-relationships between organizations and technologies were found.

The JFS TDP began with smaller studies, and Limited Objective Experiments, up to multi-million dollar experiments (e.g. Human Factors Experiment 3 - HF3 in May 2010, and HF4 in Dec 2010).

The series of experiments were planned as part of Experimentation Campaign, with increasing complexity as the project matured. The Project's work garnered international attention early on, leading to international papers (NATO Research and Technology Organisation, 2010) and the establishment of the Coalition Attack Guidance Experiment (CAGE) series, as well as a new coalition Science and Technology (S\&T) panel within The Technical Cooperation Program Joint Systems and Analysis Group Technical Panel 8 on Combined Fires Experimentation and Demonstration (TTCP JSA TP8).

The JFS TDP created a "Joint Fires Test Bed" that included C4ISR technologies, as well as M\&S technologies. This Test Bed evolved into the "Integrated Test Bed" which is currently in use by the Canadian Forces Warfare Centre (CFWC) to assist other military organizations, in addition to the needs of JFS TDP: 
It is planned that the full exploitation of the JFS TDP will be achieved through the transfer of its capabilities and technologies to the CFWC, as well as other Canadian Department of National Defence organizations, likely before the Spring of 2013.

\subsubsection{Case Study Report: FITE JCTD}

The Future Immersive Training Environment Joint Capability Technology Demonstration (FITE JCTD) was a United States Joint Forces Command (US JFCOM) project. It ran over two years, with an overall budget of \$36M USD. The Project's objective was to inform future training acquisitions on immersive technologies for tactical training. This was accomplished by integrating various training and M\&S technologies, for soldiers to wear to "immerse" them in a virtual reality training environment, such as fighting in an urban area. The project involved major "integration spirals" that culminated in operational demonstrations involving soldiers, where feedback on the usefulness and application of the systems being trialed were elicited.

\subsubsection{Data Sources}

As detailed in Chapter 3, the replication logic used was such that project documents were gathered, in order to extract data on the People (Organizations), Technologies, and Relationships therein. The data was extracted from documents freely available on the internet, conference / symposium papers, or through releasable documentation. These data sources for FITE JCTD were 
remarkably smaller as compared to JFS TDP, however, there was adequate data to map out and find linkages and overlaps.

The final data set from the FITE JCTD Project included over 230 pages of Project documentation, which were used to generate the network map.

\subsubsection{Network Map}

The following is a summary of the key information extracted from the FITE JCTD Project data, and inputted in the Network Map.

People (Organizations). There were eight (8) key military sponsors of the FITE JCTD Project, six (6) industry partners / contractors, with an additional 74 other organizations that observed or had other subordinate roles. Only the key military and industrial partners were represented in the innovation network map at this point. Figures 4-9 and 4-10 depict the key organizations involved in FITE JCTD, firstly from Industry (Figure 4-9) and within Government (Figure 4-10). Within these figures, the organizations are depicted with a purple rectangular box, and the organizations that have a formal affiliation with FITE JCTD in some regards have a pink pyramid symbol in their box. Of note, there are two organizations in the US DOD that are both affiliated with JFS TDP and FITE JCTD (boxes with pink and grey symbols - US JFCOM and M\&S CO). Additionally, even at this high-level there is one common contractor between FITE JCTD and JFS TDP: Bohemia Interactive. This shall be discussed later in the Cross-Case deductions. 
With regards to Inter- and Intra-Governmental Linkages, there were even more organizations involved, as depicted in Figure 4-10.

Technologies. Sımılarly, there were a number of technology groups that were Identified withın the FITE JCTD Project Data. Figure 4-11 depıcts the key M\&S and other technologies that were involved In FITE JCTD, denoted by a pınk pyramıd (of note, the bottom group of technologies are categorized under "Modellıng and Sımulatıon Technologies")

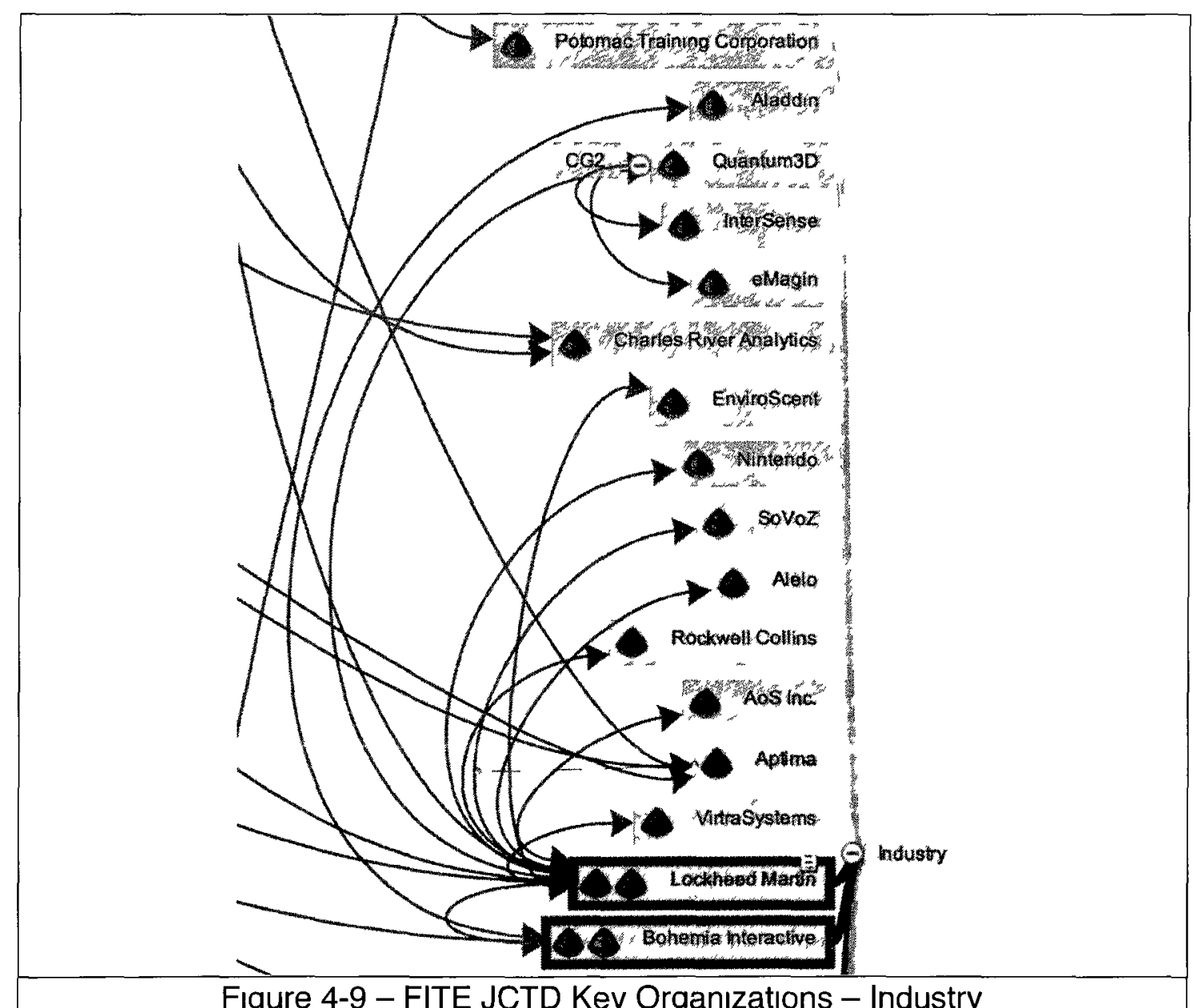

Figure 4-9 - FITE JCTD Key Organızatıons - Industry 


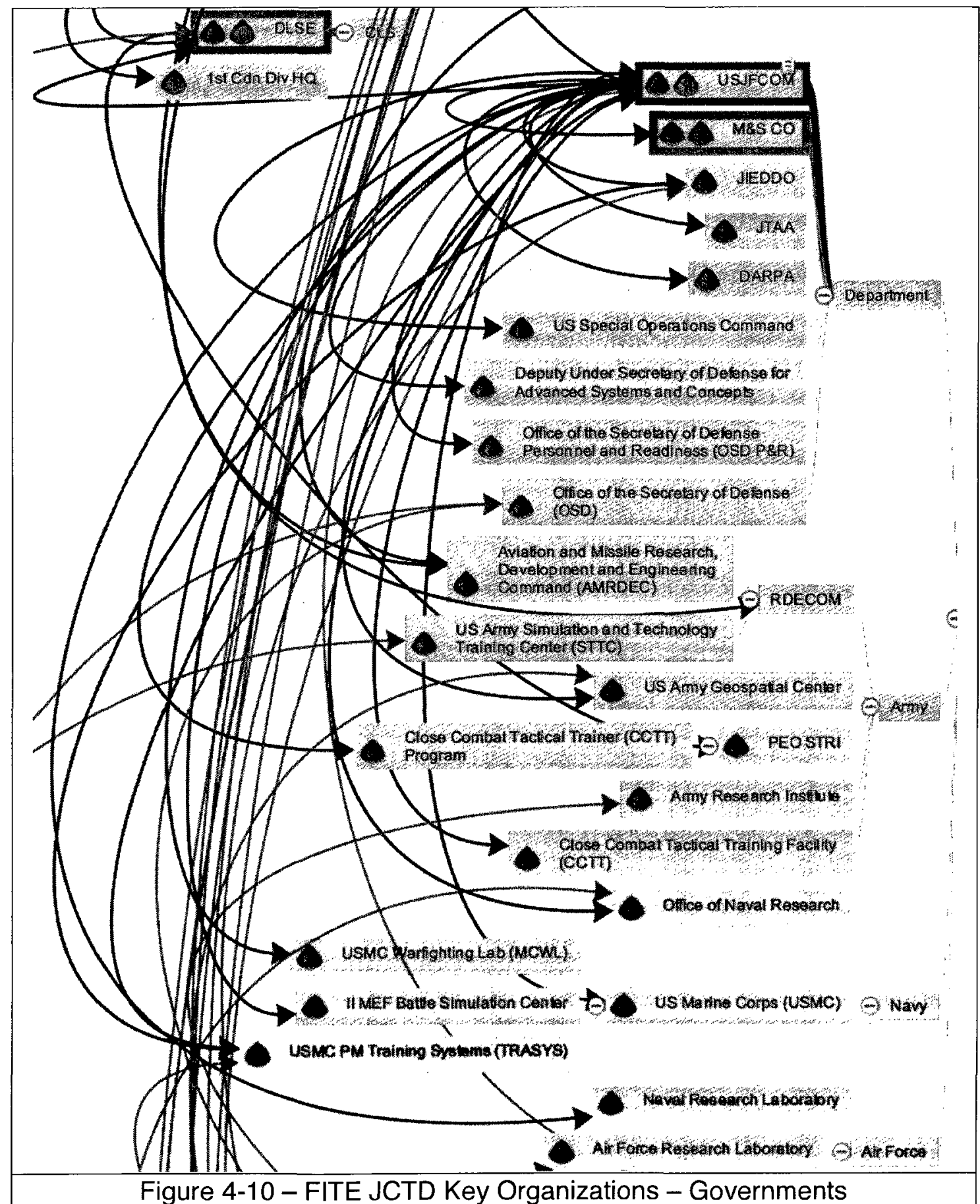




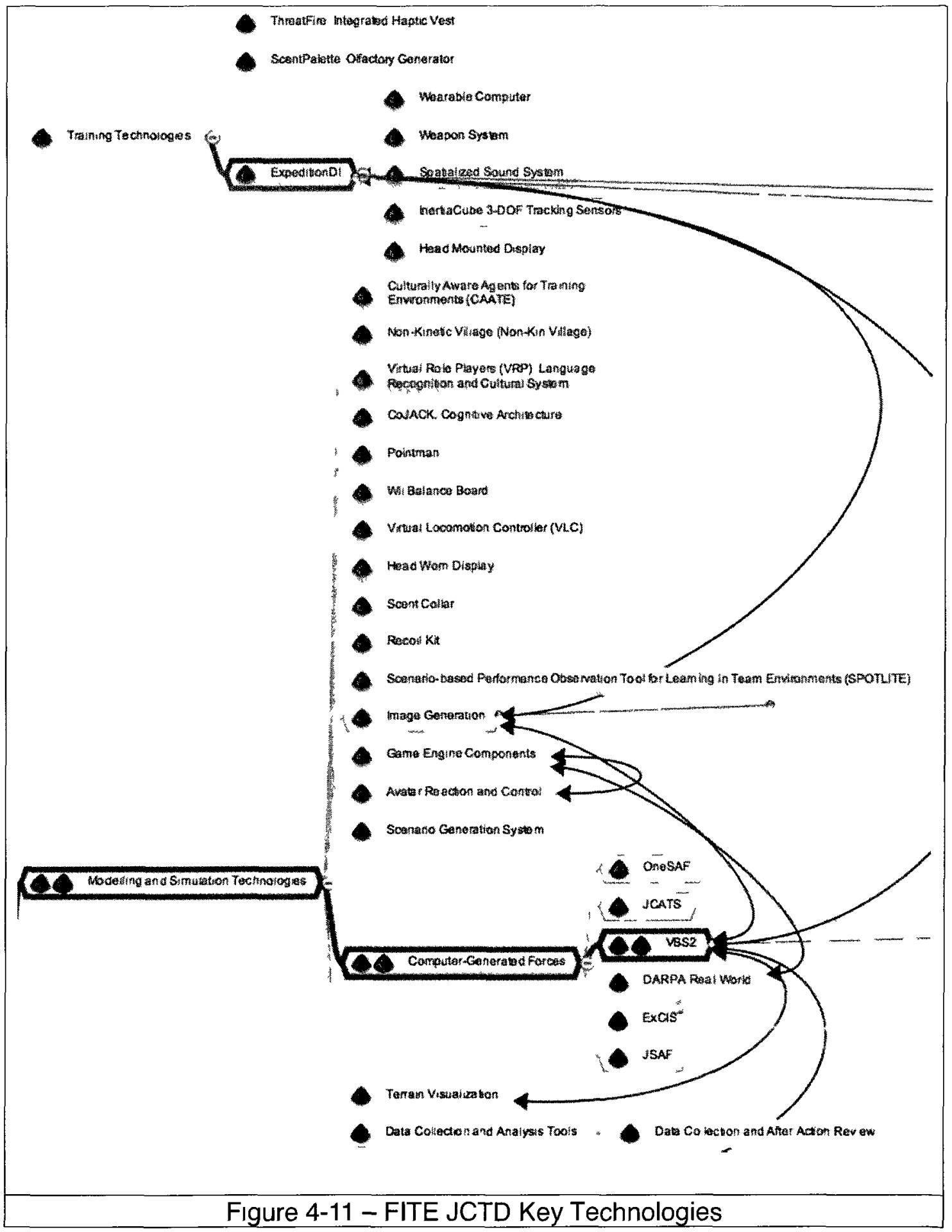


Relationships. The available data set within FITE JCTD was noticeably more restricted, As such, there was less detail available as was available for JFS TDP in the area of the inter-relationships and dependencies. However, there was still some noteworthy linkages that are represented. It was not possible to graphically depict the inter-relationships within FITE JCTD within this report due to the map's size and complexity - displaying it here in this form would render it illegible. However, it is viewable through the detailed Innovation Network Map in Appendix 1, as well as portions thereof are in the above Figures. A higher-level review of the relationships shall be discussed in Chapter 5 .

\subsubsection{Case Analysis}

Officially, the work done in FITE JCTD was a relatively short length of time (two years), and unofficial reports suggest that the majority of development and integration was done within nine months.

Additionally, it was noted in many of the papers that there are solid plans to transfer and exploit much of the work done soon, with the intent of fielding evolutions of these systems as soon as July 2011.

The project seemed squarely focused on the US military at the beginning. However, building on the success of the project, there are proposals and activities to begin a Coalition-FITE (C-FITE) program, as well as some potential to exploit the work from FITE JCTD into the four- and five-nation Science and Technology community, namely The Technical Cooperation Program (TTCP). 
The development done in FITE JCTD is planned to directly influence the procurement of over $\$ 285$ million U.S. dollars of Immersive Training Systems for the U.S. military over the next five years.

\subsubsection{Cross-Case Deductions}

\subsubsection{Combined Network Map}

There was some commonality on both the People (Organizations) side, and Technologies. They are highlighted in Figure 4-12 - the Combined Network Map. As this is not legible, Figures 4-13, 4-14 and 4-15 offer closer views of the Common Government Organizations, Industry members and Technology respectively. It is recommended to consult the detailed Innovation Network Map at Appendix 1 for more detail. The software version of Appendix 1 is intended to be much more user-friendly and interactive (either HTML, or native MINDMAP formats). The Case Studies' Contrasting Elements shall be discussed next. 


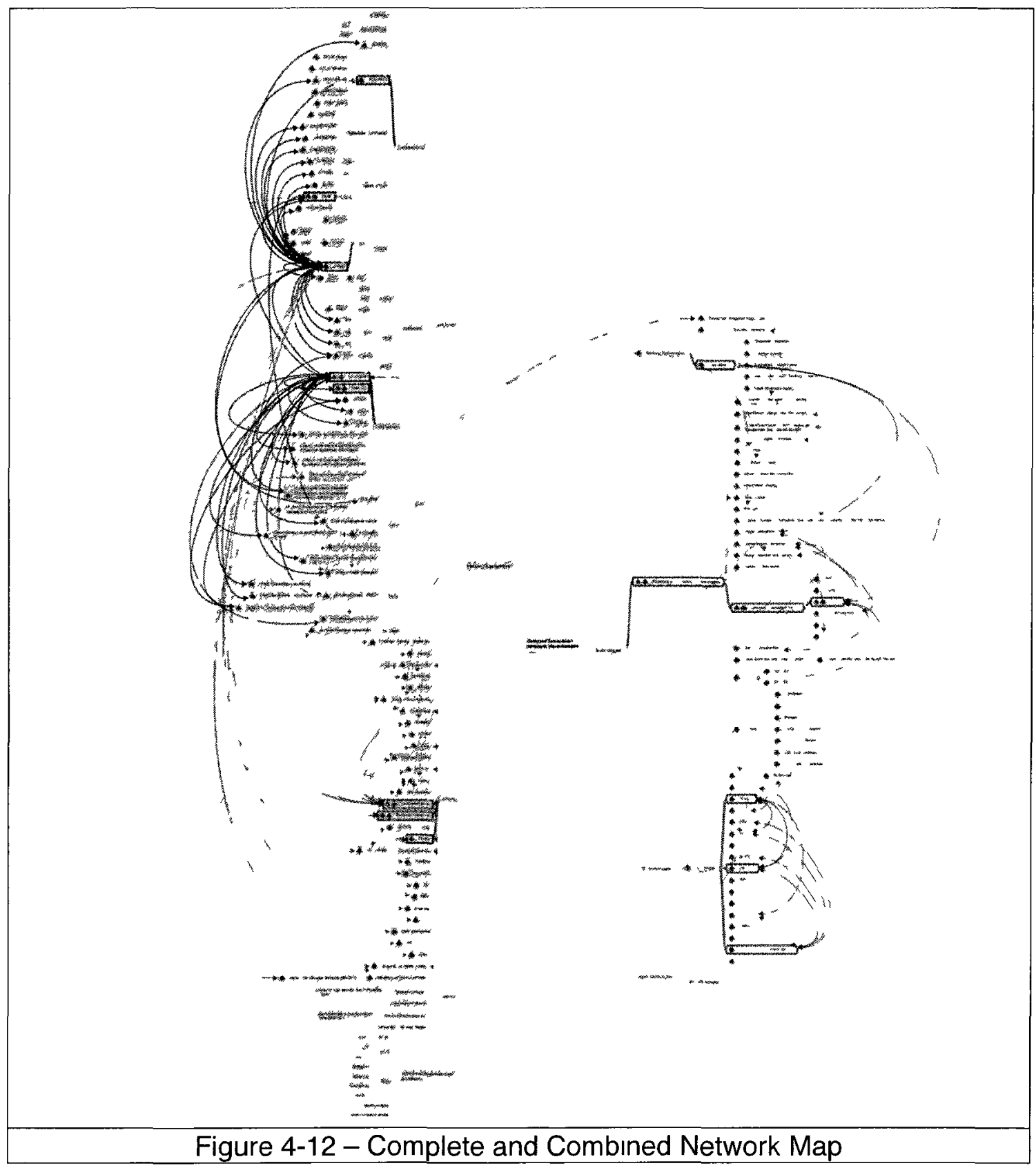




\subsubsection{Case Studies' Contrasting Elements}

The different demonstration projects were chosen due to a few reasons firstly, since they used M\&S in different ways, and secondly since they approached innovation and collaboration differently (with regards to funding levels and international participation).

On the one hand, FITE JCTD was an American military technology demonstration project, focused on developing an immersive training system for dismounted US soldiers (from either the Marine Corps, or the Army), of which the M\&S technologies were a key component. The intentional development of the M\&S components was part of the mandate of the project (e.g. developing VBS2 to support the system). On the other hand, JFS TDP was focused on developing Command, Control, Communications, Computers, Intelligence, Surveillance, and Reconnaissance (C4ISR) systems in a series of experiments, where M\&S was used as a stimulation for the experiment. The key products / technologies under development were the C4ISR systems, or moreover, the integration thereof.

With regards to the contrasting approaches to innovation, the FITE JCTD had higher density of funding: much shorter timeline, and much greater funding. The number of core technologies under evaluation or development was smaller within FITE JCTD. However, there were no accurate sources of Technology Readiness Levels (TRLs) for the core technologies under development that were made available to this research. 
With regards to the contrasting approach to collaboration, the global breadth of each Innovation Network seemed to differ as well: the JFS TDP had, and continues to exploit its work through international fora (e.g. NATO Research and Technology Organisation, The Technical Cooperation Program), and has already resulted in many effects internationally. Perhaps this may be due to the fact that the project has been in effect for more than five years. However, the JFS TDP looked internationally as part of its project plan, bringing in best practices from other nations, as well as technologies from the US.

FITE JCTD was a US-only endeavour. This might have been due to the US' International Traffic in Arms Regulations (ITAR) which strictly control the export of certain military technologies. However JFS TDP (especially in its latter years) was more of an international endeavour that had more international agreements present. A possible explanation may be due to the comparative funding levels and industrial base between the two nations, where the US had a much broader industry base to draw from, larger federal budget-to-GDP ratio as compared to Canada. This suggests that the DND/CF's preferred approach is to seek out collaboration nationally and internationally, in order to get better value for money.

The two Case Studies, had somewhat different approaches to innovation and maturation of technologies. While philosophically in the same phase of product development sponsored by the Government (both use the term "Technology Demonstration"), it can be said that due to FITE JCTD's higher density of 
funding, targeting more mature technologies that it resulted in technologies and systems that were to be delivered swiftly by US DoD Acquisition Programs.

In contrast, the JFS TDP was governed by an Experimentation Campaign Plan that began with exploratory research (lower TRL for individual systems or integrated System-of-Systems) and Limited Objective Experiments that evolved into complex multinational experiments. The exploitation of JFS TDP's results into an acquisition program is still being developed.

This research does not suggest that one approach nor another is more appropriate - but rather attempts to map out the linkages, and use of M\&S in both projects.

A more thorough analysis of the relative complexity of each project, as well as net increase of technology readiness of each technology under development (e.g. based on Technology Readiness Levels) would give more insight as to the best approach for a particular endeavour - however such an analysis is beyond the scope of this work. Recommendations for Future Work in this vein are given in Chapter 9.

\subsubsection{Case Studies' Common Elements and Collaborative}

\section{Opportunities}

Both projects held large-scale (and costly) events, whether they were called "demonstrations" or "experiments". They both involved military personnel as the focus group, who were using newly integrated systems. Essentially both Projects 
had a high degree of integration of disparate systems - systems that were not necessarily designed to be working with one-another, but were brought together with a view to potential synergies between them.

People (Organizations). There were five (5) organizations common to both projects (highlighted in green and pink in Figures 4-13 and 4-14). This suggests that there may be transfer of knowledge and information within these organizations, which could have enabled more collaboration. They were:

- Government - Canadian Army Directorate of Land Synthetic Environments (DLSE)

- Government - US Joint Forces Command (US JFCOM)

- Government - US Department of Defense Modeling and Simulation Coordination Office (M\&S CO)

- Industry - Bohemia Interactive. Bohemia produces the M\&S product "Virtual Battlespace 2 - VBS2", which was used within both Case Studies.

- Industry - Lockheed Martin. Lockheed Martin was also involved within both Case Studies, however the technologies / services that they provided were not apparently common between the projects. 

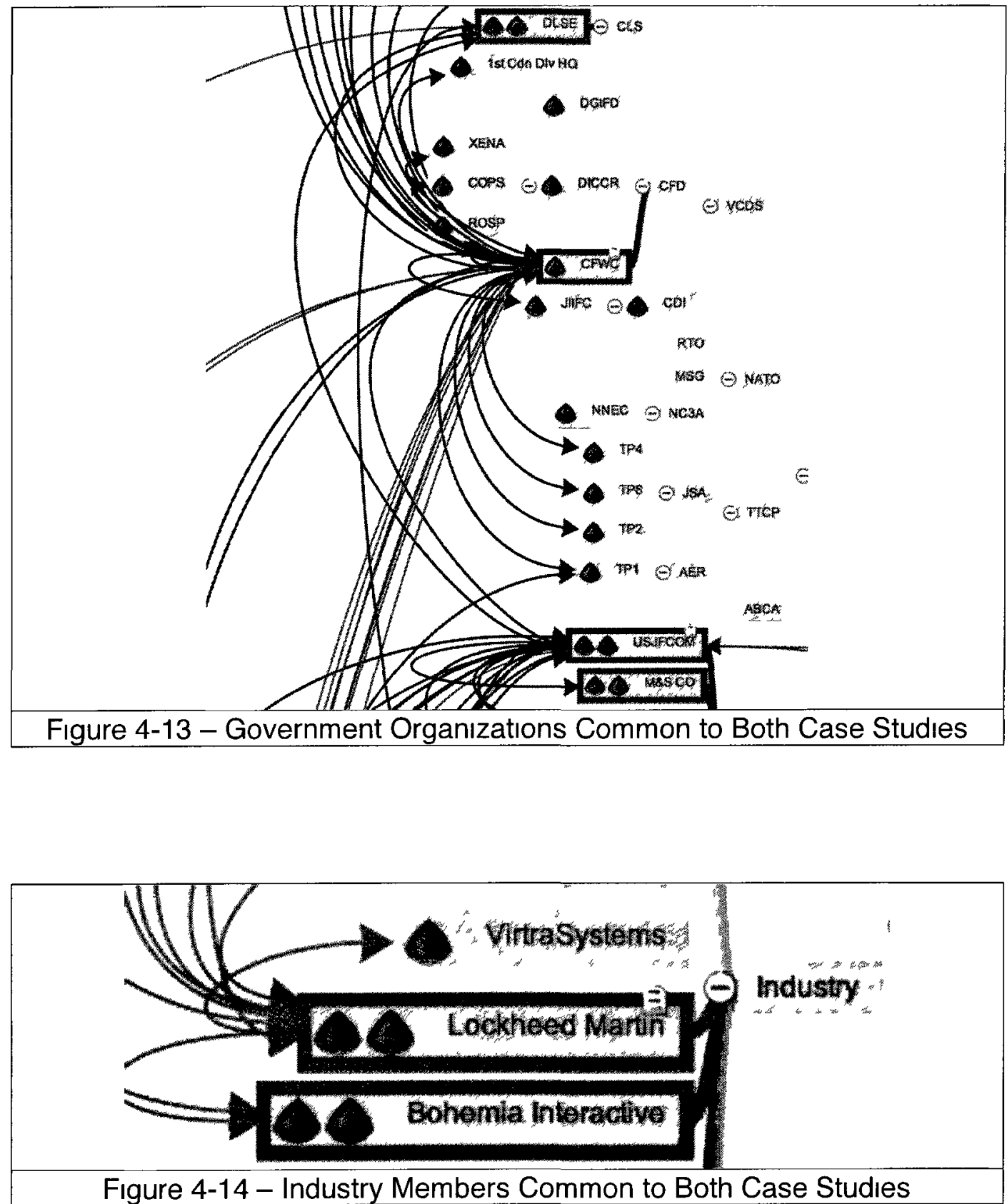

Technologies. There was one key technology that was involved in both projects - Vırtual Battlespace 2 (VBS2) from the company Bohemıa Interactıve, 
shown in Figure 4-15. However, it was used in significantly different ways. JFS TDP used VBS2 as a supporting tool, to visualize a "Bird's Eye View" of a simulated battlefield, from a simulated Unmanned Aerial Vehicle (UAV - a drone). Within FITE JCTD, VBS2 was used as a core simulation engine.

There were three Common Technology categories used within both projects: Computer-Generated Forces (CGF), Terrain Visualization, as well as Data Collection. However, it was not apparent which specific tools / technologies were used to perform these functions.

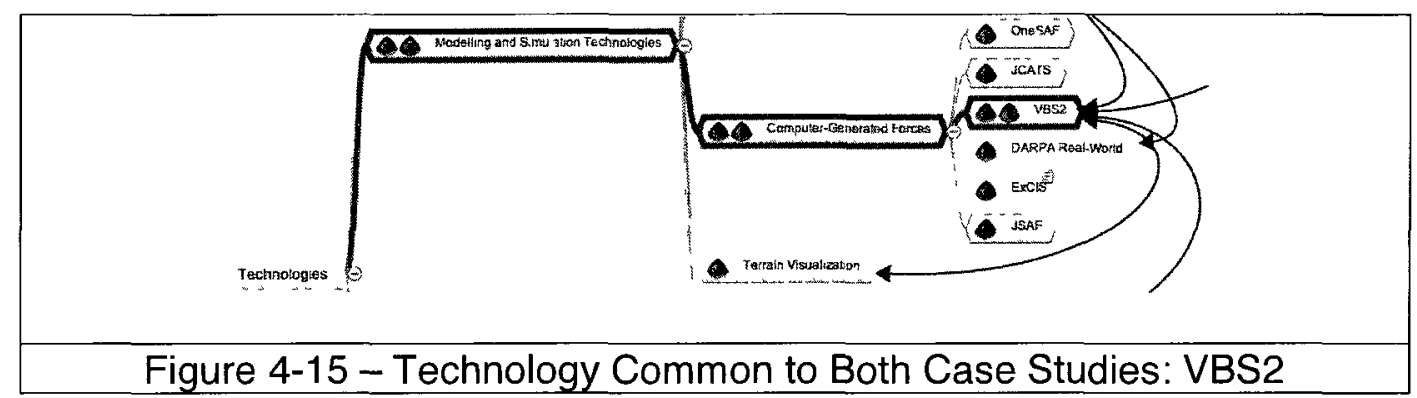

\subsubsection{Case Studies and Collaborative Agreements}

Using the "formal" inter-organizational relationships mapped between the two Case Studies (see Figure 4-1), a connection can be made to the types of Collaborative Arrangements within Bailetti and Callahan's work (Bailetti \& Callahan, 1993). Although Bailetti and Callahan's work focuses at the firm-level, this research found that their model can more broadly be applied to the Government innovation sector. Table 4-4 connects the types of formal relationships, with the Collaborative Arrangement types, and attempts to show 
relevance of their work to our Case Studies through examples from the complete Innovation Network Map (full map available at Appendix 1):

\begin{tabular}{|c|c|c|}
\hline RELATIONSHIP TYPE & $\begin{array}{l}\text { COLLABORATION } \\
\text { TYPE }\end{array}$ & EXAMPLE \\
\hline $\begin{array}{l}\text { Contract (including } \\
\text { Foreign Military Sales - } \\
\text { FMS) }\end{array}$ & $\begin{array}{l}\text { Customer } \\
\text { Interaction Module }\end{array}$ & $\begin{array}{l}\text { Many examples; The contract } \\
\text { between the US DoD's US } \\
\text { JFCOM and Lockheed Martin as } \\
\text { the overall Systems Integrator } \\
\text { for FITE JCTD is encompassed } \\
\text { in these types. }\end{array}$ \\
\hline $\begin{array}{l}\text { Professional } \\
\text { Organization } \\
\text { Membership }\end{array}$ & $\begin{array}{l}\text { Not within scope } \\
\text { of Bailetti \& } \\
\text { Callahan's model }\end{array}$ & $\begin{array}{l}\text { Membership by organizations } \\
\text { and individuals in SISO, SCS }\end{array}$ \\
\hline $\begin{array}{l}\text { Agreement - } \\
\text { Memorandum of } \\
\text { Understanding }\end{array}$ & $\begin{array}{l}\text { Joint Management } \\
\text { Module }\end{array}$ & $\begin{array}{l}\text { The TTCP MOU that unites } \\
\text { DRDC and US Army AMRDEC } \\
\text { to work on "Combined Fires } \\
\text { Experimentation and } \\
\text { Demonstration" (TTCP JSA } \\
\text { TP8) }\end{array}$ \\
\hline $\begin{array}{l}\text { Agreement - Service- } \\
\text { Level Agreement }\end{array}$ & $\begin{array}{l}\text { Intra- } \\
\text { Organizational } \\
\text { Module }\end{array}$ & $\begin{array}{l}\text { Examples between government } \\
\text { agencies; for example the "High } \\
\text { Level Architecture (HLA) Centre } \\
\text { of Excellence" agreement, } \\
\text { between CFWC (DND/CF } \\
\text { SECO) and DRDC-Atlantic, for } \\
\text { the provision of expertise and } \\
\text { services in HLA, to DND/CF }\end{array}$ \\
\hline $\begin{array}{l}\text { Agreement - Data } \\
\text { Exchange Agreement }\end{array}$ & $\begin{array}{l}\text { Technology } \\
\text { Exchange Module }\end{array}$ & $\begin{array}{l}\text { Examples exist between } \\
\text { Research and Development } \\
\text { organizations, internationally; for } \\
\text { example the Data Exchange } \\
\text { Agreement between CFWC } \\
\text { (DND/CF SECO) and US Army } \\
\text { RDECOM }\end{array}$ \\
\hline $\begin{array}{l}\text { Agreement - } \\
\text { Technology Transfer } \\
\text { Arrangement }\end{array}$ & $\begin{array}{l}\text { Technology } \\
\text { Exchange Module }\end{array}$ & $\begin{array}{l}\text { The TTA between US JFCOM / } \\
\text { FITE JCTD and PEO STRI's } \\
\text { CCTT Program, to exploit the } \\
\text { developments of FITE JCTD }\end{array}$ \\
\hline Agreement - Project & Technology & None identified in these case \\
\hline
\end{tabular}




\begin{tabular}{|l|l|l|}
\hline RELATIONSHIP TYPE & $\begin{array}{l}\text { COLLABORATION } \\
\text { TYPE }\end{array}$ & \multicolumn{1}{|c|}{ EXAMPLE } \\
\hline Arrangement & Exchange Module & $\begin{array}{l}\text { studies, however others exist in } \\
\text { other international R\&D } \\
\text { collaborations. }\end{array}$ \\
\hline Other Agreements & $\begin{array}{l}\text { Not within scope } \\
\text { of Bailetti \& } \\
\text { Callahan's model }\end{array}$ & $\begin{array}{l}\text { The JFS TDP Project Charter, } \\
\text { aligning a Project Director from } \\
\text { ADM(S\&T) and the Project } \\
\text { Manager from CFWC. }\end{array}$ \\
\hline Other Formal & $\begin{array}{l}\text { Intra- } \\
\text { Organizational } \\
\text { Module }\end{array}$ & $\begin{array}{l}\text { Many; military orders and } \\
\text { commands can be within this } \\
\text { category - for example direction } \\
\text { from CLS to DLSE to collaborate } \\
\text { with CFWC on JFS TDP. }\end{array}$ \\
\hline \multicolumn{2}{|c|}{ Table 4-4 - Relationships Types and Collaborative Arrangement Types } \\
\hline
\end{tabular}

\subsubsection{Case Studies Comparison: Modelling and Simulation}

\section{Categories}

The M\&S Categories derived earlier (Section 4.3 above), can be readily applied to the two Case Studies, allowing for a further comparison, based on the types of support to military activities that was conducted within each project. The following can be said about each project:

JFS TDP. The JFS TDP can be said to involve at least three distinct M\&S Support to Military Application Categories:

- Research, Development and Analysis. The JFS TDP was lead from DRDC, the lead Research and Development organization in DND. In the initial stages there were research studies that were conducted on emerging technologies, command and control relations, as well as 
other relevant areas, that lead to limited objective experiments, and eventually to complex and multi-national experiments. There were operational research and analysis methods that were used throughout the project.

- Concept Development and Experimentation. The JFS TDP sought to define and develop the concept of "Joint Fires Support", which was primarily achieved through a number of experiments.

- Acquisition and Life-Cycle Support. The JFS TDP has informed a number of ongoing Canadian acquisition projects, including the Joint Information and Intelligence Fusion Capabilityt Project, and the Joint Headquarters Renewal Project, amongst others.

FITE JCTD. The FITE JCTD can be said to involve at least two distinct M\&S Support to Military Applications Categories:

- Training and Education. The FITE JCTD Project was clearly defined as developing and delivering a training solution for "Small Unit" or tactical training. It involved integrating various gaming, training and simulation technologies into prototypes that were evaluated in operational demonstrations.

- Acquisition and Life-Cycle Support. The FITE JCTD Project was directed to inform future acquisitions, and Technology Transfer Agreements were set in place to ensure that the developments 
achieved in FITE JCTD were brought into acquisition programs. Within PEO STRI, the CCTT Program was directly benefiting from the development of FITE JCTD.

Of note, both projects commonly support "Acquisition and Life-Cycle Support' applications, in that their efforts were intended to directly influence future military acquisitions projects. This is evidence of the direction from strategic guidance that $R \& D$ projects should inform, and guide acquisition programs (Department of National Defence, 2006).

\subsubsection{Other Network Map Elements - Organizations}

Various professional organizations, fora were also identified. While they were not exhaustively linked in to other organizations in the Innovation Network Map, their existence was confirmed through their listing in the M\&S Body of Knowledge (Ören 2010) and through publications by both Case Study Projects in these fora. Further elaboration of these professional organizations (including key conferences, symposia or other meetings of Communities of Interest) might yield more opportunities to collaborate, and hence further populate an Innovation Map with more Collaborative Vehicles - however, fully inputting the Professional Organizations in the M\&S BoK was beyond the scope of this work. 


\subsection{Validation}

As described in the Validation Section of Chapter 3, there was a multi-layered validation approach to this work. The following is a description of some specific validation steps that were executed in the course of this research.

With regards to validity of the Constructs, multiple sources of data were used, and united into the Innovation Network Map. Each link, and organization can be linked to a source as well (denoted by Data Source legend). The constructs derived above (the Innovation Network Map - Appendix 1, and the Modelling and Simulation Support to Military Applications Categories), as well as the Case Study Reports and Cross-Case Report were reviewed by five people - peers within the CFWC, and members familiar with the Case Study Projects. To ascertain the validity of the results, this work was presented to subject matter experts within the Canadian Forces, but also internationally. The results were presented at the international level at two workshops: The Technical Cooperation Program Joint Systems and Analysis Group Technical Panel 4 on System-ofSystems Systems Engineering for Defence Modernization and the NATO Modelling and Simulation Group Panel 91 on Command and Control, Modelling and Simulation Gaps. Attendees at both workshops supported and endorsed the findings of this research. Additionally, a peer review was conducted with members within the Modelling and Simulation community. 
Within each Case Study, the validity of the data and information gathered (internal validity) was assured through confirmation (where possible) with at least two data sources.

Between Case Studies, replication logic was used to assure that the same approach was used for collecting the data, and analyzing it; for example, highlevel project documents, presentations, and papers were used to build the Innovation Network Map from both Case Study's perspectives. These documents were used to gather details on partner organizations, Project timelines, budgets, objectives, etc and were inputted into the Innovation Network Map.

The Case Study data was managed in a repository of files on a research hard drive, grouping the files into pre-analysis and post-analysis repositories. The resultant post-analysis files were used as data sources for the Innovation Network Map. These files were codified by extracting the key elements (People / Organizations, Relationships and Technologies) and inputting them into the Innovation Network Map. 


\section{DISCUSSION}

The following sections discuss various facets of the research that were not brought out in the Case Study Reports nor the Results chapter above, but require some further exposure.

\subsection{Relationships Coupling}

Some relationships (linkages) were loosely coupled (e.g. international and inter-project linkages), as well as agreements between military organizations within each country. Others (contracts) were tightly coupled, with defined deliverables and deadlines, along with resources that flowed along each relationship. Overall, the Innovation Network Map had primarily tightly coupled relationships (i.e. contracts) that enabled innovation to take place. This was supported by other formal agreements within government, and between countries, to bring other resources to bear. For example, the JFS TDP's Human Factors 3 / Coalition Attack Guidance Experiment (HF3 / CAGE) had significant international contribution from the United States. This experiment was enabled firstly by many supporting contracts with industry, but the coalition / international participation was assured through international Memoranda of Understanding $(\mathrm{MoU})$. Both of these relationships are formal agreements. However it can be said that the contracts had a tight coupling since they were enforceable (e.g. through terms and conditions with legal binding and penalties), whereas the MoUs did not necessarily have the power to force one party or another to abide - 
they were more like formalizations of intent to collaborate, and were honoured by the participants since HF3 / CAGE was a mutually beneficial event.

\subsection{Implementing the Visualization Map}

Keeping in mind the potential benefit of visualizing innovation players, relationships, and technologies, the practical aspect as to whom should manage such a repository and how it should be updated is a reality that should be broached.

It is recommended that the best implementation approach may be to manage such a repository as a "living, breathing" artifact, in a "Wiki" type fashion. This would take the burden of contributing information off to distributed collaborators, who can also benefit from the Visualization Map. While Wiki's do have their benefits in distributed management and access in an "open source"-type fashion, there are challenges with assuring accuracy of information.

Additionally, as there may be challenges with regards to competition and Intellectual Property on the side of Industry, it is likely that such a repository could best flourish if it was managed and accessible mainly on an Unclassified Defence Information System Networks (e.g. the Canadian DND Defence Wide Area Network - DWAN). Further investigation may reveal if a Classified Secret or Top Secret version would be warranted for innovation that occurs in those sensitive areas. 


\subsection{M\&S Categories Development}

This work does not suggest that the "Modelling and Simulation Support to Military Applications Categories" presented in Chapter 4 are absolute and final, but simply that there is a great deal of overlap in the keywords and expressions used, and moreover, that there is a hierarchy as well (developed in the Ontology). Its derivation was a secondary deliverable to the overall intent of this work.

However, it must be stated that the notion that there was commonality in terms, and that it is possible to organize the keywords into a hierarchy - that is the more relevant assertion. Whether there are five categories, or another number is not entirely relevant; the fact remains is that there was a clustering of terms through from a diverse span of literature sources, which can form a logical description with how M\&S can support many military endeavours, spanning from the most benign basic research laboratory, all the way to the front lines of combat.

Lastly, as described in the Literature Review (Chapter 2), having a common language to describe the application of Modelling and Simulation to Military endeavours would be of benefit and may be achievable through such standardization efforts as the M\&S BoK, and M\&S organizations such as SISO and SCS. Recommendations and Future Work with regards to the M\&S Support to Military Application Categories are suggested in Chapters 7 and 9 respectively. 


\subsection{Enterprise Architectures}

As discussed in the Literature Review (Section 2.4.4), there is an interesting development in Enterprise Architectures / Architectural Frameworks, including the U.S. Department of Defense Architectural Framework (DoDAF) standard (Department of Defense, 2010), the Canadian Department of National Defence Architectural Framework (DNDAF) standard (Department of National Defence, 2010), and the Unified Profile for DoDAF and MODAF (UPDM) standard (UPDM Group, 2010). Specifically, these frameworks attempt to standardize the description of complex System-of-Systems into inter-linked graphical views / diagrams. Of note, the Project View in DoDAF 2.0 (Department of Defense, 2010) and the Acquisition View in UPDM 2.0 (UPDM Group, 2010) show promise since the view descriptions have commonality to the Innovation Network Map herein. However, at the time of this Research, the standards (and tools to support them) were not fully matured.

Within the existing DNDAF and DoDAF standards, the Operational Views had some organizational information - however focused on the description of a System (or System-of-Systems) and its potential organizational users. Focusing on the innovation that would result in those systems is a perspective (or View) that is not currently supported by Enterprise Architecture tools. Furthermore, the Systems Views within the extant standards and toolsets are intended to focus on varying levels of complexity for the technologies. 
Details on Future Work with regards to the Innovation Network Mapping being done through Enterprise Architectures are suggested in Chapters 9.

\subsection{Project versus Network}

The notion of a project is linked to a defined beginning, span of time and end, with inputs and outputs through a project life-cycle. In support of complex projects, Enterprise Architectures were developed to formalize how systems related with other systems, from the perspectives (or views).

The issue with this is that Defence Projects (and Defence Programs that they're a part of) tend to be managed as single-projects, where the linkages between projects are not well understood, nor documented. Often the overlapping areas between projects will be from the People and Technologies (or Organization and Systems) perspectives, and as such, they could be linked between projects into an encompassing network of innovation, as suggested in this research. In essence, this research suggests that various Defence Programs (composed of Defence Projects) have some aspects of their innovation and strategy managed within a visual tool that permits the linking of technologies (or systems) and people (or organizations), as well as many collaborative vehicles (e.g. contracts and other relationships as detailed above) that link them together to truly innovate. 


\subsection{Strategy Analysis}

What we want to get out of the innovation network map is the ability to better manage complexity. With Enterprise Architectures movement there is improved ability to visualize complex systems or System-of-Systems, however this needs to evolve outside of a single Project or Program view, and evolve into capability that allows an Innovation Planner (including Top Management Teams / Directors, Managers, and possibly Engineering-level workers) to visualize the complex problem space in which they are involved. Should such a capability be built (based on recommendations in this research), it may be possible to visualize the following information more readily:

- gaps in information between systems and organizations

- collaborative opportunities and possibilities for partnerships

- identification of duplication of efforts or redundancies

- identification of critical organizations / players or technologies that require more redundancy

- identification of trends, over time (implementing a dimension of time within the tool)

- analysis of technological development and maturity, including technological maturity of system-of-systems (implementing a dimension of technological maturity, e.g. Technology Readiness Levels - TRLs) 
While TRLs can be readily applied to individual systems, it becomes more complex when considering inter-system integration. In particular, for the JFS TDP many of the individual command and control systems are already in use, in a proven operational theatre. However, the integration between systems is one of the key innovative endeavours that the JFS TDP promises to deliver. Having a tool that would enable the visualization of the system, and the aggregate technological maturity could assist Innovative Planners in better focusing their efforts on the areas that would yield best value after development.

As another example, in analyzing the Innovation Network Map (Appendix 1), we can immediately see that through this visualization, we can see the key nodes that have many arrows pointing into them - e.g. US JFCOM and CFWC. These two organizations happened to be key Project Sponsors for the projects under study. Such a visualization readily enables the untrained eye to identify that such a node in the Innovation Network has a degree of importance - which would assist an Innovator in analyzing the innovation landscape.

These are but a few suggestions and possible uses for Strategy Analysis of innovative endeavours.

\subsection{Research Findings Applicability to Other Domains}

It is believed that there are many areas outside of this context where these results and conclusions may also apply, however, investigation into their application is outside the scope of this work. For example, the Modelling and 
Simulation (M\&S) Support Categories are most applicable to military applications, however, these generic keywords may very well have utility in other parallel domains such as in Manufacturing or the Biomedical industry. Similarly, the mapping of Defence Innovation Networks may be very beneficial from a firm's perspective, or in another sector - however this was not developed further and could be an area of future research.

\subsection{Answers to Research Questions}

The main and supporting research questions within this work will now be stated and answered, based on the Results and Discussions above.

\subsubsection{Main Research Question - and Answer}

The main research question was stated as

"How do defence innovators collaborate to innovate using Modelling and Simulation, and can an innovation network viewpoint help identify areas for improving collaboration?"

This research has shown that innovation is achieved within these Case Studies, largely through formal contracts between Government and Industry, and further supported by formal agreements - both within a given government, and between governments / militaries. M\&S technologies were used in different ways between the Case Studies (as described in Section 4.4.4.5), and the development of the M\&S Support to Military Application Categories showed that there is a spectrum 
of applications for M\&S to the defence sector. M\&S technologies themselves did not directly enable collaboration, but they were a focal group of technologies that were used extensively by both Case Studies. This research also showed that there are communities of practice for M\&S, and there is a movement towards the professionalization and formalization of M\&S as a Discipline, and possibly as an Industry.

With regards to Innovation Networks, the sections above showed that the complex mixture of People, Technologies (and Relationships) can be represented as a network, and is appropriate for the Case Studies in question. Areas for potential improvement in collaboration were identified, and the potential benefit for an Innovation Network Viewpoint for Strategy Analysis was described above.

\subsubsection{Supporting Research Questions - and Answers}

Question 1 (Q1). How do defence innovators use Modelling and Simulation (M\&S) technologies in their innovative processes?

Answer 1 (A1). Within the JFS TDP, the M\&S technologies were used in a supporting role in order to evaluate and integrate C4ISR systems, and evaluate Joint Fires Support concepts. The M\&S technologies, and their integration with C4ISR technologies developed themselves, in the execution of the project. Within the FITE JCTD, the M\&S and training technologies were 
a focal group technologies that were developed to support training, in concert with other training technologies.

Q2. How do defence innovators collaborate, and what are the types of relationships in defence innovation?

A2. Defence innovators collaborate through a combination of tightly and loosely coupled formal relationships, as well as loosely coupled informal relationships. This includes formal contracts between industry partners, and mainly, between government and industry. Relationships identified also included Memoranda of Understanding, Service-Level Agreements, Project Arrangements, Technology Transfer Arrangements, and others.

Q3. Is an innovation networks view appropriate for defence innovators? A3. Yes - the complex mixture of People, Technologies (and Relationships) can be represented as a network, and is appropriate for the Case Studies in question, and it is believed is appropriate for representing the complex interactions between defence innovators writ large.

Q4. What is the mapping of collaborators, partners, and key stakeholders involved in given demonstration projects? 
A4. This is shown, in detail, in Appendix 1 - the Innovation Network Map.

Q5. Can visualization of an innovation network assist in planning strategies for defence innovation (specifically, research and development demonstration projects)?

A5. Yes - this research showed that it was possible to visualize key stakeholders and that it would be of benefit to defence innovation planners (see Discussion sections above and Results chapter).

Q6. Are there areas for improved collaboration, increased reuse within the given demonstration projects?

A6. Yes - there were areas identified for potential improved collaboration and increased reuse, both with regards to the Virtual Battlespace 2 (VBS2) M\&S technology, but also with regards to collaboration between the Government and Industry organizations, of which there were five that were common to both projects - indicating that there exist some relationships that could be exploited. 


\section{CONCLUSIONS}

Innovation using Modelling and Simulation (M\&S) is not just rapid prototyping nor Computer-Aided Design (CAD) nor Computer-Aided Software Engineering (CASE) tools which use modelling techniques. This research uncovered that there is an emergent M\&S community that has made strides towards professionalization and recognition as an Industry, and a Profession.

The development of the M\&S Support to Military Applications Categories are a useful and valid start to describe an hierarchical relationship of terms to describe how M\&S is used in the Defence sector. With many terms currently used, there is an overlap that should be structured, and agreed upon, through extant professional fora. Of note, although M\&S technologies had their foundation and were largely developed for the Training and Education community, their current application spans a spectrum of applications of which "Training" is but one application category.

The capability development environment is dynamic, complex and interdependent - where collaboration in innovation increasingly essential. This work showed that an Innovation Network viewpoint (and, arguably, Business Ecosystems) can be used within the realm of military Modelling and Simulation (M\&S). The evolving research in Innovation Theory (Business Ecosystems and Innovation Networks) has application and benefit to Government (Defence). 
It was shown that Innovation Planners should distinctly and visually map out "Collaborative Vehicles", including Formal and Informal relationships such as Contracts, Memberships, Agreements, Data-Exchange Agreements (DEA), Technology Transfer Agreements (TTA), Contracts, Memoranda of Understanding (MoUs), Service-Level Agreements (SLA), and others. These Collaborative Vehicles truly enable the exchange of resources, whether tangible (people, equipment) or intangible (ideas, knowledge).

Mapping and then visualizing defence innovation networks has benefits for identifying linkages and gaps, not otherwise (easily) possible with current programmatic methods. It was also stated that Defence Innovators should evolve management of Programs, Portfolios, Strategic relationships beyond "flat" methods such as using Microsoft Office tools (e.g. Spreadsheets, Documents, Presentations, Static diagrams) and isolated databases (e.g. web portals to independent databases)

This research uncovered many recommendations that can possibly be initiated now, and as such, are presented in the next Chapter. 


\section{RECOMMENDATIONS}

There are a number of actions that can be possibly initiated now, using the deliverables of this work. The following recommendations are offered for M\&S practitioners, as well as non-M\&S military organizations.

\subsection{Categorization Evolution and Adoption}

It is recommended that the aforementioned M\&S Support Categories be adopted within military communities of practice. These categories can (and should) evolve and be further refined. They should be considered for inclusion within the Modelling and Simulation Body of Knowledge (M\&S BoK) (Ören 2010).

\subsection{Network Encompassing Projẻcts: Collaborative Network Mapping}

It is recommended that this Proof-of-Concept visualization tool be built upon, and managed within the Canadian Department of National Defence (DND) as a collaborative tool (e.g. wiki-style map).

It is recommended that a notion that a given project is managed and shepherded within a network of innovative partnerships be adopted by defence organizations. This is already done to a degree within DRDC and JFCOM, however the community's "People, Processes and Technologies" that enable the management of our innovation (e.g. Spreadsheets, Documents) can themselves evolve some more.

This would be enabled by having a tool that would allow easy input and extraction of data. As well, analysis of that data would result in information and 
knowledge that would guide defence innovation. The following section details some high-level requirements for such a tool.

\subsection{Tool Evolution and High-Level Requirements}

Through the conduct of this research, and the amalgamation of a number of data sources into the Proof-of-Concept Innovation Network Map (Appendix 1), there were many lessons learned, and basic requirements derived that could advise the evolution of an Innovation Network Map and Visualization tool. These requirements are by no means exhaustive - and the further definition and refinement of them should is an area of Future Research and Development unto itself.

The following high-level requirements were extracted through this research. It is strongly believed that an evolution of a visualization tool would be of immense benefit to Innovation Planners. As such, the following High-Level Tool Requirements are recommended.

\subsubsection{Tool Data Structure Requirements}

DS1. The underlying data structure for an innovation network map must represent the beginning date, end date, scope, organizations and technologies for a particular relationship.

DS2. The data structure must represent details on the organizations (nodes)

DS3. The data structure should be able to represent people within an organization. 
DS4. The data structure must be able to represent a notion of hierarchy and decomposition of organizations.

DS5. The data structure must be able to capture the reference / source of each item of data put into it, (e.g. website or document reference).

DS6. The data structure must be able to capture the identification of the user inputting data (e.g. date/time stamp, and User Identification about user changing a given node, link)

DS7. The data structure must allow for multiple users to collaborate / contribute to portions of the map, simultaneously

\subsubsection{Tool Analysis Requirements}

AN1. The tool must be able to support Social Network Analysis (SNA) including node centrality measures (degree, betweenness, closeness, Eigenvector) centrality, shortest path between nodes, identification of key players and other SNA methods (Cheliotis, 2010).

AN2. The tool must be able to export SNA reports to common Microsoft Office formats (e.g. Excel, Word).

AN3. The tool must be able to support Business Ecosystem analysis, including automatic identification of important players. This includes the ability to automatically identify critical organizations / players or technologies that require more redundancy 
AN4. The tool must be able to automatically identify gaps between subsets of organizations and subsets of technologies

AN5. The tool must be able to dynamically change perspective, based on a focal node under analysis, showing other nodes around them as a central node.

AN6. The tool must be able to show path(s) between any two nodes, if any path does exist.

AN7. The tool should have an automatic way of showing duplication of technologies, or "User Groups" for a particular technology.

AN8. The tool should readily enable the identification of information gaps, between systems and organizations.

AN9. The tool should enable the identification of trends, over time (implementing a dimension of time within the tool)

AN10. The tool must enable the analysis of technological development and maturity, including technological maturity of system-of-systems (implementing a dimension of technological maturity, e.g. Technology Readiness Levels - TRLs)

\subsubsection{Tool Interoperability Requirements}

The following are some sample Tool Interoperability Requirements:

IN1. The tool must be able to export its data to common Social Network Analysis, Mind Mapping and Office Automation formats (e.g. XML, HTML and Microsoft Office formats). 
IN2. The tool must be able to be collaboratively edited by many users, connected through digital network.

IN3. The tool should have a web interface, to allow common look-and-feel, and accessibility between remote contributors.

\subsubsection{Tool Visualization Requirements}

VS1. The tool must be able to represent link / relationship direction and strength, which may have different weighting between each node (i.e. organization A may be more dependent on organization $B$, whereas organization $B$ does not fully dependent on organization A).

VS2. The tool must be able to scale the level of complexity (i.e. number of nodes / links) in a given visualization.

\subsection{General Recommendations}

TRLs. The use of Technology Readiness Levels (TRLs) to manage the overall development of these projects has been (apparently) relegated to a background and supporting tool. TRLs can have the benefit of giving a brief snapshot (at a given moment in time) of a given technology's level of maturity. From a programmatic view, TRLs can give a measure of risk in the early stages, but also can be a measuring stick as a technology (and its integration with other technology) develops through a project (Department of Defense 2009; DionSchwartz 2008; Nolte, Kennedy and Dziegiel n.d.). As such, TRLs could be used as a "measuring stick" for project monitoring. Furthermore, an evolution of TRLS 
to better support complex systems and Systems of Systems (SoS) would likely have great benefit to measuring development and innovation when multiple systems are involved, and the integration itself of the component is the area under development. 


\section{LIMITATIONS}

There are some limitations that were identified in the conduct of this research. They are briefly stated herein.

Case-study-based research itself has risk of applicability beyond the cases selected, as such it is possible that the findings of this research may have limited application to other Defence Projects.

As there was a limited data set available for the projects studied, it is possible to have missed valuable data that would have possibly been available in other data sources. It is believed that if more data would be available, it would further strengthen the People (Organizations), Technologies and Relationships that were mapped out, adding more value, content and complexity to the overall Innovation Network Map. Of the project data sources available, there were instances where information was inputted based on only a singular data source, and it could not be corroborated.

Due to the manual input of data into the innovation network map, and visual evaluation of the information by people thereafter, it is possible that human error may have resulted in accuracies in the presentation of the data.

The Proof of Concept Visualization of the Innovation Network Map (Appendix 1) was not scalable if it was to be implemented in short time, due to the manual input of data. Further development should identify extant databases of 
technological architectures, organizational and programmatic information, and import them into a relevant Innovation Network Map.

Lastly, the data structure for the Proof of Concept Visualization of the Innovation Network Map (Appendix 1) was based on a Commercial-Off-The-Shelf (COTS) Tool - CS Odessa's MINDMAP. As such, the visualization is limited to the fields and structures that were available within its current configuration. The proprietary data structure was mitigated through export functionality to other data types, however that data type set (.XML, .HTML, .OPML) was also limited. 


\section{FUTURE WORK}

In the conduct of this work, there were many tangential lines of investigation and development that had to be scoped out. This Chapter summarizes many future research that the author believes merit pursuit.

\subsection{Open-Source and Government-Off-The-Shelf}

The Innovation Network approach described herein, should be applied to Open-Source or Government-Source projects and products. Examples of Government-Off-The-Shelf (GOTS) technologies include "America's Army", Joint Semi-Automated Forces (JSAF), and One Semi-Automated Forces (OneSAF). These simulation products are examples where there has been a large user community built up, which enables a degree of collaboration. As discussed in this research, these products and their surrounding network of supporting actors and users form an innovation network. Due to limited time, and the discovery of their practices later in this research, it was not possible to further analyze these communities' practices and methods of collaboration and innovation.

\subsection{Ecosystems and Government}

More research should be done to further delve into the application of ecosystems to Government-University-Industry collaboration, and innovation in the Defence sector, especially considering the unique cluster of innovative capability within Canada's National Capital Region. A formal evaluation on the appropriateness of the Business Ecosystems concept for specific Government- 
Off-The-Shelf (GOTS) Software, such as OneSAF, JSAF, America's Army should be done. This could be compared and contrasted with strong M\&S user-groups for commercial products such as Virtual BattleSpace 2 (VBS2). Where appropriate, it may be of merit to derive an ecosystems or innovation network map of relationships and data flows within one of these networks.

\subsection{Developing an Innovation Network Management Environment}

The recommended "High-Level Tool Requirements" in Chapter 7 should be further researched and developed, and focused into a tool that enables an "Innovation Network Management Environment". The BLOOM Project, led by a team within Carleton University, is developing an "Ecosystem Browser". This Project is very promising, and is one technological option to possibly pursue that may be able to incorporate the requirements that started to be developed in Chapter 7. As another technological option, extant Business Portfolio management software suites should be evaluated as well.

\subsection{Converging Innovation Networks and Enterprise Architectures}

Much development has occurred in recent years in Enterprise Architectures, as discussed above. With the emergence of recent Enterprise Architecture standards, it is possible that Project or Acquisition views will meet part of the Innovation Network map requirements discussed above.

An effort should be expended, as high priority development, to determine if future DoDAF 2.0 and UPDM 2.0 toolsets, would be able to support the needs of 
Innovation Networks, and the high-level requirements detailed in Chapter 7. Furthermore, this work should inform the development of future Enterprise Architecture standards as well (e.g. UPDM 3.0).

\subsection{Review Extant Canadian DND Innovation Databases}

There are extant Canadian Department of National Defence (DND) databases which manage many defence investments. The Canadian Defence Research and Development Canada (DRDC) uses a Microsoft Excel-based group of interconnected spreadsheets to host a database of DRDC projects and initiatives. This database is duly named the "Collaborative Planning and Management Environment - CPME". Furthermore, the largest repository of Canadian Defence Program and Projects is the Vice Chief of Defence Staff's Capability Investment Database (CID). The CID manages 1195 defence projects totaling almost \$5B (CAD) in 2009-2010. The CID is a "flat" web-based database, that offers the viewers with only basic ability to view individual acquisition projects. These databases do have limitations, and should be explicitly evaluated for their feeding into an Innovation Network planning tool. It may be possible that a future effort would transition these relatively non-visual databases into a new data structure, as discussed in this research.

\subsection{Maturation of Technology Readiness in Projects}

A more thorough analysis of the relative complexity of each project, as well as net increase of technology readiness of each technology under development 
(e.g. based on Technology Readiness Levels) would give more insight as to the best approach for a particular endeavour. It is recommended that the use of Technology Readiness Levels (TRLs) be investigated as a potential metric to aid Innovation Planners - from both an Innovation Networks perspective, but also from a perspective of how they can be used through Innovative processes as well.

\subsection{Visualizing Processes}

In the conduct of this research, many complex inter-woven processes were uncovered. These "Business Processes" were outside the scope of this research, however they are an immensely interesting area of research that is thought to have much applicability to innovation, and moreover, improvement of innovative endeavours. Figure 9-1 shows some high-level processes that were identified in the conduct of this research.

It is recommended that an exploration of the "Process" perspective of the problem space be addressed, likely through such technologies such as Business Process Modelling Notation (BPMN) and Business Process Modelling Language (BPML). As the "People, Process, Technologies" model suggests, the Process perspective is an important component that must be evaluated to give a holistic view of the problem space.

This is directly stated in a closing quote by Adner, below. 
"Successful innovation requires trackıng your partners and potential adopters as closely as you track your own development process." (emphasıs added - Adner, 2006)

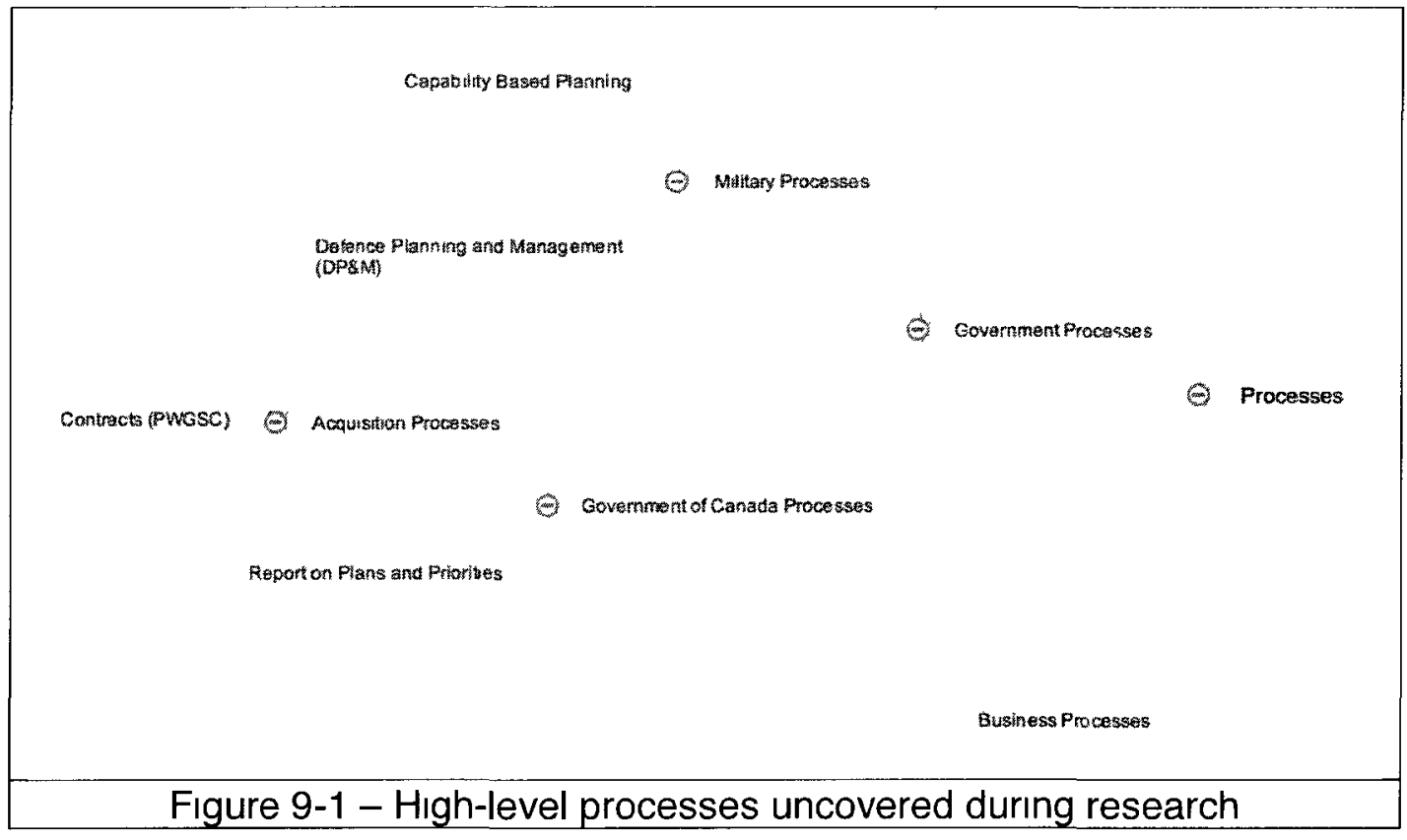




\section{REFERENCES}

Abrahamson, E., 2004, Change without pain: How managers can overcome initiative overload, organizational chaos, and employee burnout, Harvard Business Press, Boston, MA.

Adner, R., 2006, Match your innovation strategy to your innovation ecosystem, Harvard business review, 84(4), pp. 98-107; 148.

Alberts, D.S. \& Hayes, R.E., 2003, Power to the edge: command, control in the information age, CCRP Publication Series, Washington, DC.

Alberts, D.S. \& Hayes, R.E., 2007, Planning: complex endeavors, CCRP Publications, Washington, DC.

Anggraeni, E., den Hartigh, E. \& Zegveld, M., 2007, Business ecosystem as a perspective for studying the relations between firms and their business networks, ECCON 2007 Annual Meeting.

Bailetti, A.J., 2009, Business Ecosystems: A new form of organizing creative individuals worldwide, FOCUS Presentation to MaRS Collaboration Centre, Toronto. Retrieved June 26, 2010, from http://www.slideshare.net/brianhurley/ecosystemsfeb12-to-focus

Bailetti, A.J. \& Callahan, J.R., 1993, The coordination structure of international collaborative technology arrangements. R\&D Management 23 (2): 129-146. 
Basole, R.C., 2009, Structural Analysis and Visualization of Ecosystems: A Study of Mobile Device Platforms, Journal of Information Technology (24), pp. 144-59.

Bloom, P.N. \& Dees, G., 2008, Cultivate Your Ecosystem, Stanford Social Innovation Review (Winter 2008).

Carayannis, E.G. \& Campbell, D.F.J., 2006, Knowledge creation, diffusion, and use in innovation networks and knowledge clusters, Praeger.

Carayannis, E.G., Assimakopoulos, D.G. \& Kondo, M., 2008, Innovation networks and knowledge clusters: findings and insights from the US, EU and Japan, Palgrave Macmillan, New York.

Cheliotis, Giorgos. Social Network Analysis including a tutorial on concepts and methods. Retrieved February 5, 2011 from http://www.slideshare.net/gcheliotis/social-network-analysis-3273045

Christensen, C.M., Anthony, S.D. \& Roth, E.A., 2004, Seeing what's next: using the theories of innovation to predict industry change, Harvard Business School Press

Coll, S., 2009, The Future of Soldiering, The New Yorker.

den Hartigh, E. \& van Asseldonk, T., 2004, Business ecosystems: A research framework for investigating the relation between network structure, firm strategy, 
and the pattern of innovation diffusion, ECCON 2004 Annual Meeting: CoJumping on a Trampoline, The Netherlands.

den Hartigh, E., Tol, M. \& Visscher, W., 2006, The health measurement of a business ecosystem, Proceedings of the European Network on Chaos and Complexity Research and Management Practice Meeting.

den Hartigh, E., Tol, M., Wei, J., Visscher, W. \& Zhao, M., 2005, Modeling a business ecosystem: An agent-based simulation, ECCON 2005 Annual Meeting.

Department of Defense, 2007, DoDD 5000.59: Modeling and Simulation Management, DoD Directive.

Department of Defense, 2009, The 2008 Modeling and Simulation Corporate and Crosscutting Business Plan, Retrieved November 21, 2010, from http://www.msco.mil/files/Modeling\%20and\%20Simulation\%20Corporate\%20and \%20Crosscutting\%20Business\%20Plan_F.2.pdf

Department of Defense 2010, Product Manager OneSAF, PEO STRI Product Catalog. Retrieved December 4, 2010, from http://www.peostri.army.mil/PRODUCTS/ProductCatalog2010.pdf Department of Defense, DoD 2002, Mandatory Procedures for Major Defence Acquisition Programs and Major Automated Information System Acquisition Programs, US Government. 
Department of Defense, DoD 2008, Live Virtual Constructive Architecture Roadmap, LVCAR.

Department of Defense, DoD 2009a, Coalition Warrior Interoperability Demonstration 2009 Final Report: Assessment Briefs, Hampton, VA. Retrieved June 26, 2010, from http://www.cwid.org/2009\%20Final\%20Report/pdffiles/booklet.pdf Department of Defense, 2009b, US DoD Technology Readiness Assessment Deskbook, TRA Deskbook.

Department of National Defence, 2005, The Technology Demonstration Project Management Guidebook, Defence Research and Development Canada.

Department of National Defence, 2006a, Defence Administrative Order and Directive 2010-0: Modelling and Simulation, Retrieved June 26, 2010, from http://www.admfincs.forces.gc.ca/dao-doa/2000/2010-0-eng.asp

Department of National Defence, 2006b, Defence Administrative Order and Directive 2010-1: Modelling and Simulation Management, Retrieved June 26, 2010, from http://www.admfincs.forces.gc.ca/dao-doa/2000/2010-1-eng.asp

Department of National Defence, 2008, Canada First Defence Strategy, Retrieved June 26, 2010, from http://www.forces.gc.ca/site/pri/firstpremier/June18_0910_CFDS_english_low-res.pdf 
Department of National Defence, 2009a, Department of National Defence and Canadian Forces Architecture Framework (DNDAF) Version 1.6, DNDAF 1.6. Retrieved June 26, 2010, from http://www.img.forces.gc.ca/pub/af-ca/index-eng.asp Department of National Defence, 2009b, DRDC CORA Website, Retrieved November 28, 2010, from http://www.cora.drdc-rddc.gc.ca/what-quoi-eng.asp Department of National Defence, 2009c, The Future Security Environment 20082030, Part I: Current and Emerging Trends, Department of National Defence.

Department of National Defence 2010, DND / CF Website, Retrieved November 28, 2010, from http://www.forces.gc.ca/site/home-accueil-eng.asp\#panel-1

Department of National Defence, 2005, Land Force Command Order 28-1, LFCO 28-1.

Department of National Defence, 2010a, Canadian Forces Warfare Centre: Capability Definition Paper, CFWC CDP.

Department of National Defence, 2010b, DND and CF Modelling and Simulation Strategic Vision and Objectives, Government of Canada.

Department of National Defence, 2006, Defence Science and Technology Strategy. Science and Technology for a Secure Canada, Government of Canada. Re- 
trieved October 21, 2010, from http://www.drdc-rddc.gc.ca/sciences/strat/strateng.pdf

Dhanaraj, C. \& Parkhe, A., 2006, Orchestrating innovation networks, Academy of Management Review, 31(3), p. 659.

Eisenhardt, K.M., 1989, Building theories from case study research, Academy of management review, 14(4), pp. 532-50.

Eisenhardt, K.M. \& Graebner, M.E., 2007, Theory-building from cases: Challenges and opportunities, Academy of Management Journal, 50(1), pp. 25-32.

Eppler, M J. 2006. A comparison between concept maps, mind maps, conceptual diagrams, and visual metaphors as complementary tools for knowledge construction and sharing. Information Visualization 5 (3): 202-210.

Gilbert, N., Pyka, A. \& Ahrweiler, P., 2001, Innovation networks-a simulation approach, Journal of Artificial Societies and Social Simulation, 4(3), pp. 1-13.

Goerzen, A., 2005, Managing alliance networks: Emerging practices of multinational corporations, Academy of Management Executive, 19(2), pp. 94-107.

GovMonitor 2010, DOE Invests $\$ 5.3$ Million For Innovation Ecosystems, The Gov Monitor. Retrieved October 13, 2010, from 
http://www.thegovmonitor.com/world_news/united_states/doe-invests-5-3-millionfor-innovation-ecosystems-38728.html

Gray, B., 2008, Enhancing transdisciplinary research through collaborative leadership, Am J Prev Med, 35(2 Suppl), pp. S124-32.

Hagel III, J., Brown, J.S. \& Davison, L., 2008, Shaping strategy in a world of constant disruption, Harvard Business Review, 86(10), pp. 81-9.

I/ITSEC, 2010, I/ITSEC 2010 Program Guide, I/ITSEC Website. Retrieved December 4, 2010, from http://www.iitsec.org/attendees/Pages/Brochures.aspx lansiti, M. \& Levien, R., 2002, The New Operational Dynamics of Business Ecosystems: Implications for Policy, Operations and Technology Strategy, Cambridge, Massachusetts: Harvard Business School Working Paper, pp. 1-113. lansiti, M. \& Levien, R., 2004a, The keystone advantage, Harvard Business School Press Boston.

lansiti, M. \& Levien, R., 2004b, Strategy as ecology, Harvard Business Review, 82(3), pp. 68-81.

lyer, B., Lee, C.H. \& Venkatraman, N., 2006, Managing in a Small World Ecosystem: Some Lessons from the Software Sector, California Management Review, 48(3), pp. $28-47$. 
Jansen, S., Brinkkemper, S. \& Finkelstein, A., 2009, Business Network Management as a Survival Strategy: A tale of Two Software Ecosystems.

Kilkenny, M. \& Nalbarte, L., 2000, Keystone sector identification, TVA Rural Studies, pp. 00-8.

Kim, B., Johnson, B., Youssef, R., Vallerand, A.L., Herdman, C., Gamble, M., Lavoie, R., Kurts, D. \& Gladstone, K., 2005, JSMARTS Initiative, DRDC Technical Note.

Law, A.M., 2007, Simulation modeling and analysis, 4 ed. McGraw-Hill, Boston.

Lowood, H. \& Lenoir, T., 2003, Theaters of war: The military-entertainment complex, URL: http://www. stanford. edu/dept/HPST/TimLenoir/Publications/LenoirLowood\_TheatersOfWar. pdf\# search=\% 22lowood\% 20lenoir\% 20military, 22.

Miles, M.B. \& Huberman, A.M., 1994, Qualitative data analysis: An expanded sourcebook, SAGE publications, Inc,.

Moore, J.F., 1993, Predators and prey: a new ecology of competition, Harvard Business Review, 71(3), p. 75.

Moore, J.F., 2006, Business ecosystems and the view from the firm, Antitrust Bulletin 51 , p. 31. 
Muller, P., 2010, The Interservice/Industry Training, Simulation \& Education Conference (I/ITSEC), The Future Immersive Training Environment (FITE) JCTD: Improving Readiness Through Innovation.

Muller, P., Schaffer, R. \& Carswell, J., 2010, The Interservice/Industry Training, Simulation \& Education Conference (I/ITSEC), The Future Immersive Training Environment JCTD: Technical Challenges in Demonstrating Virtual Reality for Infantry Training.

Nance, R.E. \& Sargent, R.G., 2002, Perspectives on the Evolution of Simulation, Operations Research, 50(1), pp. 161-72.

NATO, 2010, Modelling and Simulation Centre of Excellence Initiative, NATO. Retrieved December 3, 2010, from https://transnet.act.nato.int/WISE/COE/Individual/MS/MOUConfere/2ndMOUConf /copy_of_ReferenceD/File/file/_WFS/M\%26S\%20COE\%20Brochure.pdf NATO Research and Technology Organisation, 2010, Guide to Modelling \& Simulation for NATO Network-Enabled Capability. Retrieved February 26, 2010, from http://ttp.rta.nato.int/public//PubFullText/RTO/TR/RTO-TR-MSG-062///\$TRMSG-062-ALL.pdf

National Center for Simulation, 2010, OMB Rejects NTSA-led effort to establish NAICS codes for M\&S Industry -- Call for Action, Retrieved March 1, 2011 from 
http://www.simulationinformation.com/news/omb-rejects-ntsa-led-effort-establishnaics-codes-ms-industry-call-action.

Near, 2007, A Canadian Defence and Security Innovation Centre: An Idea Whose Time Has Come, Canadian Military Journal, 9.

Norman 2010, Keyword Search and Analysis Tool Website, GitHub. Retrieved November 28, 2010, from http://mwnorman.github.com/

Ören 2002, Rationale for a Code of Ethics for Simulationists, Summer Computer Simulation Conference. Retrieved December 3, 2010, from http://www.site.uottawa.ca/ oren/pubs/D84_Rationale.pdf

Ören, T.I., 2007, Proceedings of the 2007 summer computer simulation conference, The importance of a comprehensive and integrative view of modeling and simulation. pp. 996-1006.

Ören, TI 2010, Modeling and Simulation Body of Knowledge Index, University of Ottawa SITE. Retrieved November 28, 2010, from http://www.site.uottawa.ca/ oren/MSBOK/MSBOK-index.htm Pearce, T.W. \& Bailetti, A.J., 2007, SISO SIW, Open Source Software - Beyond the Download Button. 
Powell, W.W., Koput, K.W. \& Smith-Doerr, L., 1996, Interorganizational collaboration and the locus of innovation: Networks of learning in biotechnology, Administrative science quarterly, $41(1)$, pp. 116-45.

Provan, K.G., Fish, A. \& Sydow, J., 2007, Interorganizational networks at the network level: A review of the empirical literature on whole networks, Journal of Management, 33(3), p. 479.

Repenning, N.P., 2002, A simulation-based approach to understanding the dynamics of innovation implementation, Organization Science, 13(2), pp. 109-27. Roelandt, T.J.A. \& den Hertog, P., 1999, Boosting innovation: the cluster approach, Organisation for Economic Co-operation and Development, Paris.

Roman \& Surdu, 2010, Simulation Support to Operations: Bringing Simulation to the Fight, ModSimWorld Canada. Retrieved November 28, 2010, from http://www.modsimworldcanada.ca/en/presentations/Paul\%20Roman-S1-T1R4.pdf

Roman, P.A. \& Surdu, J.B., 2009, The Interservice/Industry Training, Simulation \& Education Conference (I/ITSEC), Simulation Support to Operations-Bringing Simulation to the Fight.

Salas A.J., 2007, Health of Business Ecosystems, a structural approach, Thesis, Delft University of Technology. 
Schrage, M., 2000, Serious play: how the world's best companies simulate to innovate, Harvard Business School Press, Boston, Mass.

SCS, 2010, Society for Modeling and Simulation International Website, SCS. Retrieved December 3, 2010, from http://www.scs.org/

Shane, S.A., 2009, Technology strategy for managers and entrepreneurs, Pearson/Prentice Hall, Upper Saddle River, NJ.

SISO 2010, Simulation Interoperability Standards Organization Website, SISO. Retrieved December 3, 2010, from http://www.sisostds.org/

Smith, R., 2006, Technology disruption in the simulation industry, Journal of Defense Modeling and Simulation, 3(1), p. 3.

Sokolowski, J.A. \& Banks, C.M., 2009, Principles of modeling and simulation: A multidisciplinary approach, Wiley

TTCP, 2010, The Technical Cooperation Program, Retrieved October 28, 2010, from http://www.ttcp.org

TTCP, 2006, Guide for Understanding and Implementing Defense Experimentation (GUIDEx)-Version 1.1, The Technical Cooperation Program (TTCP). Retrieved June 26, 2010, from http://www.dtic.mil/ttcp/GUIDExBookFeb2006.pdf 
Wainer, G.A., 2009, Discrete-Event Modeling and Simulation: A Practitioner's Approach, CRC, Boca Raton.

Weiss, M. \& Gangadharan, G.R., 2009, Modeling the mashup ecosystem: structure and growth, R\&D Management, 40(1), pp. 40-9.

Yin, R.K., 2003a, Applications of case study research, Sage Publications, Thousand Oaks.

Yin, R.K., 2003b, Case Study Research-Third Edition, Sage Publications, Inc, Thousand Oaks, California.

Youssef, R., Kim, B., Pagotto, J., Vallerand, A., Lam, S., Pace, P., Pogue, C. \& Greenley, A., 2006, Toward an Integrated Executable Architecture and M\&S Based Analysis for Counter Terrorism and Homeland Security, Transforming Training and Experimentation through Modelling and Simulation, pp. 7-1.

Youtie, J. \& Shapira, P., 2008, Building an innovation hub: A case study of the transformation of university roles in regional technological and economic development, Research policy, 37(8), pp. 1188-204.

Zeigler, B.P., 1984, Multifacetted modelling and discrete event simulation, Academic Press, London. 
Zeigler, B.P., Praehofer, H. \& Kim, T.G., 2000, Theory of modeling and simulation: Integrating discrete event and continuous complex dynamic systems, Academic Press.

Zyda, M \& Sheehan, J., 1997, Modeling and simulation: Linking entertainment and defense. National Research Council. 
Appendix 2 - List of Abbreviations

Master's Thesis - Visualizing Innovation: Modelling and Simulation in Support of Defence Innovation Networks

\begin{tabular}{|c|c|}
\hline ABBR. & 促, TERM \\
\hline ACT & (NATO) Allied Command Transformation \\
\hline ADM(IM) & $\begin{array}{l}\text { (DND) Assistant Deputy Minister of Information } \\
\text { Management }\end{array}$ \\
\hline ADM(Mat) & (DND) Assistant Deputy Minister of Materiel \\
\hline$A D M(S \& T)$ & $\begin{array}{l}\text { (DND) Assistant Deputy Minister of Information } \\
\text { Management }\end{array}$ \\
\hline AMRDEC & $\begin{array}{l}\text { (US Army) Aviation and Missile Research } \\
\text { Development and Engineering Center }\end{array}$ \\
\hline C-FITE & Coalition - Future Immersive Training Environment \\
\hline C4ISR & $\begin{array}{l}\text { Command, Control, Communications, Computers, } \\
\text { Intelligence, Surveillance and Reconnaissance }\end{array}$ \\
\hline CAD & Canadian Dollars \\
\hline CAD & Computer-Aided Design \\
\hline CAGE & Coalition Attack Guidance Experiment \\
\hline CANADACOM & (DND/CF) Canada Command \\
\hline CANSOFCOM & $\begin{array}{l}\text { (DND/CF) Canada Special Operations Forces } \\
\text { Command }\end{array}$ \\
\hline CASE & Computer-Aided Soft \\
\hline CCRP & (U.S.) Command and Control Research Program \\
\hline CCTT & Close Combat Tactical Trainer \\
\hline CD\&E & Concept Development and Experimentation \\
\hline CEFCOM & (DND/CF) Canada Expeditionary Forces Command \\
\hline CEO & Chief Executive Officer \\
\hline $\mathrm{CF}$ & Canadian Forces \\
\hline CFDS & Canada First Defence Strategy \\
\hline CFWC & Canadian Forces Warfare Centre \\
\hline CGF & Computer-Generated Forces \\
\hline CMP & CF Chief of Military Personnel \\
\hline $\mathrm{CoE}$ & Centre of Excellence \\
\hline CORA & $\begin{array}{l}\text { (DRDC) Centre for Operational Research and } \\
\text { Analysis }\end{array}$ \\
\hline COTS & Commercial-Off-The-Shelf \\
\hline CWID & Coalitioni Warrior Interoperability Demonstration \\
\hline DASIC & Defence And Security Innovation Centre \\
\hline DEA & Data Exchange Agreement \\
\hline DND & Department of National Defence (Canada) \\
\hline
\end{tabular}




\begin{tabular}{|l|l|}
\hline ABBR & Department of National Defence Architectural \\
\hline FNDAF & Department of Defense (United States) \\
\hline DoD & Department of Defense Architectural Framework \\
\hline DoDAF & Defence Research and Development Canada \\
\hline DRDC & DND Wide Area Network \\
\hline DWAN & Enterprise Architectures \\
\hline EA & CF Environmental Chiefs of Staff \\
\hline ECS & Force Development \\
\hline FD & Force Employment \\
\hline FE & Force Generation \\
\hline FG & $\begin{array}{l}\text { Future Immersive Training Environment Joint } \\
\text { Capabilities Technology Demonstration }\end{array}$ \\
\hline FITE JCTD & Foreign Military Sales \\
\hline FMS & Future Security Environment \\
\hline FSE & Global Command Control System - Air \\
\hline GCCS-A & Gross Domestic Product \\
\hline GDP & (JFS TDP) Human Factors 3 Experiment \\
\hline HF3 & High-Level Architecture \\
\hline HLA & High-Level Architecture \\
\hline HLA & Interservice / Industry Training, Simulation and \\
\hline EdiTSEC & Internation Conference Traffic in Arms Regulations \\
\hline ITAR & Joint Automated Deep Operations Coordination \\
\hline JADOCS & System \\
\hline JCTD & Joint Capabilities Technology Demonstration \\
\hline JFCOM & (US) Joint Forces Command \\
\hline JFS TDP & $\begin{array}{l}\text { Joint Fires System Technology Demonstration } \\
\text { Project }\end{array}$ \\
\hline JSMARTS & $\begin{array}{l}\text { Joint Simulation Modelling for Acquisition Rehearsal } \\
\text { Training and Support }\end{array}$ \\
\hline LVC & Live, Virtual and Constructive Simulation \\
\hline M\&S & Modelling and Simulation \\
\hline M\&S BoK & Modelling and Simulation Body of Knowledge \\
\hline MOD & Modeling and Simulation Coordination Office \\
\hline MODAF & (U.K.) Ministry of Defence \\
\hline MoU & Ministry of Defence Architectural Framework \\
\hline MSG & Memorandum of Understanding \\
\hline NATO & (NATO RTO Modelling and Simulation Group) \\
\hline NMSG & NATO Modelling and Simulation Group \\
\hline
\end{tabular}




\begin{tabular}{|c|c|}
\hline ABBR. & 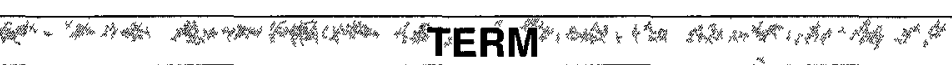 \\
\hline NNEC & NATO Network-Enabled Capability \\
\hline NTSA & (US) National Training and Simulation Association \\
\hline OMB & Office of Management and Budget \\
\hline OTACR & $\begin{array}{l}\text { Operations and Planning, Training and Education, } \\
\text { Acquisition and Support, Concept Development and } \\
\text { Experimentation, Research, Development and } \\
\text { Analysis }\end{array}$ \\
\hline PA & Project Arrangement \\
\hline PASS & Publish And Subscribe Server \\
\hline PEO STRI & $\begin{array}{l}\text { (US Army) Program Executive Office Simulation, } \\
\text { Training, Rehearsal and Instrumentation }\end{array}$ \\
\hline PMBOK & Project Management Body of Knowledge \\
\hline R\&D & Research and Development \\
\hline RTO & (NATO) Research and Technology Organisation \\
\hline S\&T & Science and Technology \\
\hline SBA & Simulation-Based Acquisition \\
\hline SCS & Society for Modeling and Simulation International \\
\hline SEBA & Synthetic Environment-Based Acquisition \\
\hline SECO & $\begin{array}{l}\text { (DND/CF) Synthetic Environment Coordination } \\
\text { Office }\end{array}$ \\
\hline SISO & Simulation Interoperability Standards Organization \\
\hline SLA & Service-Level Agreement \\
\hline sow & Statement Of Work \\
\hline TDP & Technology Demonstration Project / Program \\
\hline TIM & $\begin{array}{l}\text { (Carleton University) Technology Innovation } \\
\text { Management Program }\end{array}$ \\
\hline TRL & Technology Readiness Level \\
\hline TTA & Technology Transfer Agreement \\
\hline TTCP & The Technical Cooperation Program \\
\hline $\begin{array}{l}\text { TTCP AER } \\
\text { TP1 }\end{array}$ & $\begin{array}{l}\text { The Technical Cooperation Program Aerospace } \\
\text { Group, Technical Panel } 1\end{array}$ \\
\hline $\begin{array}{l}\text { TTCP JSA } \\
\text { TP8 }\end{array}$ & $\begin{array}{l}\text { The Technical Cooperation Program Joint Systems } \\
\text { and Analysis Group Technical Panel } 8\end{array}$ \\
\hline UAV & Unmanned Aerial Vehicle \\
\hline UPDM & Unified Profile for DoDAF and MODAF \\
\hline USD & United States Dollars \\
\hline V-Sim & Visualization and Simulation Centre \\
\hline VBS2 & Virtual Battlespace 2 \\
\hline VCDS & (CF) Vice Chief of Defence Staff \\
\hline VMASC & Virginia Modeling and Simulationg Center \\
\hline
\end{tabular}

